\title{
Pan-specific and partially selective dye-labeled peptidic inhibitors of the polycomb paralog proteins
}

Natalia Milosevich ${ }^{\mathrm{a}}$, James McFarlane ${ }^{\mathrm{a}}$, Michael C. Gignac ${ }^{\mathrm{a}}$, Janessa Li ${ }^{\mathrm{a}}$, Tyler M. Brown ${ }^{\mathrm{a}}$, Chelsea R. Wilson ${ }^{\mathrm{a}}$, Lindsey Devorkin ${ }^{\mathrm{b}}$, Caitlin S. Croft ${ }^{\mathrm{a}}$, Rebecca Hof ${ }^{\mathrm{a}}$, Irina Paci ${ }^{\mathrm{a}}$, Julian J. Lum $^{\mathrm{b}}$, Fraser Hof ${ }^{\mathrm{a} *}$

${ }^{a}$ Department of Chemistry, University of Victoria, Victoria BC, V8W 3V6, Canada ${ }^{b}$ BC Cancer - Trev and Joyce Deeley Research Centre, Victoria BC, V8R 6V5, Canada *Corresponding author: Fraser Hof. Email: fhof@uvic.ca

KEYWORDS: CBX, methyllysine reader proteins, polycomb paralogs, peptidomimetics, epigenetics

ABSTRACT: Epigenetic regulation of gene expression is in part controlled by post-translational modifications on histone proteins. Histone methylation is a key epigenetic mark that controls gene transcription and repression. There are five human polycomb paralog proteins (Cbx2/4/6/7/8) which use their chromodomains to recognize trimethylated lysine 27 on Histone 3 (H3K27me3). Recognition of the methyllysine side chain is achieved through multiple cation-pi interactions within an 'aromatic cage' motif. Despite high structural similarity within the chromodomains of this protein family, they each have unique functional roles and are linked to different cancers. Selective inhibition of different CBX proteins is highly desirable for both fundamental studies and potential therapeutic applications. We will report on a series of peptidic inhibitors that selectively target certain polycomb paralogs. We have identified peptidic scaffolds with sub-micromolar potency, and will report examples that are pan-specific and that are partially selective for individual members within the family. These results highlight important structure-activity relationships that allow for selectivity to be achieved through interactions outside of the methyllysine binding aromatic cage motif.

\section{INTRODUCTION}

Post-translational modifications on histones control the functions of chromatin through the actions of various epigenetic protein complexes. ${ }^{1}$ Methyllysine reader proteins bind to posttranslationally methylated lysine residues via an aromatic cage motif. ${ }^{2}$ The five human polycomb paralog proteins (CBX2/4/6/7/8) recognize trimethyllysine residues on histone 3 and each participate in the multi-protein Polycomb Repressive Complex 1 (PRC1). ${ }^{3}$ PRC1 serves to activate or silence genes by altering accessibility and compaction of chromatin. ${ }^{4}$

Each CBX protein has unique functional roles and displays distinct activities in different stages of cancer and in different tissues. ${ }^{5-8}$ To better understand the biology of these proteins and 
to test their potential as drug targets, chemical tools are needed to understand the phenotypes generated by inhibition. Significant progress has been made in understanding the biological impacts of inhibiting $\mathrm{CBX} 7,{ }^{9,10}$ but comparatively much less is understood about the other CBX proteins. $^{11}$

Typical approaches to generating small-molecule inhibitors have proven very challenging for CBX proteins. Early efforts in our group at virtual and small molecule screening for CBX7 did not yield potent inhibitors (unpublished results). The challenges associated with screening small molecules against the CBX proteins have also been reported by others. ${ }^{9,11,12}$

We have previously reported a peptide-driven approach to identify a series of submicromolar inhibitors targeting CBX4/CBX7 and CBX6. ${ }^{12-14}$ Potent peptidic inhibitors of CBX4/CBX7 have also been identified by the Frye group and have shown activity in cellular based studies. ${ }^{9,15}$ The first small molecule inhibitors of any CBX protein also targeted CBX7. ${ }^{10,16}$ Recent work on new approaches to target the CBX proteins has identified inhibitors of CBX7 and CBX8 using a DNA-encoded library. ${ }^{17}$

No selective inhibitors have been reported for the other CBX proteins. Relatively little is known about the many biological roles of $\mathrm{CBX} 2 / 4 / 6 / 8$, and nothing is known about the impacts of chemical inhibition of any of these proteins. The delay in progress is because of the many challenges in targeting the $\mathrm{CBX}$ proteins. $\mathrm{CBX}$ chromodomains bind to their native substrates with weak affinity, ${ }^{3}$ undergo an induced fit mode of binding, ${ }^{9}$ and are between $79-98 \%$ similar within the family (Figure 1, Table 1).

Significant structural differences exist between the HP1 homologs (CBX1/3/5) and the polycomb paralogs $(\mathrm{CBX} 2 / 4 / 6 / 7),{ }^{3}$ but the differences within the polycomb paralog family are subtle. The polycomb paralog proteins bind Kme3 through cation-pi interactions in their conserved aromatic cage (Figure 1B, C). The aromatic cage is nearly identical within the family, but differences exist in the protein structure in the nearby beta-groove (Figure 1B). Discovery and exploitation of these structural differences outside of the methyllysine binding motif are necessary for the development of selective inhibitors.

Our initial reports of CBX inhibitors first established the pentapeptide sequence AcFALKme3S and related analogs as potent inhibitors of CBX7 (Table 1). ${ }^{12,13}$ A co-crystal structure of the Ac-FAYKme3S complex with CBX7 shows the peptide ligand forming several key binding interactions in the peptide-binding groove (Figure 1). The N-terminus of the ligand 
sits in the protein's beta-groove, and the ligand's $(-2)$ Ala residue points into a small hydrophobic pocket called the $(-2)$ pocket. The hydrophobic clasp of the CBX proteins, made up of residues Val10 and Leu49, fold and clamp around the ligand (Figure 1A). The Kme3 group of the ligand forms several cation-pi interactions in the protein's aromatic cage, and the C-terminal Ser residue of the ligand peptide hydrogen bonds with the carboxylate side chain of Glu43 (Figure 1B).

We have previously reported a CBX6 ligand that contains a valine residue at the $(-2)$ position relative to the ligand's Kme3 residue. ${ }^{14}$ This substitution exploited differences within the family of the size of the protein's $(-2)$ hydrophobic pocket. In this work, we report novel SAR of peptidic ligands that explore multiple regions of the CBX-ligand binding interface.

Table 1. Binding affinities for previously reported peptidic ligands with $\mathrm{CBX} 7$ and $\mathrm{CBX8} .{ }^{12}$

\begin{tabular}{lccl}
\hline & $\begin{array}{l}\text { IC }_{50} \text { values } \\
\text { determined } \\
\text { CBX7- }\end{array}$ & $\begin{array}{l}\mathrm{K}_{d} \text { values }(\mu \mathrm{M}) \\
\text { determined by } \\
\text { H3K27me3 } \\
\text { disruption }\end{array}$ & \\
ITC & & \\
\hline Ligand & CBX7 & CBX7 & CBX8 \\
Ac-FALKme3S & $11 \pm 0.4$ & $2 \pm 0.2$ & $14.2 \pm 2$ \\
Ac-FAYKme3S & $6 \pm 0.4$ & $2 \pm 0.1$ & $12 \pm 1.4$ \\
pBr-FALKme3S & $5 \pm 0.3$ & $0.3 \pm 0.05$ & $5 \pm 0.3$ \\
\hline
\end{tabular}

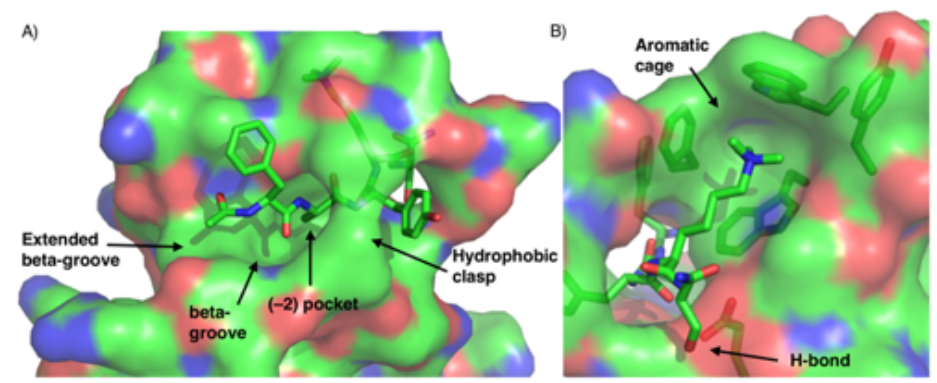

Figure 1. Key regions of the $\mathrm{CBX}$ proteins responsible for binding. A and B) Co-crystal structure of Ac-FAYKme3S in complex with CBX7 (pdb: 4MN3). Key structural features of the proteins binding pocket are labeled with black arrows.

The goal of this work was to further study the structural determinants of recognition, so that we can better target each family member. A secondary goal was to create novel dye-labeled inhibitors as chemical tools that would allow for new biochemical and biophysical studies of the CBX proteins. To this end, we synthesized a small library of peptidomimetic compounds and tested each compound with a panel of CBX proteins. The peptides synthesized are labeled with 
the fluorescent dye fluorescein isothiocyanate (FITC). Labeled inhibitors were used in for multiple forms of testing, including direct fluorescence polarization assays (to determine affinity), microarray testing (to determine selectivity), and live cell imaging (to determine uptake and cellular localization). Each of these studies is unprecedented for the majority of methyllysine reader proteins in the $\mathrm{CBX}$ family.

\section{Results}

\section{Synthesis of peptides}

Peptides were synthesized using standard Fmoc solid-phase peptide synthesis protocols. Peptides contained either a beta-alanine residue at the N-terminus or a Lys(Mtt) residue at the Cterminus to allow dye labeling while still on resin. Fmoc-beta alanine was deprotected using standard protocols and the peptide was then reacted with FITC to produce compounds $\mathbf{1}$ and $\mathbf{2}$. Peptides containing a C-terminal Lys-(Mtt) residue were selectively deprotected under mildly acidic conditions, followed by a reaction with FITC to give compounds 3, 4, 8-11 (Scheme 1).

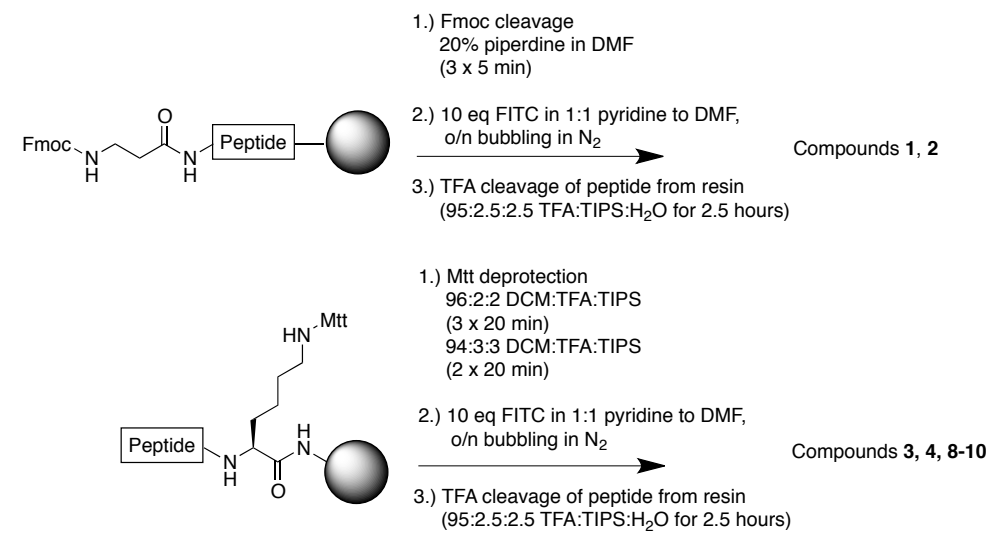

Scheme 1. Synthesis of peptidic compounds 1-4 and 8-10.

\section{Fluorescence polarization-driven studies to understand polycomb paralog SAR} Dye labeling $\mathrm{CBX} 7$ inhibitor and $\mathrm{N}$-terminal modifications

A dye-labeled analog of our previously identified CBX7 inhibitor FALKme3S was synthesized with a N-terminal beta-alanine residue (compound 1) for covalent attachment to FITC. Compound 1 was screened against all CBX polycomb paralogs and the HP1 homolog CBX1. 1 displayed potent binding to all CBX proteins tested, near equipotent binding to CBX2/4/6/7 and weaker binding to CBX1 (an HP1 paralog) and CBX8 (Figure 2A). The 
previously reported $\mathrm{K}_{d}$ values of Ac-FALKme3S with CBX7 and CBX8 are similar and within the same magnitude of those reported for the dye-labeled analog 1 (Table 1, Figure 2A).
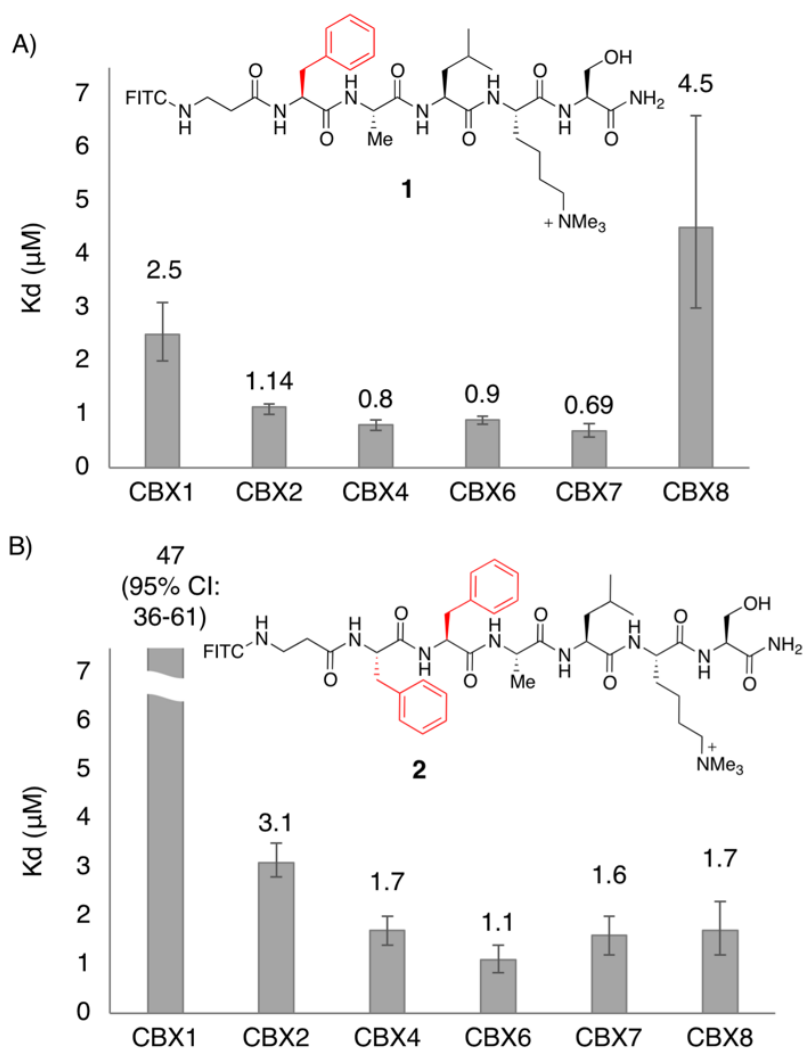

Figure 2: Peptidic inhibitors for CBX proteins and corresponding dissociation constants for CBX1/2/4/6/7/8. A) Binding affinities and chemical structure of compound 1, B) binding affinities and chemical structure of compound 2. Error bars are reported as asymmetric 95\% confidence intervals from experiments done in triplicate.

The addition of a second phenylalanine to the $\mathrm{N}$-terminus of 1 resulted in an increase in binding to CBX8 (2.6-fold) and decrease in binding to CBX7 (2.3-fold) (Figure 2B, 2).

Compound 2 showed a 19-fold decrease in binding to CBX1, 2 to 3-fold decrease in binding to CBX2/4 and no significant change in binding to CBX6.

\section{Salt bridge interactions between ligands and $\mathrm{CBX} 6$ and $\mathrm{CBX} 8$}

Another key structural difference between $\mathrm{CBX} 7 / \mathrm{CBX} 8$ is the presence of a Arg9 residue in the protein near the $\mathrm{C}$-terminus of the ligand interacts (Figure 3A). We predicted that an anionic substitution at the (+2) position would improve binding to CBX6/8 but not CBX7. Where the N-terminus is free of dye modification, we used the $p$-bromobenzamide end-capping group that we had previously shown to provide a boost in potency (pBr-FALKme3S, Table 1). Two analogous compounds were synthesized containing either a Leu residue at the $(+2)$ position 
(compound 3) or a Glu residue (compound 4) (Figure 3). Compound $\mathbf{3}$ was a potent inhibitor of CBX6 and CBX7 with $\mathrm{K}_{\mathrm{d}}$ values of 78 and $11 \mathrm{nM}$. Addition of a Glu residue in the (+2) position provided compound 4 (previously reported). ${ }^{14}$ The $(+2)$ Glu gave a small increase in binding to CBX6 (1.6-fold) and CBX8 (1.4-fold), no change in binding to CBX7 and a decrease in binding to CBX1 (2.7-fold) (Figure 3C, D).
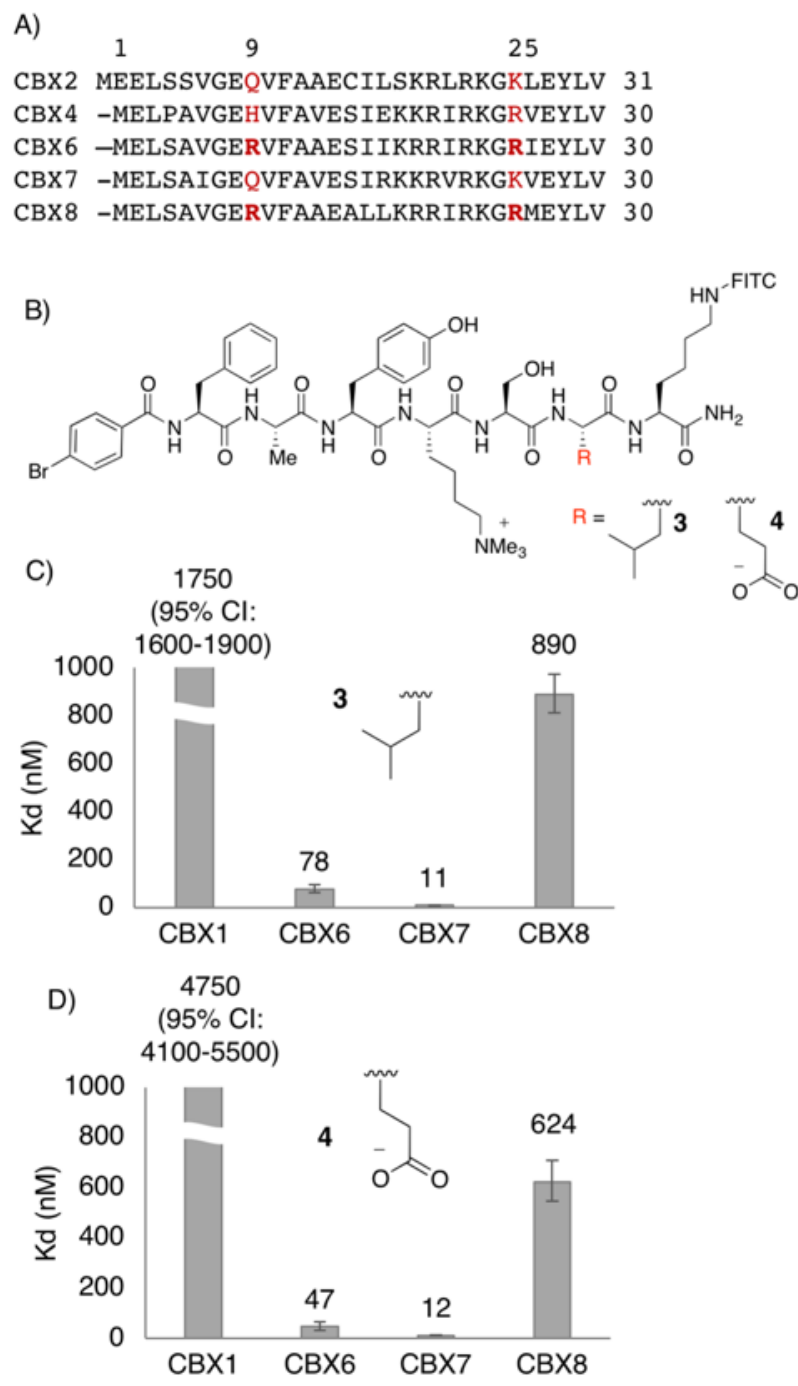

Figure 3: Interactions between anionic ligand substituent and cationic protein residue in CBX6/CBX8. A) Sequence alignments highlighting residues predicted to interact with anionic ligand substituents determined using ClustalW2 alignment, B) Chemical structure of compounds $\mathbf{3}$ and $\mathbf{4}, \mathrm{B}$ ) and C) Binding affinities of $\mathbf{3}$ and $\mathbf{4}$ to $\mathrm{CBX} 1 / 6 / 7 / 8$. $\mathrm{K}_{\mathrm{d}}$ values are reported in $\mathrm{nM}$ and error bars are reported as asymmetric $95 \%$ confidence intervals from experiments done in triplicate.

To investigate further the role of the Glu residue and to understand the effects of the dye on binding, we synthesized analogues of compounds $\mathbf{3}$ and $\mathbf{4}$ lacking the C-terminal lysine and 
FITC label. A competitive FP assay was used to determine the $\mathrm{IC}_{50}$ values of the unlabeled compounds 5, 6 and 7 (Figure 4). Compound 4 was used as the dye-labeled probe in the competitive FP assay because of its good solubility and low $\mathrm{K}_{\mathrm{d}}$ values for all $\mathrm{CBX}$ proteins. Compound 5, lacking a residue at the (+2) position, displayed binding to CBX7 with 5- and 30fold selectivity over CBX6 and 8 respectively. The addition of a Leu residue at the $(+2)$ position (6) did not significantly change binding to any of the CBX proteins tested. Compound 7 with a (+2) Glu residue gave a 1.7- and 1.4-fold increases in binding to CBX6 and 8, respectively, and a 1.6-fold decrease in binding to CBX7. The trends in binding affinities observed with the dyelabeled compounds $\mathbf{3}$ and $\mathbf{4}$ are consistent with the trends seen for the unlabeled compounds $\mathbf{6}$ and 7. Each of these sets of binding data suggest that the ligands' $(+2)$ Glu residue favors binding to $\mathrm{CBX} 6$ and $\mathrm{CBX} 8$ over $\mathrm{CBX} 7$. 

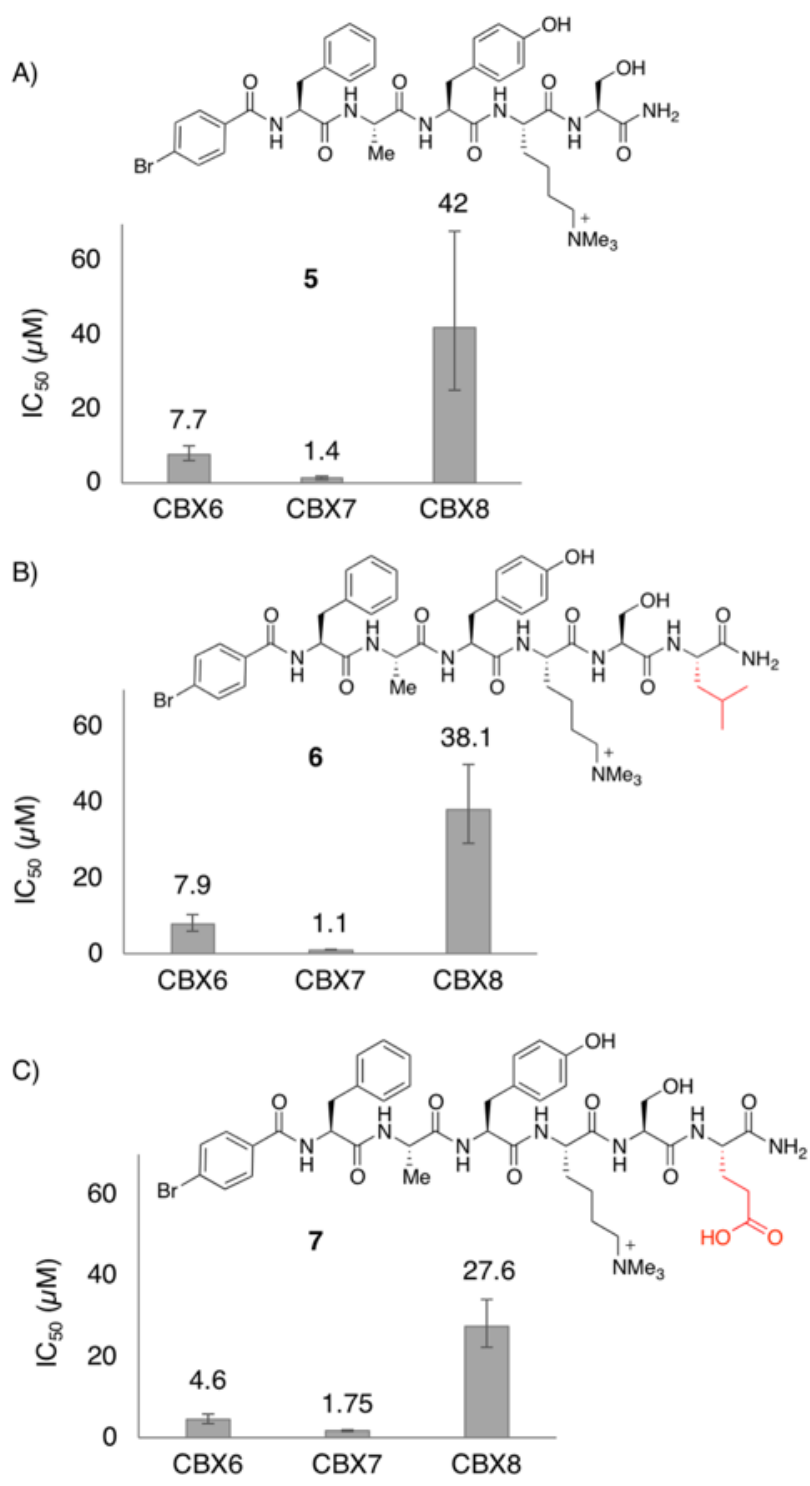

Figure 4: $\mathrm{IC}_{50}$ values of unlabeled ligands 5-7 for CBX6/7/8 determined by competitive FP. A) Binding affinities and chemical structure of compound 5, B) compound 6, C) compound 7. Error bars are reported as asymmetric $95 \%$ confidence intervals from experiments done in triplicate.

\section{Docking and MD simulations of compound 6 and 7}

We sought to further examine the importance of the salt bridge interaction to binding of compounds 6 and 7, using an accelerated sampling molecular dynamics technique developed in our group. ${ }^{18}$ The SLICE method is a hybrid, iterative stochastic deterministic methodology that fuses AutoDock Vina ${ }^{19}$ and the Amber16 molecular dynamics suite. ${ }^{20}$ The method allows for fast structural identification of binding complexes of highly flexible hosts with peptidomimetic ligands. Binding of compounds 6 and 7 with CBX8 was investigated using SLICE. 
Two 1-ns SLICE iterations were used to generate partially-induced-fit host configurations of CBX8. A third docking round of the ligands on the resulting host configurations provided starting points for a $100 \mathrm{~ns}$ molecular dynamics production run. After the two SLICE iterations, only the glutamate-containing compound 7 was observed to bind in the presumed correct orientation with the trimethyllysine placed in the aromatic cage. Template docking for compound 6, using bound configurations of compound 7, was performed to generate initial coordinates for the final production molecular dynamics of bound compound $\mathbf{6}$. The simulation was required to examine the behavior of a leucine in the electropositive region of CBX8 depicted in Figure 5. Figure 5. Final SLICE structure of compound 7 with CBX8. The initial docked pose of compound 7 (purple) glutamate (red) predicts a salt bridge with Arg25 instead of the proposed Arg9. The electrostatic potential surface area $\left(\mathrm{APBS}^{21}\right)$ of $\mathrm{CBX} 8$ shows the entire region adjacent to the aromatic cage as an electropositive environment (blue surface) consisting of several potentially competing arginine residues.

The SLICE application to compounds 6 and 7 consistently showed a preference of CBX8 for 7. However, the docked initial structure for the final production MD run presented a salt bridge of the Glu residue with Arg25, instead of the assumed Arg9 (Figures 3A and 6B). This is a consequence of two factors: (i) The protein surfaces of CBX6/8 in the area surrounding the aromatic cage present significant positive charge, for which both Arg9 and Arg25 are jointly responsible; ${ }^{3}$ (ii) the docking procedure is insufficient to tease out effectively the binding differences between Arg9 and Arg25 in the complex solvation and thermal environment in which the binding process takes place. However, the Arg25 salt bridge dissociated in the initial stages of the production MD run. 


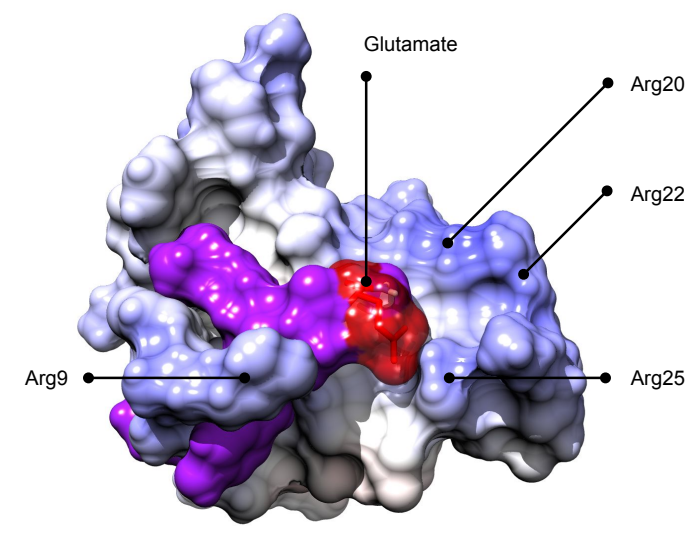

Figure 5. Final SLICE structure of compound 7 with CBX8. The initial docked pose of compound 7 (purple) glutamate (red) predicts a salt bridge with Arg25 instead of the proposed Arg9. The electrostatic potential surface area $\left(\mathrm{APBS}^{21}\right)$ of $\mathrm{CBX} 8$ shows the entire region adjacent to the aromatic cage as an electropositive environment (blue surface) consisting of several potentially competing arginine residues.

The SLICE application to compounds 6 and 7 consistently showed a preference of CBX8 for 7. However, the docked initial structure for the final production MD run presented a salt bridge of the Glu residue with Arg25, instead of the assumed Arg9 (Figures 3A and 6B). This is a consequence of two factors: (i) The protein surfaces of CBX6/8 in the area surrounding the aromatic cage present significant positive charge, for which both Arg9 and Arg25 are jointly responsible ${ }^{3}$ (ii) the docking procedure is insufficient to tease out effectively the binding differences between Arg9 and Arg25 in the complex solvation and thermal environment in which the binding process takes place. However, the Arg25 salt bridge dissociated in the initial stages of the production MD run. 
A)

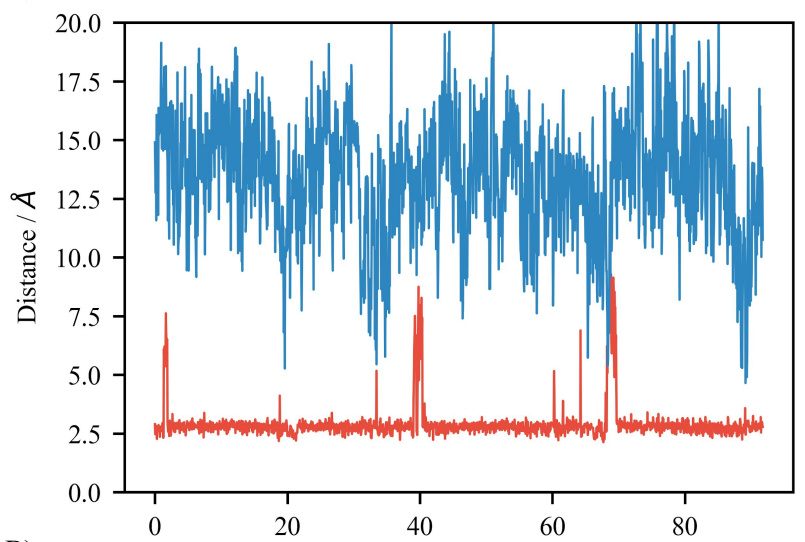

B)

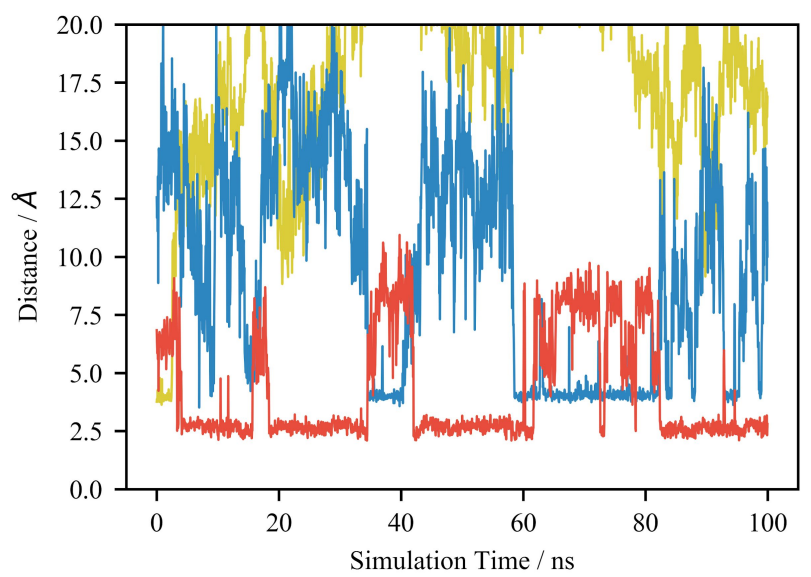

C)

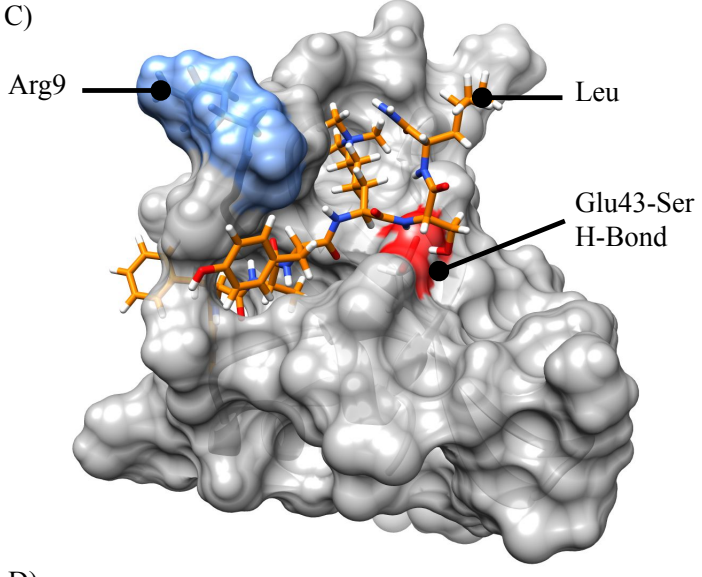

D)

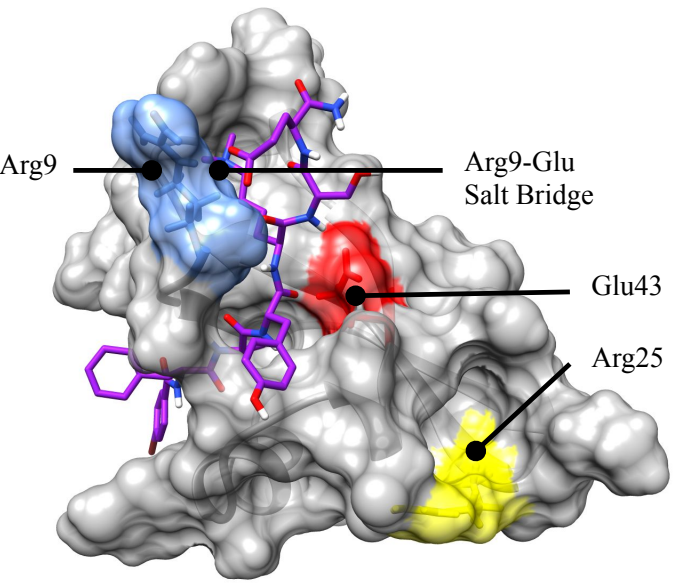

Figure 6. Highlighted interactions of CBX8 with compounds 6 and 7. A) The evolution of the distance between compound 6 leucine $\delta$-carbon and CBX8 Arg9 guanidinium carbon through the $100 \mathrm{~ns}$ simulation is shown in blue. The compound 6 serine $\mathrm{OH}$ - Glu43 $\delta$-carbon distance is shown in red, highlighting the stability of the hydrogen bond in this complex. In (B), distances shown are for: compound 7 glutamate $\delta$-carbon - Arg25 guanidinium carbon (yellow), glutamate $\delta$-carbon - Arg9 guanidinium carbon (blue), and compound 7 serine $\mathrm{OH}-\mathrm{Glu} 43 \delta$-carbon (red). C) MD Snapshot of compound 6 (stick representation) with the relevant residues on CBX8 highlighted in red and blue. D) MD Snapshot of compound 7 (stick representation) with CBX8 (with the relevant residues highlighted in blue, red and yellow).

In fact, monitoring the $100 \mathrm{~ns}$ trajectories for interaction distances showed the docked Arg25 salt bridge to be unstable compared to the interaction with Arg9. The latter was maintained for nearly half of the simulation, as shown in Figure 6B. An interesting feature arising from the simulation is the hydrogen bond between the compound 7 serine and Glu43 on CBX8. The bond shows a reverse correlation with the formation of the Arg9 salt bridge: both interactions cannot exist at the same time. The penalty of losing a hydrogen bond likely reduces the increased binding activity expected by the addition of newly formed salt bridge for 
compound 7. On the other hand, compound 6 maintained its Ser-Glu43 hydrogen bond throughout the simulation, as its leucine residue showed no preference of interaction in the region adjacent to the aromatic cage. Hydrophobic clasp distances, $(-2)$ pocket placement, and aromatic cage interactions were stable for both compounds throughout the simulations and suggest that the key differences between the binding of $\mathbf{6}$ and $\mathbf{7}$ are the local interactions of the Leu/Glu substitutions (see Figure 7).

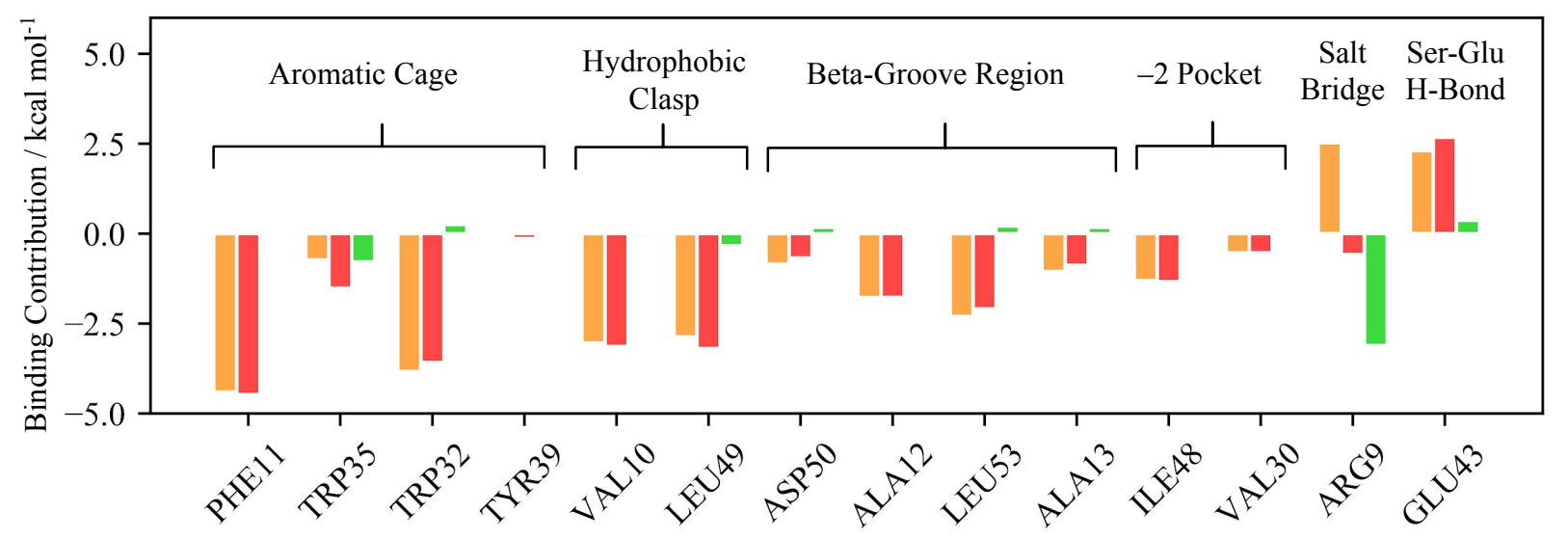

Figure 7. MMPBSA per-residue binding free energies for CBX8 residues in the interaction region. Orange and red bars show energy values for the interaction with compound $\mathbf{6}(\mathrm{E} 6)$ and 7 (E7), respectively. The relative stabilization contribution of compound 7, (E7-E6), is presented in green. Residues that did not contribute to binding for either compounds 6 and 7 were not included.

\section{Binding energy contributions}

To explore the contributions of competing interactions to the binding energy, we calculated the per-residue free energies of binding using MMPBSA.py. ${ }^{22}$ Coordinates for the calculation for host/ligand/complex were all taken from the $100 \mathrm{~ns}$ trajectory. This single trajectory approach ignores the induced-fit energy penalty of the host, which is likely significant, based on our experience with apo-protein simulations of CBX8. However, this contribution is also likely the same for $\mathbf{6}$ and $\mathbf{7}$, given their structural similarities, and can be neglected for the purpose of this comparison.

Further energy decomposition, specifically the electrostatic and solvation energies of the residues involved in the Arg8 salt-bridge and surface Glu43 hydrogen bond (Table 2), support our structural findings regarding the competition between salt bridge and hydrogen bond formation for compound 7. Overall, the hydrogen bond interaction for compound 7 is weaker than that of compound $\mathbf{6}$. This is an overall result that arises from significantly more stable 
electrostatic contributions for compound $\mathbf{6}$, due to residence time, balanced out by a proportionally large solvent exclusion effect.

On the other hand, the salt bridge interaction favors compound 7 , as initially designed: The interactions in the salt bridge region are slightly destabilizing for compound $\mathbf{6}$, whereas the intermittent compound $7 \mathrm{Glu}$ - Arg9 interaction provides an overall stabilizing effect. Note that the values listed in Table 2 are overall per-residue values, and not pairwise energies.

The difference of the total MMPBSA binding free energies for Compounds 6 and 7, using the Poisson Boltzmann solvent, were found to be $3.79 \mathrm{kcal} / \mathrm{mol}$ in favor of compound 7 .

Table 2. MMPBSA.py Per-Residue Energies for Selected Residues in Salt Bridge and Adjacent Glu43 Hydrogen Bond

\begin{tabular}{rlcccc} 
& & Eel $^{\alpha}$ & Esol $^{\beta}$ & Etot $^{\gamma}$ & Eint $^{\varepsilon}$ \\
\hline $\begin{array}{r}\text { CBX8 / compound 6 } \\
\text { Hydrogen Bond }\end{array}$ & Glu43 (CBX8) & -37.32 & 40.61 & 2.31 & -4.16 \\
& & & & & \\
& & & & & \\
& Ser1 (compound 6) & -13.01 & 7.07 & -6.47 & \\
Salt Bridge Region & Arg8 (CBX8) & 33.13 & -29.38 & 2.52 & 2.05 \\
& Leu2 (compound 6) & -0.49 & 0.65 & -0.47 & \\
\hline CBX8 / compound 7 & & & & & \\
Hydrogen Bond & Glu43 (CBX8) & -16.08 & 19.71 & 2.68 & -2.11 \\
& Ser1 (compound 7) & -9.97 & 5.71 & -4.79 & \\
Salt Bridge Region & Arg8 (CBX8) & -22.58 & 23.66 & -0.58 & -2.81 \\
& Glu2 (compound 7) & -68.53 & 66.89 & -2.23 & \\
& Glu2 (Compound 7) & -68.53 & 66.89 & -2.23 & \\
\hline
\end{tabular}

Electrostatic potential $^{\alpha}$, PBSA solvation energy ${ }^{\beta}$, total per-residue energy ${ }^{\gamma}$, and combined total energies $^{\varepsilon}$ (sum of $\mathrm{E}_{\text {tot }}$ for the two residues) are presented for the interacting residues on CBX8 and the two ligands. All energies reported in $\mathrm{kcal} / \mathrm{mol}$.

\section{Ligand substitutions at the $(-1)$ and $(-2)$ position}

Returning to synthesis and testing of new ligands, we sought to explore substitutions of the (-2) residue within the scaffold of 4. An additional difference between CBX7 and CBX8 is the hydrophobic $(-2)$ pocket. The $(-2)$ pocket is different sizes in $\mathrm{CBX} 7$ and CBX8. We sought to exploit this difference by adding a larger alkyl substituent at the $(-2)$ position. Within the scaffold of compound 4, the methyl substituent at the (-2) position was replaced with an ethyl group to produce compound $\mathbf{8}$ (Figure $8 \mathrm{~A}$ ). ${ }^{14}$ This subtle change weakened binding to all 
partners except CBX8. Significantly weaker binding was observed for 8 with CBX1 (31-fold), between a 2- to 5-fold decrease in binding for CBX2/4/6/7 and no change in binding to CBX8.

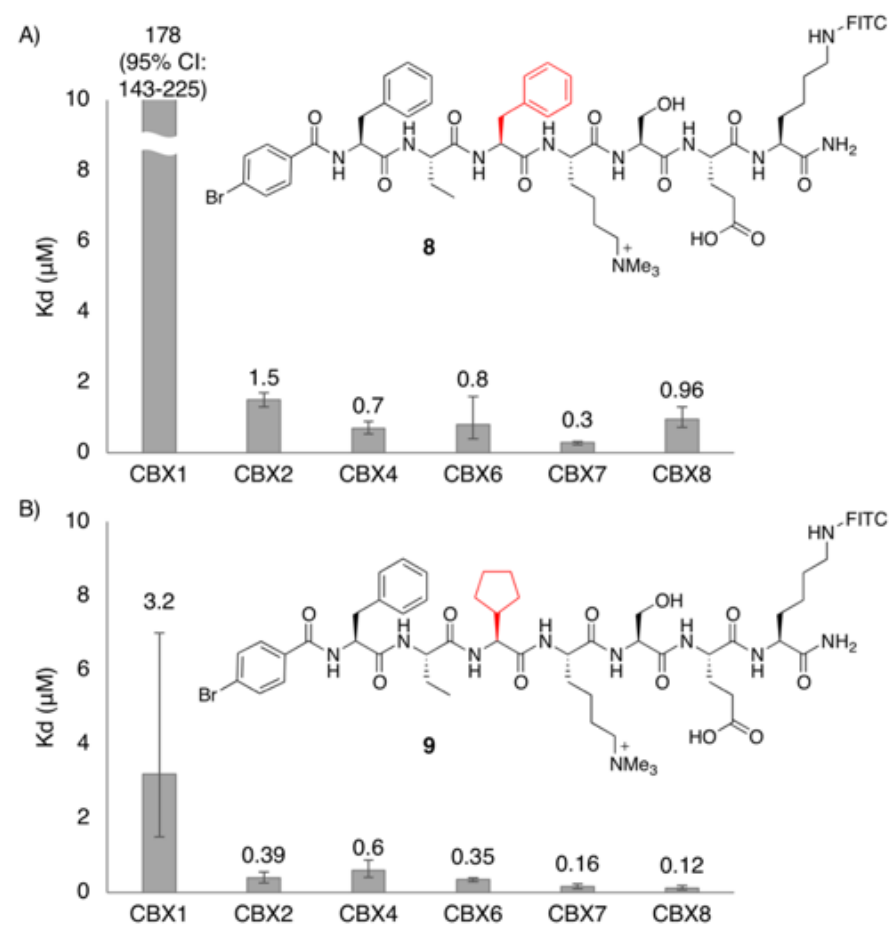

Figure 8: Peptidic inhibitors 8 and 9 and corresponding dissociation constants for CBX1/2/4/6/7/8. A) Binding affinities and chemical structure of compound 8, B) and compound 8. Error bars are reported as asymmetric $95 \%$ confidence intervals from experiments done in triplicate.

We next replaced the Phe residue with a cyclopentyl moiety at the $(-1)$ position to give compound 9 (Figure 8B). This swap produced the most potent CBX8 inhibitor reported to date with a $\mathrm{K}_{d}$ value of $120 \mathrm{nM}$. In addition to improving potency for CBX8, the cyclopentyl side chain in the (-1) position increased binding to all CBX proteins tested. Compound 9 is 26 -fold selective for CBX8 over CBX1, 3-fold selective over CBX2/6, and 5-fold selective over CBX4. The difference in affinity of 9 for CBX7 and CBX8 is not significant.

We hoped to push further toward CBX8 selectivity by adding a second Phe residue to 9, as in compound $\mathbf{2}$. To this end, we synthesized compound $\mathbf{1 0}$ containing an acetylated N-capping Phe residue in combination with the (-2) ethyl group and (-1) cyclopentyl side chain (Figure 9A). 10 is the first compound in this series with stronger affinity to CBX8 compared to CBX7. $\mathbf{1 0}$ is most potent for CBX6, and is 4 and 2-fold selective for CBX6 and 8 over CBX7. In respect to $\mathrm{CBX} 8, \mathbf{1 0}$ is between $14-135 \mathrm{x}$ selective over $\mathrm{CBX} 1 / 2 / 4$. 
Replacing the (-2) and (-1) substituents of $\mathbf{1 0}$ to Ala-Leu residues known to be favored by $\mathrm{CBX} 1 / 2 / 4 / 7$ did not significantly change binding to these proteins, but did decrease binding to CBX6 and 8 by a factor of 2.7 and 3.5 (Figure 9B). Compounds $\mathbf{1 0}$ and $\mathbf{1 1}$ are selective for CBX6/7/8 over CBX1/2/4.

Selective inhibition of CBX7 over CBX4 has not yet been reported. The CBX4 chromodomain is the most similar to CBX7 (similarity score of $90 \%$ ), ${ }^{3,14}$ both bind the native histone substrate with similar affinity, ${ }^{3}$ and almost all CBX7 ligands reported to date have had similar affinities for CBX4. ${ }^{9} 10,12,13$ Interestingly, both $\mathbf{1 0}$ and $\mathbf{1 1}$ show significantly weaker binding to CBX4 compared to CBX7. Future efforts on selective inhibition of CBX7 may benefit from extended engagement of the peptide-binding groove.

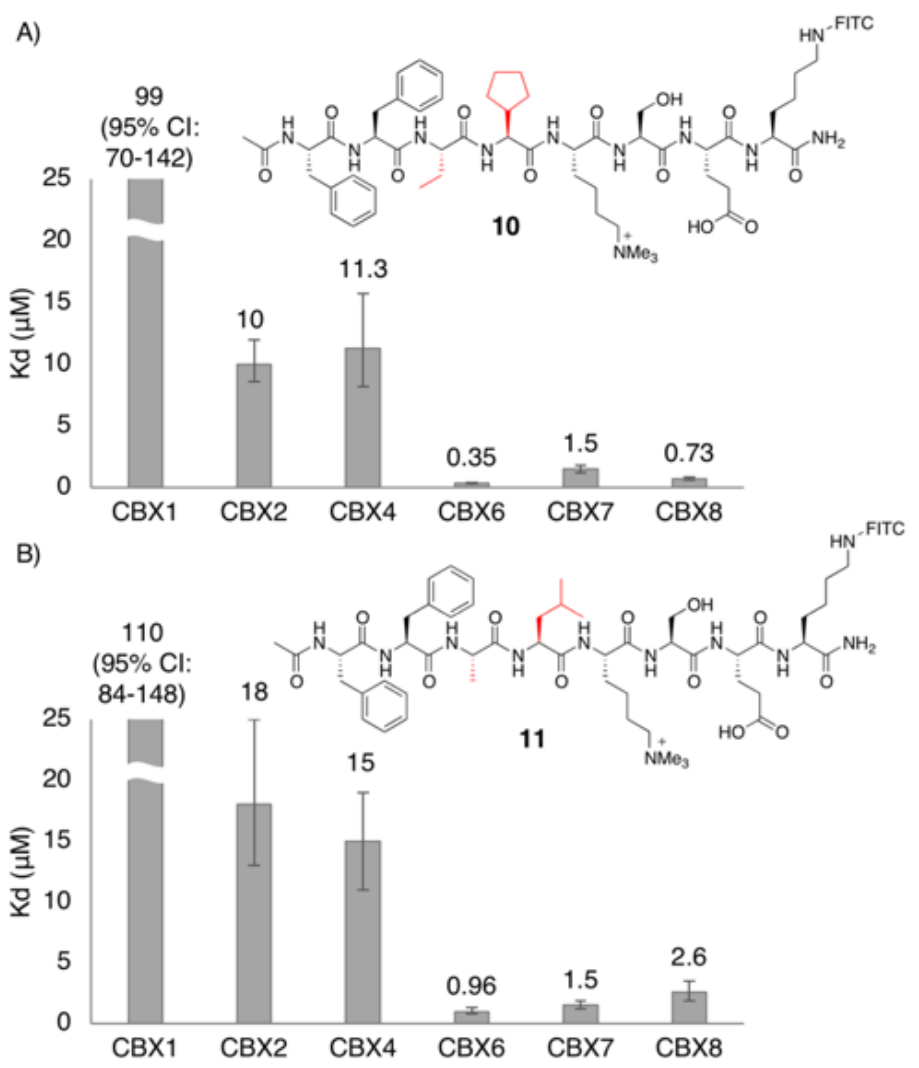

Figure 9: Peptidic inhibitors $\mathbf{1 0}$ and $\mathbf{1 1}$ and corresponding dissociation constants for CBX1/2/4/6/7/8. A) Binding affinities and chemical structure of compound 10, B) and compound 11. Error bars are reported as asymmetric $95 \%$ confidence intervals from experiments done in duplicate for CBX1/2/4/6/7 and triplicate for CBX8.

\section{Selectivity studies using a methyl reader protein microarray}

Using a microarray to test our fluorescently tagged peptides provides both validation of our FP results and more diverse knowledge on selectivity beyond the CBX family of proteins. 
We utilized a protein microarray made up of 98 different recombinant human methyl reader proteins (including all CBX proteins) arrayed in duplicate. ${ }^{23}$ Initial testing of tetramethylrhodamine isothiocyanate (TRITC) dye-labeled inhibitors produced the expected binding trends but with a high degree of background fluorescence. To prevent this, a biotinylated analog of $\mathbf{3}$ was synthesized (compound 12, Figure 10). The microarray was incubated with the probe, and the binding of the probe was imaged using a fluorescent streptavidin reagent.

The inhibitor tested in the microarray showed excellent selectivity for CBX proteins over a broad selection of other methyl readers. Some off-target binding to the chromodomain Y like (CDYL) proteins was observed, ${ }^{24}$ along with weak off-target binding to the chromodomaincontaining mortality factor 4-like protein (MORF4L1 or MRG15). Compound 12 showed the highest selectivity for CBX4 and 7, with weaker binding observed to CBX2/6/8 (Figure 10).

A)

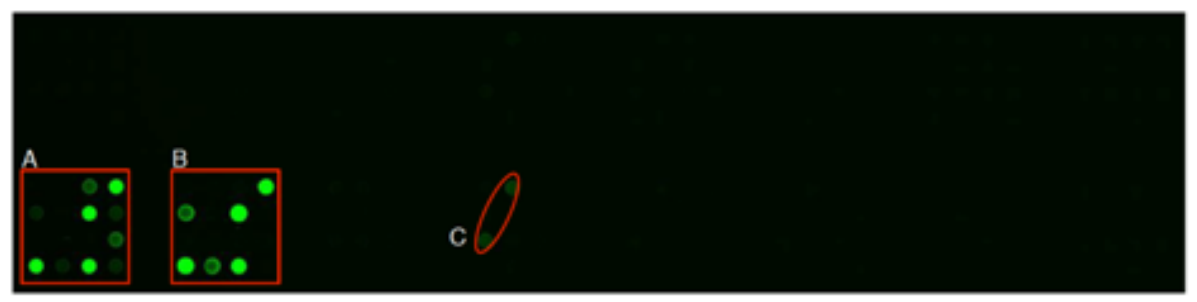

B) A. $\mathrm{CBX} 2, \mathrm{CBX} 4$, $\mathrm{CBX} 6, \mathrm{CBX} 7$ CBX8

B. CDY1, CDYL1b, CDYL2

C. MRG15

BOX A
\begin{tabular}{|l|l|l|l|l|l|l|l|}
\hline ARID4A & ARID $4 B$ & CBX2 & CBX 4 \\
\hline CBX6 & Blank & CBX7 & CBX8 \\
\hline ARID $4 B$ & ARID $4 A$ & Blank & CBX 2 & HP $1 \beta$ & CBX3 & CDY1 \\
\hline CBX7 & CBX6 & CBX 4 & CBX8 & Blank & CDY2 & MSL3 \\
\hline HP1 $1 \beta$ & CBX 5 & Blank & CBX3 \\
\hline CDYL2 & CDYL1b & CDY1 & MSL3 \\
\hline
\end{tabular}

C)

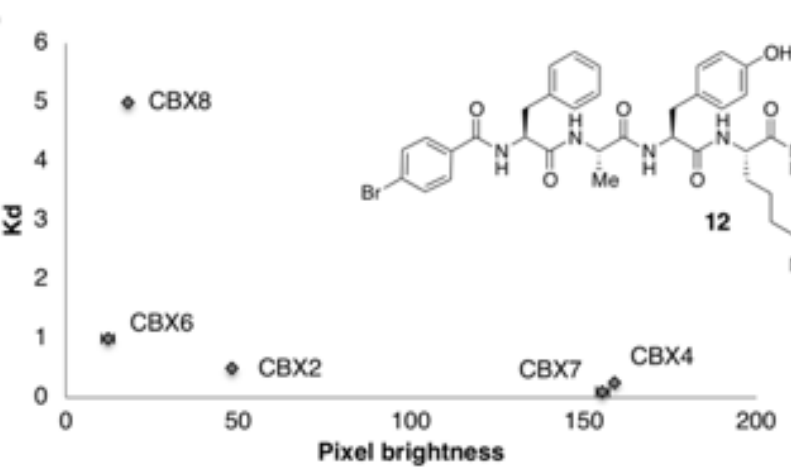

Figure 10: Protein microarray made up of 98 human methyl reader proteins shows peptidic inhibitors are selective against a broad set of methyl reader targets. Proteins were coated onto the wells in each plate with each square representing a family of proteins. A) Protein microarray with compound 12. B) Legend of proteins in box A and B. Box A contains polycomb paralogs, box B contains HP1 homologs and CDYL proteins, and box $\mathrm{C}$ highlights weak off target binding to MRG domains. The full map of the protein microarray is available in Supporting Figure S26.

C) $\mathrm{K}_{d}$ values of compound 3 (dye labeled analog of 12) with CBX proteins plotted against brightness of each spot from protein microarray (quantified using ImageJ) and chemical structure of biotin-tagged compound 12. 
To ensure this data was in agreement with $\mathrm{K}_{\mathrm{d}}$ values we collected from our FP assays, ImageJ software was used to quantify the brightness of each microarray spot and this was plotted against the $K_{d}$ values for analogous dye-labeled compound of 12 (Figure 10C). In general, it is clear that proteins with weak $K_{d}$ values also have weak pixel intensity showing that the microarray data is in qualitative agreement with our solution-phase results. CBX6 shows significantly less pixel brightness than would be expected from its $\mathrm{K}_{d}$ for this probe ligand, suggesting that microarrayed CBX6 does not accurately represent solution activity.

\section{Cell-based data}

We sought to determine the ability of the dye-labeled peptidic agents to be used in cellbased studies. Our efforts to study the inhibitors in cells included live cell imaging, flow cytometry, and MTT-based viability studies.

Cell-based studies showed varying degrees of cellular uptake and minimal changes cell cycle distribution as well as viability. Live cell imaging and immunofluorescence confocal imaging using TOV21G ovarian carcinoma cells and PC3 prostate cancer cells, treated with compounds $\mathbf{2}$ and $\mathbf{4}$ did not show compounds entering the cytoplasm or nucleus. Inhibitors were seen in characteristic punctate dots in the cytoplasm at concentrations above $10 \mu \mathrm{M}$, suggesting endosomal entrapment (data not shown). Flow cytometry experiments with TOV21G cells treated with compound $\mathbf{2}$ showed uptake of the inhibitor, supported by the formation of a population of fluorescent cells in each case (Figure S1). In the presence of the inhibitor, there was no observable change in the distribution of cells across Go, G1, S or G2/M (Table S1). This is also consistent with compounds being taken up in endosomes, but not able to escape to cytoplasm or nucleus in order to have a biological effect. We also carried out MTT assays, used to measure metabolic activity and cell viability, with TOV21G cells treated with inhibitor $\mathbf{4}$, and unlabeled analogs 6 and 7. A slight decrease in cell viability was seen for the cells treated with $\mathbf{4}$, however we did not observe a dose-response for the unlabelled analogs 6 and 7 (Figure S2). We conclude that these compounds are unfortunately not suitable for cell-based activity studies.

\section{Discussion}

Potent inhibitors were developed that are either pan-specific or partially selective within the polycomb paralog family. While none of the inhibitors developed were selective for a single 
CBX protein, we have identified several compounds with sub-micromolar affinity including two inhibitors that bind $\mathrm{CBX} 6 / 7$ with $\mathrm{IC}_{50}$ values $<100 \mathrm{nM}(\mathbf{3}, \mathbf{4})$.

Several compounds displayed class selectivity, with preferential binding to CBX6/7/8 over $\mathrm{CBX} 1 / 2 / 4$. We report inhibitors with a novel affinity for $\mathrm{CBX} 6 / 8$ over $\mathrm{CBX} 7$, which is unusual because $\mathrm{CBX} 7$ almost always gives higher affinity binding to peptidic and small molecule ligands..$^{9,10,12,13,15-17}$ This includes the most potent CBX8 inhibitor to date $(9,120 \mathrm{nM})$ and an inhibitor that is 2-fold selective for CBX8 over CBX7 (10). Our work also produced the first peptidic inhibitor that is 10 -fold selective for $\mathrm{CBX} 7$ over the highly similar chromodomain of CBX4 (compound 10).

We have identified areas of the peptide-binding groove that are different within the family of CBX proteins and form distinct interactions with the peptide ligands reported. Substitutions at the $(-1)$ position effect the hydrophobic clasp of the CBX proteins and alter binding affinities differentially within the family. Addition of a cyclopentyl moiety in the (-1) position increases binding to all $\mathrm{CBX}$ members with the greatest increase observed for binding to CBX8. The addition of two Phe residues at the N-terminus of the ligand diminishes binding to $\mathrm{CBX} 1 / 2 / 4$ to give inhibitors that are selective for $\operatorname{CBX} 6 / 7 / 8(\mathbf{9}, \mathbf{1 0})$. We predict that future efforts targeting the extended beta-groove, $(-1)$ and $(-2)$ position of the protein will aid in the discovery of selective inhibitors.

Substitutions at the $(+2)$ position of the ligand that participate in salt-bridge interactions alter the binding to $\mathrm{CBX} 6$ and $\mathrm{CBX} 8$. Our prediction that a Glu residue at the $(+2)$ position could improve binding affinity to CBX6 and 8 by interacting with Arg9 was partially correct. We did observe favorable salt-bridge interactions with a ligand (+2) Glu interacting with the protein residues Arg9 and Arg25 in MD simulations with CBX8. However, this interaction destabilized a key hydrogen bond between the (+1) serine in the ligand with Glu43 in CBX8.

The inhibitors developed are highly selective for the CBX polycomb proteins over other methyllysine reader proteins. The protein microarray studies with 12 show the inhibitors to be highly selective for the CBX polycomb paralogs over many other methyllysine readers. Potent off-target binding was observed with the CDY proteins. The peptidomimetic inhibitor UNC3866 targeting $\mathrm{CBX} 4 / \mathrm{CBX} 7$, was discovered to have off target binding to the CDY proteins. ${ }^{9}$ The authors followed up this work by repurposing the scaffold to develop a combinatorial peptide library resulting in the discovery of potent inhibitors of CDYL1/CDYL2. ${ }^{24}$ Future optimization 
of the inhibitors is needed to differentiate binding between the two highly similar families of chromodomains.

While the dye-labeled agents gave access to new biochemical assays, our efforts to use them in cell-based studies were unsuccessful. Several earlier CBX inhibitors have shown poor cellular activities due to low permeability, and the addition of FITC is unlikely to have improved this situation. Poor solubility of the peptidic inhibitors was another challenge and limited our ability to test higher concentrations of the inhibitors. Future efforts to use the reported inhibitors in cell-based studies will require alternative delivery strategies.

\section{Conclusion}

The goals of this work were to study the structural determinants of recognition for the $\mathrm{CBX}$ proteins and to create dye-labeled inhibitors as tools for biochemical and biophysical studies of the CBX proteins. We have successfully created potent inhibitors for each CBX polycomb paralog protein. The inhibitors reported are useful tools for biochemical assays and for future competitive based screens for the discovery of new ligands.

The SAR learned from this work provides new insights into the structure and molecular recognition properties of these proteins outside of the previously well explored aromatic cage binding pocket. This SAR lays the foundation for creating highly selective and cell-permeable chemical tools to study the role of CBX proteins in epigenetic regulation, which we will report in due course.

\section{ASSOCIATED CONTENT}

\section{Supporting Information}

Supplementary Figures and experimental methods are available below.

\section{AUTHOR INFORMATION}

Corresponding Author

* Fraser Hof. Email: fhof@uvic.ca

\section{Author Contributions}

The manuscript was written by N.M with revisions provided by F.H. N.M carried out the experimental design, synthesis, and characterization of peptides and binding affinities. J.M wrote 
and conceived of the modeling and MD simulations with input for revisions provided by I.P. C.C and C.W assisted with peptide synthesis. M.G, T.B and R.B grew and purified all CBX proteins. N.M, M.G and T.B carried out the FP assays. J.L and L.D conducted the cell-based studies. All authors have given approval to the final version of the manuscript.

\section{Funding Sources}

N.M and F.H thank the Prostate Cancer Foundation of British Columbia, West Coast Motorcycle Ride to Live, and CCSRI. Funding for the computational studies was provided by the National Science and Engineering Research Council of Canada, the Canada Foundation for Innovation, and the British Columbia Knowledge Development Fund. This research was in part performed in part using the Compute Canada and WestGrid computing resources.

\section{ACKNOWLEDGMENT}

F.H thanks the Canada Research Chairs program. Probing of arrayed methyl reader domains was made possible via the UT MDACC Protein array and analysis core (PAAC) CPRIT Grant RP180804 (Directed by Mark T. Bedford).

\footnotetext{
ABBREVIATIONS

Ac, acetyl; arg, arginine; CBX, chromobox; CDY, chromodomain Y, chromodomain, chromatin organization modifier; DNA, deoxyribonucleic acid; FITC, fluorescein isothiocyanate; FP, Fmoc, fluorenylmethoxyloxycarbonyl; FP, fluorescence polarization; Glu, glutamic acid; H3, histone 3; H3K9me3, trimethylated lysine 9 on histone 3; H3K27me3, trimethylated lysine 27 on histone 3; HP1, heterochromatin protein; $\mathrm{IC}_{50}$, inhibitory concentration that reduces effect by 50 percent; K, lysine; Kme3, trimethyllysine; $\mathrm{K}_{\mathrm{d}}$, dissociation constant; Leu, leucine; MeCN, acetonitrile; MD, molecular dynamics; MORF4L1, mortality factor 4-like protein.
}

\section{REFERENCES}

1. Rothbart SB, Strahl BD. Interpreting the language of histone and DNA modifications. Biochim Biophys Acta. 2014;1839(8):627-643.

2. Musselman CA, Khorasanizadeh S, Kutateladze TG. Towards understanding methyllysine readout. Biochim Biophys Acta. 2014;1839(8):686-693. 
3. Kaustov L, Ouyang H, Amaya M, et al. Recognition and specificity determinants of the human cbx chromodomains. J Biol Chem. 2011;286(1):521-529.

4. Aranda S, Mas G, Di Croce L. Regulation of gene transcription by Polycomb proteins. Science advances. 2015;1(11):e1500737.

5. Richly H, Aloia L, Di Croce L. Roles of the Polycomb group proteins in stem cells and cancer. Cell Death Dis. 2011;2:e204.

6. Vincenz C, Kerppola TK. Different polycomb group CBX family proteins associate with distinct regions of chromatin using nonhomologous protein sequences. Proc Natl Acad Sci U S A. 2008;105(43):16572-16577.

7. Ma RG, Zhang Y, Sun TT, Cheng B. Epigenetic regulation by polycomb group complexes: focus on roles of CBX proteins. Journal of Zhejiang University Science B. 2014;15(5):412-428.

8. Koppens M, van Lohuizen M. Context-dependent actions of Polycomb repressors in cancer. Oncogene. 2015;35:1341.

9. Stuckey JI, Dickson BM, Cheng N, et al. A cellular chemical probe targeting the chromodomains of Polycomb repressive complex 1. Nat Chem Biol. 2016;12(3):180-187.

10. Ren C, Morohashi K, Plotnikov AN, et al. Small-molecule modulators of methyl-lysine binding for the CBX7 chromodomain. Chem Biol. 2015;22(2):161-168.

11. Milosevich N, Warmerdam Z, Hof F. Structural aspects of small-molecule inhibition of methyllysine reader proteins. Future Med Chem. 2016;8(13):1681-1702.

12. Simhadri C, Daze KD, Douglas SF, et al. Chromodomain antagonists that target the polycomb-group methyllysine reader protein chromobox homolog 7 (CBX7). J Med Chem. 2014;57(7):2874-2883.

13. Simhadri C, Gignac MC, Anderson CJ, et al. Structure-Activity Relationships of Cbx7 Inhibitors, Including Selectivity Studies against Other Cbx Proteins. ACS Omega. 2016;1(4):541551.

14. Milosevich N, Gignac MC, McFarlane J, et al. Selective Inhibition of CBX6: A Methyllysine Reader Protein in the Polycomb Family. ACS Med Chem Lett. 2016;7(2):139-144.

15. Stuckey JI, Simpson C, Norris-Drouin JL, et al. Structure-Activity Relationships and Kinetic Studies of Peptidic Antagonists of CBX Chromodomains. J Med Chem. 2016;59(19):8913-8923. 
16. Ren C, Smith SG, Yap KL, et al. Structure-Guided Discovery of Selective Antagonists for the Chromodomain of Polycomb Repressive Protein CBX7. ACS Med Chem Lett. 2016;7(6):601-605.

17. Denton KE, Wang S, Gignac MC, et al. Robustness of In Vitro Selection Assays of DNA-Encoded Peptidomimetic Ligands to CBX7 and CBX8. SLAS Discov. 2018;23(5):417-428.

18. James M, Katherine K, Irina P. Accelerated Molecular Dynamics for Structural Prediction in Protein/Peptide Binding: The SLICE Method. 2019.

19. Trott O, Olson AJ. AutoDock Vina: improving the speed and accuracy of docking with a new scoring function, efficient optimization, and multithreading. $J$ Comput Chem. 2010;31(2):455-461.

20. AMBER 2018 [computer program]. San Francisco: University of California; 2018.

21. Jurrus E, Engel D, Star K, et al. Improvements to the APBS biomolecular solvation software suite. Protein Sci. 2018;27(1):112-128.

22. Miller BR, McGee TD, Swails JM, Homeyer N, Gohlke H, Roitberg AE. MMPBSA.py: An Efficient Program for End-State Free Energy Calculations. Journal of Chemical Theory and Computation. 2012;8(9):3314-3321.

23. Kim J, Daniel J, Espejo A, et al. Tudor, MBT and chromo domains gauge the degree of lysine methylation. EMBO Rep. 2006;7(4):397-403.

24. Barnash KD, Lamb KN, Stuckey JI, et al. Chromodomain Ligand Optimization via Target-Class Directed Combinatorial Repurposing. ACS Chemical Biology. 2016;11(9):24752483. 


\section{Supplementary information for:}

Pan-specific and partially selective dye-labeled peptidic inhibitors of the polycomb paralog proteins

Natalia Milosevich ${ }^{\mathrm{a}}$, James McFarlane ${ }^{\mathrm{a}}$, Michael C. Gignac ${ }^{\mathrm{a}}$, Janessa Li ${ }^{\mathrm{a}}$, Tyler M. Brown ${ }^{\mathrm{a}}$, Chelsea R. Wilson ${ }^{\mathrm{a}}$, Lindsay Devorkin ${ }^{\mathrm{b}}$, Caitlin S. Croft ${ }^{\mathrm{a}}$, Rebecca Hof ${ }^{\mathrm{a}}$, Irina Paci ${ }^{\mathrm{a}}$, Julian J. Lum $^{\mathrm{b}}$ and Fraser Hof ${ }^{\mathrm{a} *}$

aDepartment of Chemistry, University of Victoria, Victoria BC, V8W 3V6, Canada ${ }^{\mathrm{b}}$ BC Cancer Agency - Trev and Joyce Deeley Research Centre, Victoria BC, V8R 6V5, Canada

*Email: fhof@uvic.ca

\section{Table of Contents}

Supplementary Figures S1-S2 and Supplementary Table S1

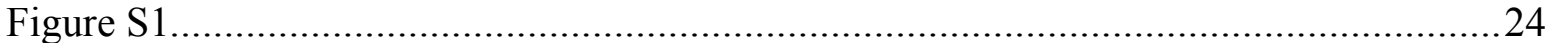

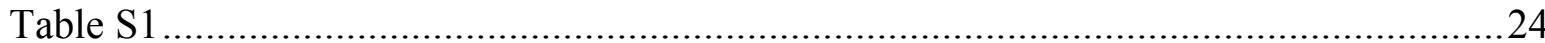

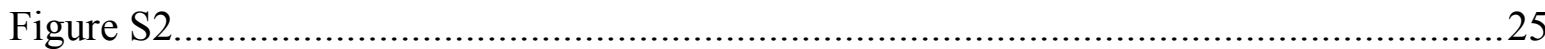

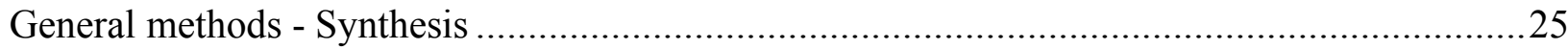

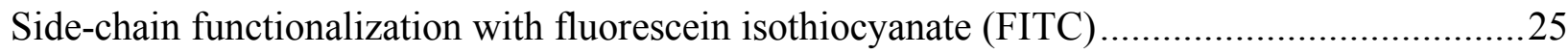

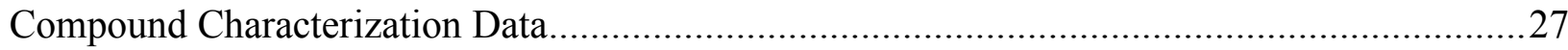

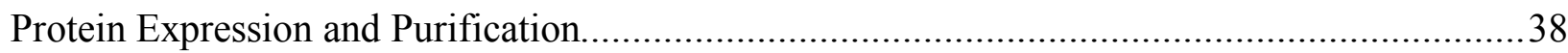

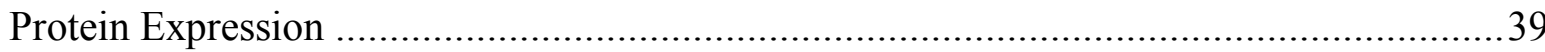

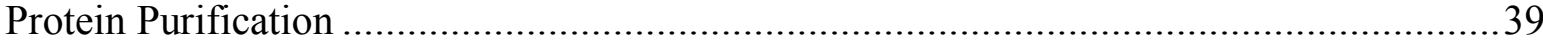

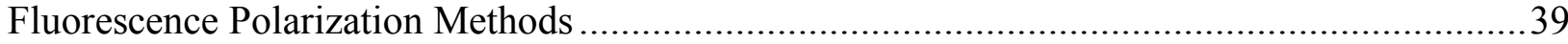

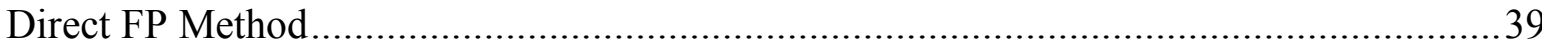

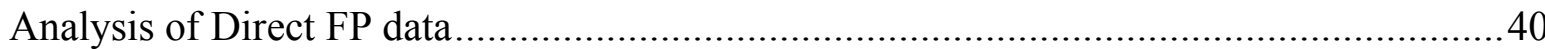

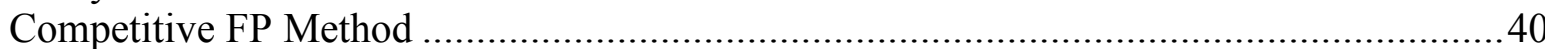

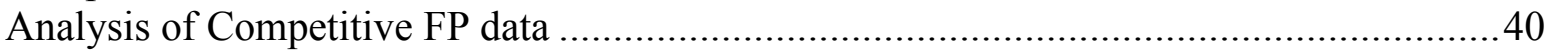

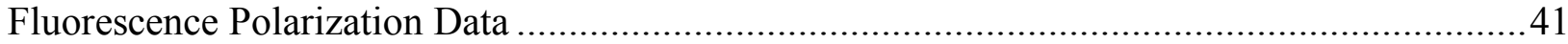

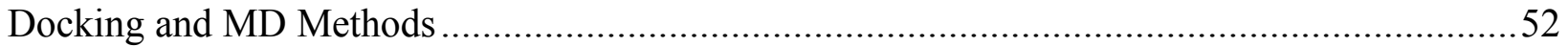

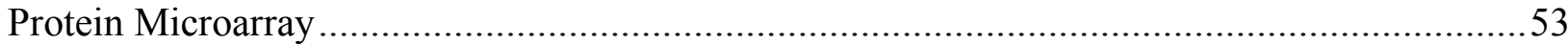

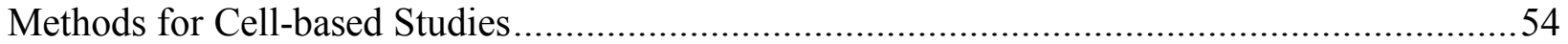

FACS analysis of Inhibitor Uptake, Cell Viability and Cell Cycle Distribution...................54

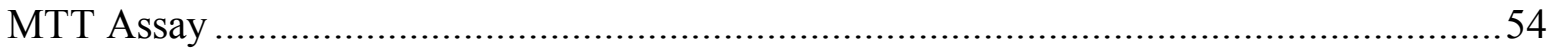

*Fraser Hof. e-mail: fhof@uvic.ca 


\section{Supplementary Figures S1-S2 and Supplementary Table S1}
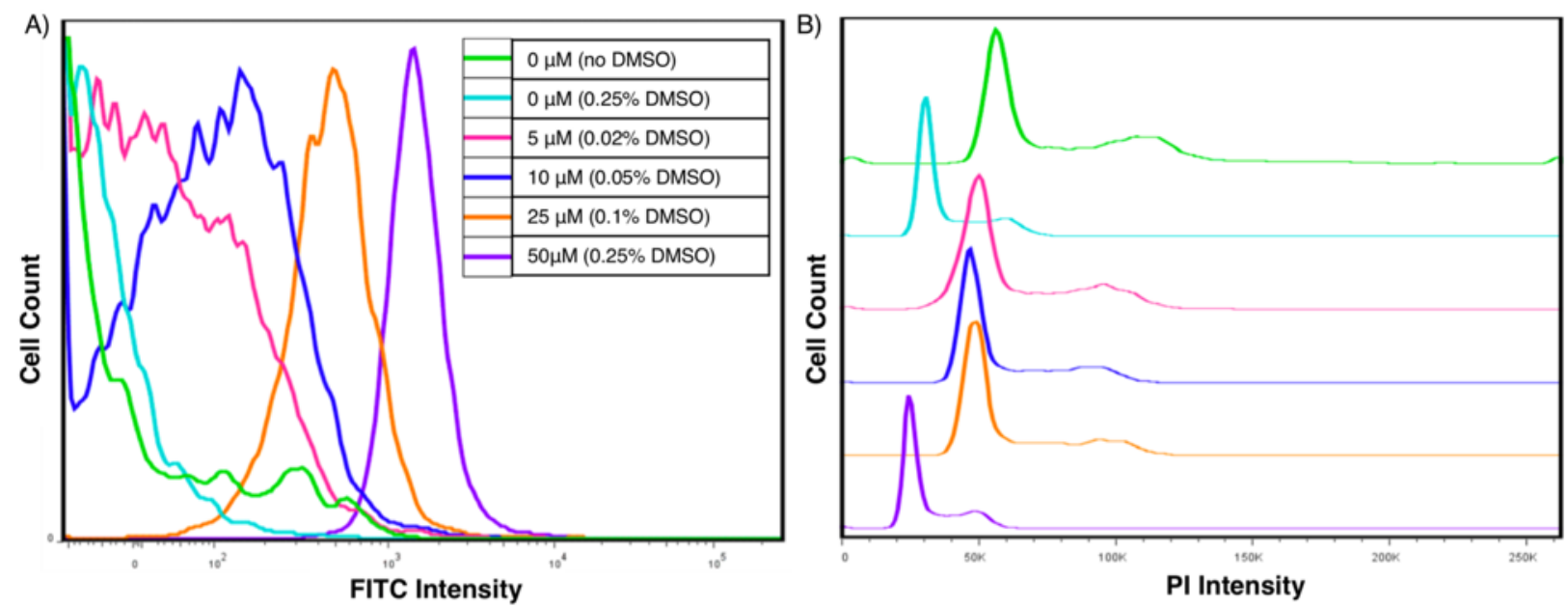

Figure S1: Uptake efficiency and PI based cell cycle analysis for TOV21G cells treated with compound 2 show uptake of inhibitor with no change to cell cycle distribution. A) Uptake efficiency based on FITC intensity. Samples treated with equivalent volume of vehicle control (DMSO - light blue trace compared to purple trace) show increased fluorescent signal arising from $50 \mu \mathrm{M}$ treatment of compound 2. B) Cell cycle distribution (G1, S and G2) based on PI intensity. Samples treated with equivalent volume of vehicle control (DMSO - light blue trace compared to purple trace) show no change in cell cycle distribution. Samples were run on Becton Dickinson FACS Calibur ${ }^{\mathrm{TM}}$ and analyzed using FlowJo 7.6.5 software.

Table S1: Cell cycle distribution (G1, S, G2) of TOV21G cells remained constant with varying concentrations of compound 2 (measured from Figure S1).

\begin{tabular}{lccc}
\hline Concentration of 2 & G1 (\%) & S (\%) & G2 (\%) \\
\hline $0 \mu \mathrm{M}$ (no DMSO) & 49 & 14 & 21 \\
$0 \mu \mathrm{M}(0.25 \%$ DMSO) & 66 & 14 & 12 \\
$5 \mu \mathrm{M}(0.02 \%$ DMSO) & 60 & 13 & 16 \\
$10 \mu \mathrm{M}(0.05 \%$ DMSO) & 65 & 14 & 12 \\
$25 \mu \mathrm{M}(0.1 \%$ DMSO) & 66 & 15 & 11 \\
$50 \mu \mathrm{M}(0.25 \%$ DMSO) & 68 & 12 & 12 \\
\hline
\end{tabular}


A)

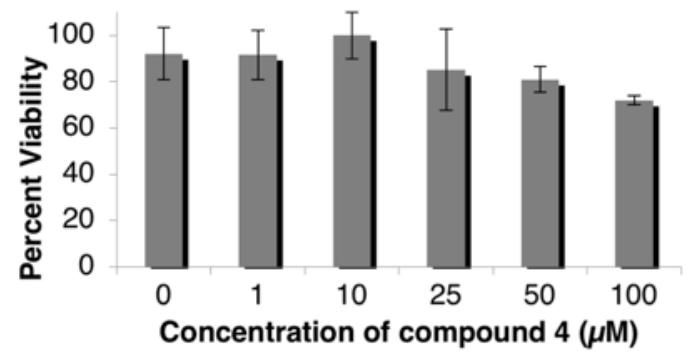

B)

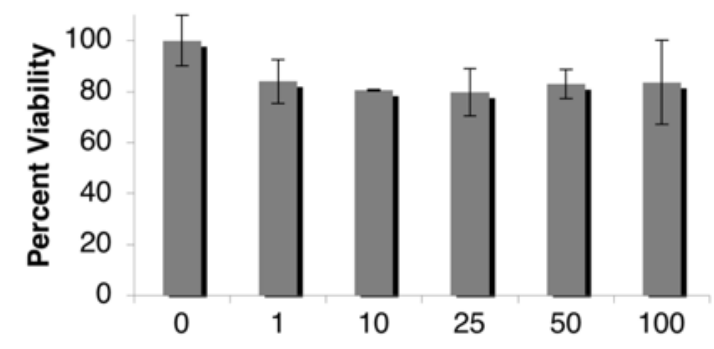

C)

Concentration of compound $6(\mu \mathrm{M})$

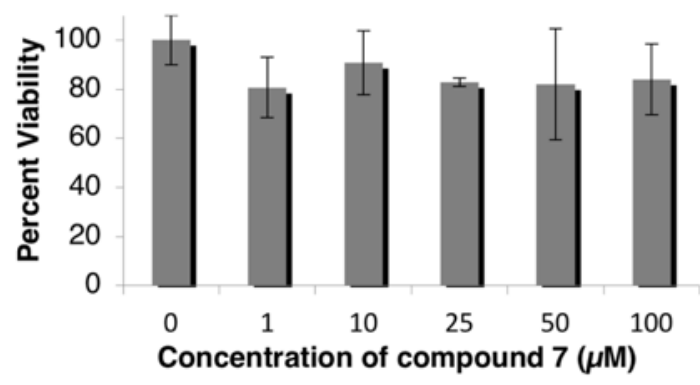

Figure S2: Cell viability determined using an MTT assay carried out with TOV21G cells treated with compounds 4, 6 and 7. A) Percent viability of TOV21G cells treated with 4, B) Percent viability of TOV $21 \mathrm{G}$ cells treated with 6, C) Percent viability of TOV21G cells treated with 7 .

\section{General methods - Synthesis}

Fmoc-Lys(Me) ${ }_{3}-\mathrm{OH}$ was purchased from GL Biochem. All other natural and un-natural amino acids, and coupling agents were purchased from ChemImpex. Compounds were synthesized on Rink amide resin using CEM Liberty microwave synthesizer standard Fmoc protocols using HBTU as coupling agent.

\section{Side-chain functionalization with fluorescein isothiocyanate (FITC)}

Side-chain functionalization with fluorescein isothiocyanate (FITC) was achieved by incorporation of either a Fmoc-beta-Alanine or a side-chain Mtt-protected lysine (see Figure 3). For functionalization of Fmoc-beta-Alanine, Fmoc was removed following standard protocols after synthesis was completed on resin. A solution of $20 \%$ piperdine in DMF $(10 \mathrm{~mL})$ was added 
to the resin and bubbled with $\mathrm{N}_{2}$ for 5 minutes (repeated $3 \times$ ). The resin was washed $3 \times$ with DMF between each reaction. FITC (5 equiv) was added to a $10 \mathrm{~mL}$ solution of 1:1 DMF and pyridine. This solution was added to the resin and bubbled with $\mathrm{N}_{2}$ at ambient temperature overnight.

For functionalization of side-chain Mtt-protected lysine, the Mtt protecting group was cleaved after complete synthesis on resin. Selective cleavage was achieved with treatment of 2:2:96 TFA/triisopropylsilane $/ \mathrm{CH}_{2} \mathrm{Cl}_{2}$ for 20 minutes $(\times 4)$. The resin was filtered and washed with $\mathrm{CH}_{2} \mathrm{Cl}_{2}(3 \times 5 \mathrm{~mL})$ and DMF $(3 \times 5 \mathrm{~mL})$. FITC ( 5 equiv) was added to a $10 \mathrm{~mL}$ solution of $1: 1$ DMF and pyridine. This solution was added to the resin and bubbled with $\mathrm{N}_{2}$ at ambient temperature overnight.

Following the functionalization with FITC, all peptide/resin solutions were filtered and the resin washed with DMF $(3 \times 5 \mathrm{~mL})$ and $\mathrm{CH}_{2} \mathrm{Cl}_{2}(3 \times 5 \mathrm{~mL})$ and air-dried. The product was cleaved from resin with $10 \mathrm{~mL}$ of 95:2.5:2.5 TFA/ $\mathrm{H}_{2} \mathrm{O}$ /triisopropylsilane for $2.5 \mathrm{~h}$. The solution was then concentrated in vacuo and added to cold diethyl ether to yield a crude yellow precipitate that was collected by centrifugation. Purifications by preparative HPLC were carried out using a Phenomenex Luna, $5 \mu \mathrm{m}$, C-18 column, $250 \times 21.20 \mathrm{~mm}$ column. Peptides were characterized using LC-MS and ESI-MS and purity was determined to be $>95 \%$ by analytical LC-MS. Retention times reported arise from analytical traces done on a Thermo Scientific C-18 column, $5 \mu \mathrm{m}, 4.6 \mathrm{~mm} \times 250 \mathrm{~mm}$, flow rate of $1.5 \mathrm{~mL} / \mathrm{min}$, gradient running from $90: 10$ water $(0.1 \%$ TFA) and $\mathrm{MeCN}(0.1 \%$ TFA) to $10: 90$ water $(0.1 \%$ TFA $)$ and $\mathrm{MeCN}(0.1 \%$ TFA) over 30-38 $\min$.

For side-chain functionalization with biotin, a side-chain Mtt-protected lysine was used. After synthesis on resin, the Mtt protecting groups were cleaved as described above. (+)-Biotin Nhydroxysuccinimide ester ( 5 equiv) was added to a $10 \mathrm{~mL}$ solution of DMF with DIPEA (10 equiv). This solution was then added to the resin and bubbled with $\mathrm{N}_{2}$ at ambient temperature overnight. Cleavage and purification is the same as described above. 


\section{Compound Characterization Data}

A)

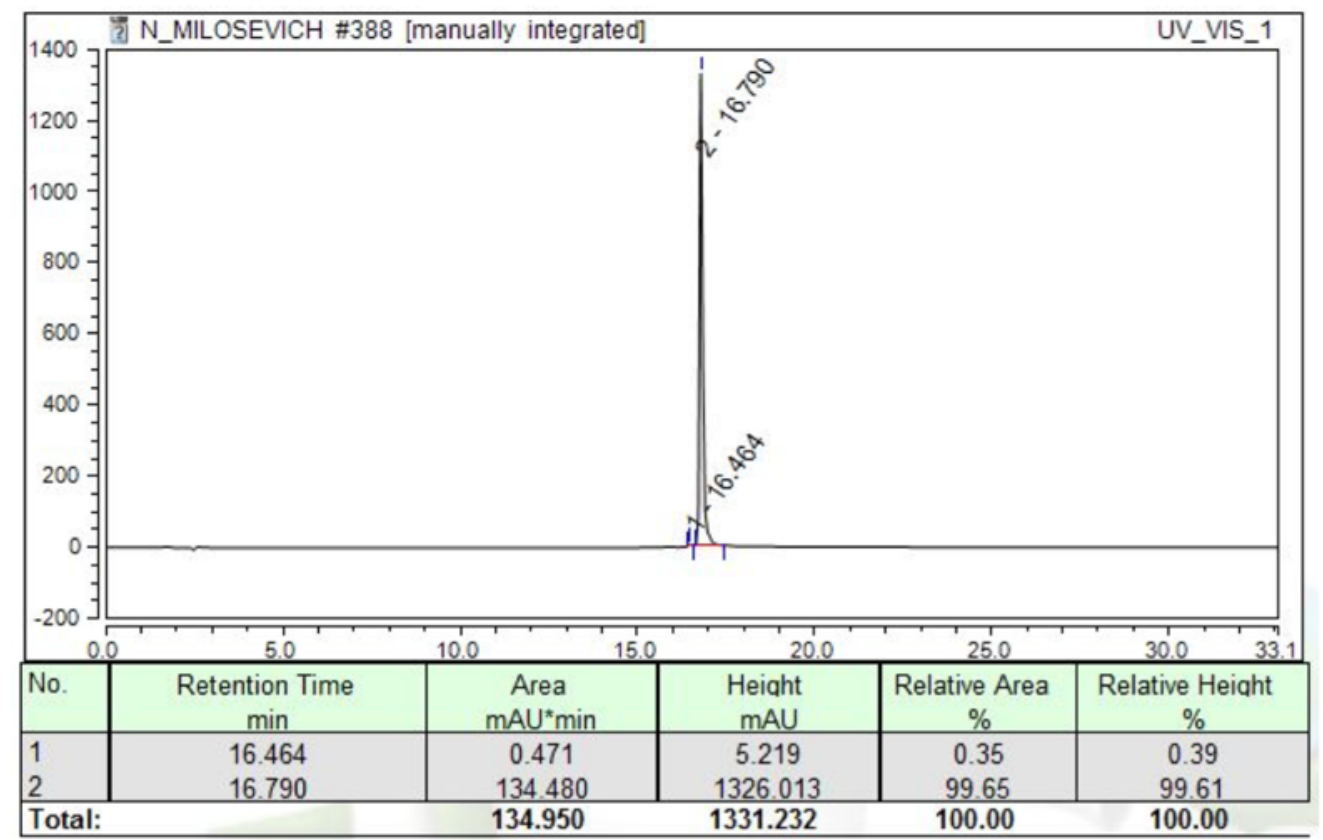

B)

NM-1-91(2)pure \#22-42 RT: 0.65-1.27 AV: $21 \quad \mathrm{NL}: 1.05 \mathrm{E}$

$\mathrm{T}:+\mathrm{p}$ ESI Full ms [100.00-2000.00]

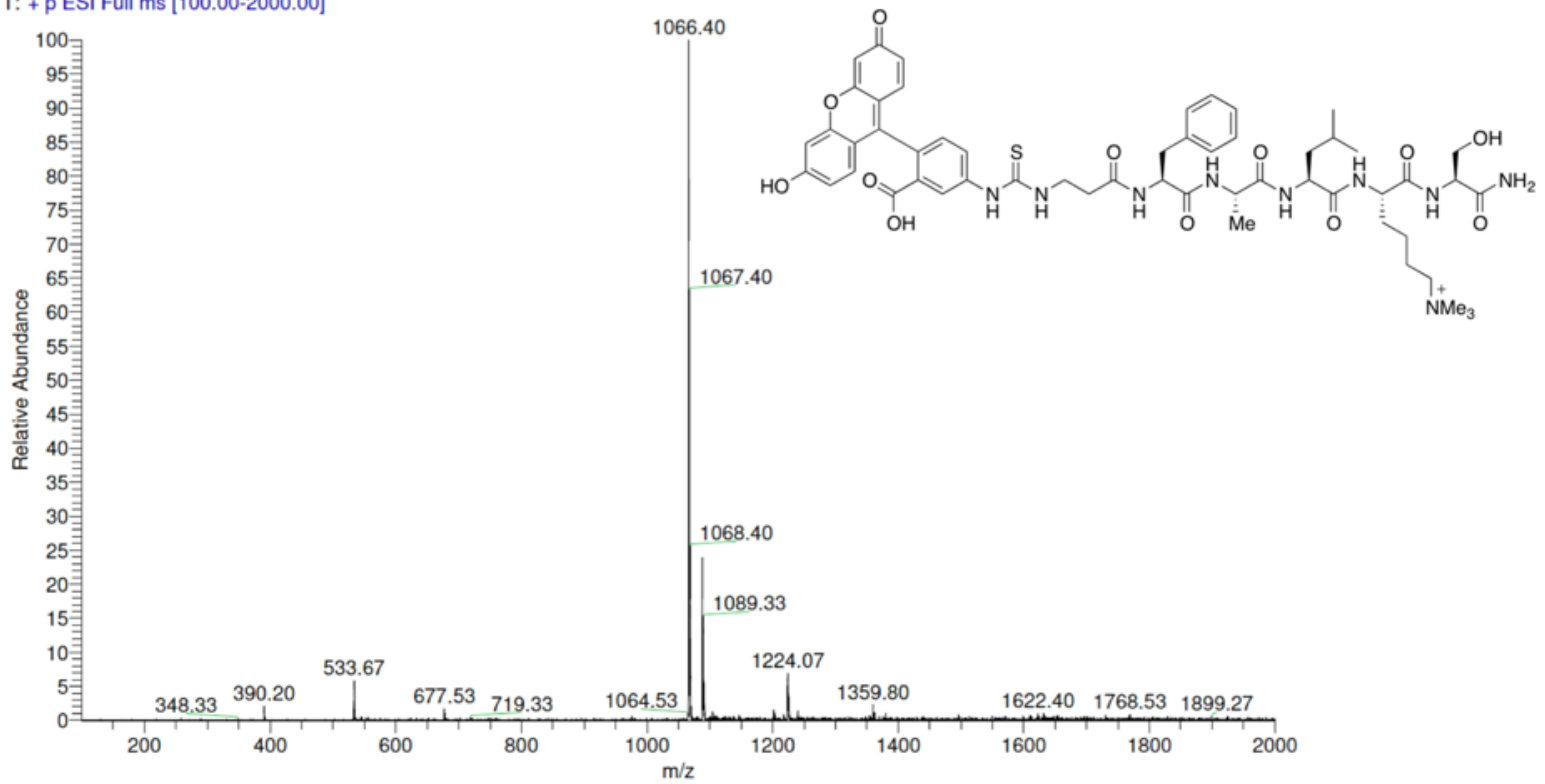

Figure S3. Characterization data for compound 1 A) Analytical LC/MS trace, B) Low resolution mass spectrum. LR-ESI-MS: [m/z] calcd. for $\mathrm{C}_{54} \mathrm{H}_{68} \mathrm{~N}_{9} \mathrm{O}_{12} \mathrm{~S}: 1066.47$; found: 1066.40 . 
A)

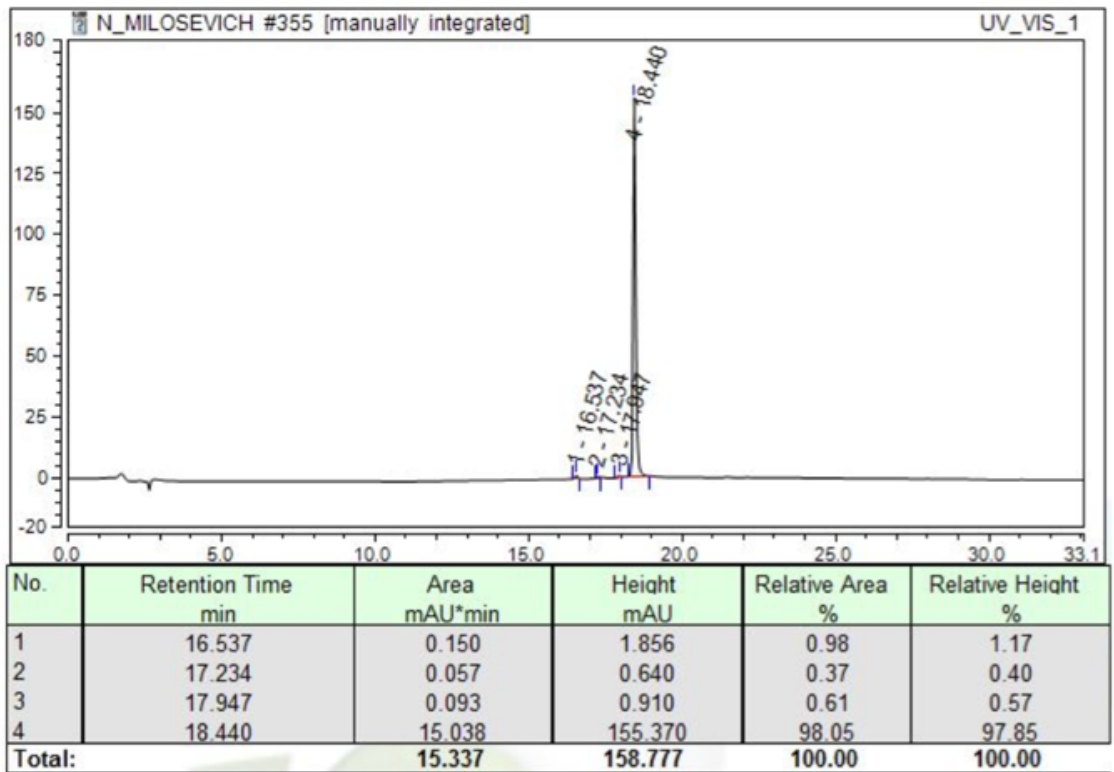

B) NM-1-91(1) \#20-39 RT: 0.64-1.28 AV: $20 \quad \mathrm{NL}: 4.26 \mathrm{E}$

$\mathrm{T}:$ + p ESI Full ms [100.00-2000.00]

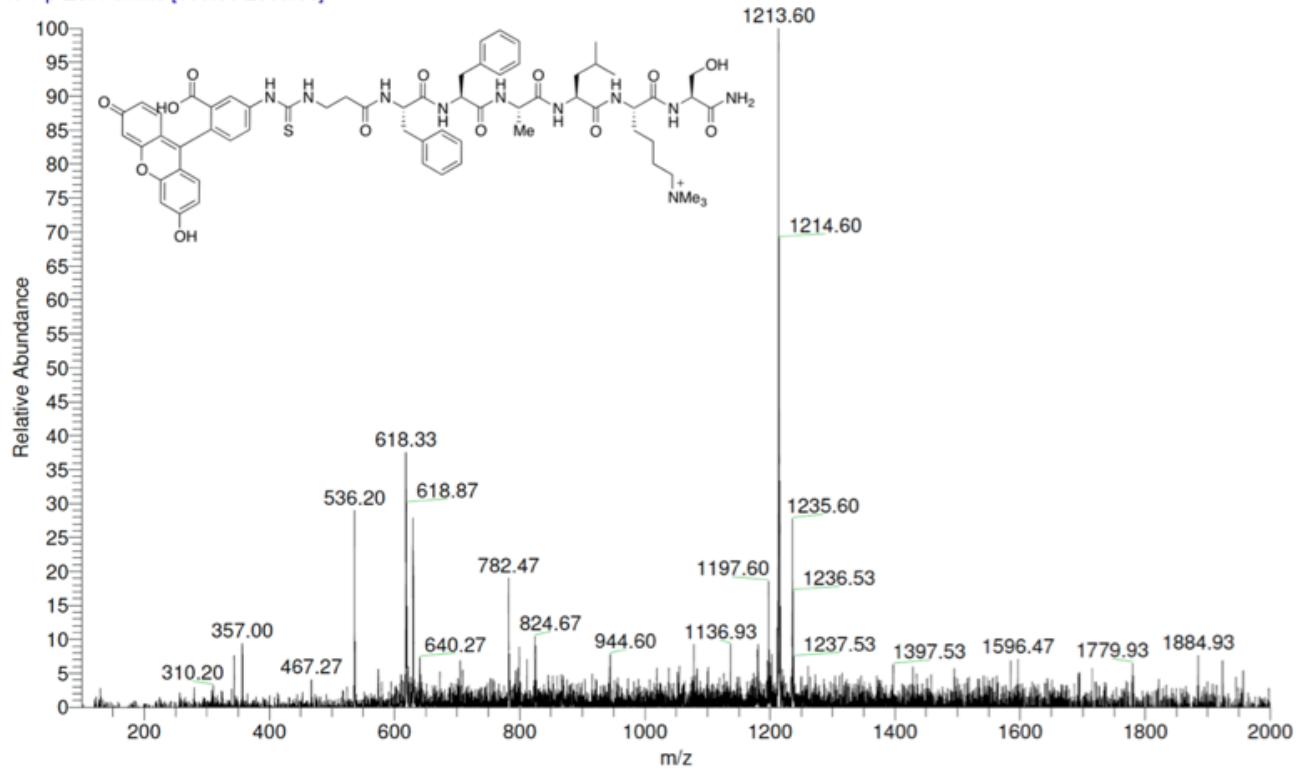

Figure S4. Characterization data for compound 2. A) Analytical LC/MS trace, B) Low resolution mass spectrum. LR-ESI-MS: $[\mathrm{m} / z]$ calcd. for $\mathrm{C}_{63} \mathrm{H}_{77} \mathrm{~N}_{10} \mathrm{O}_{13} \mathrm{~S}: 1213.54$; found: 1213.60 . 
A)
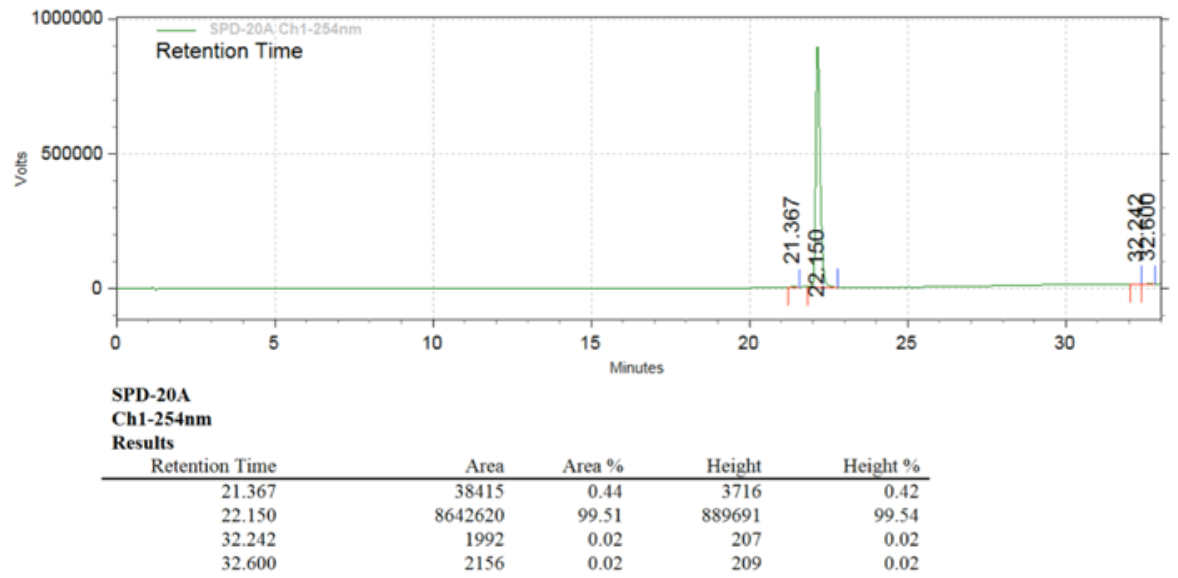

\begin{tabular}{r|r|r|r|r|}
\hline Totals & 8685183 & 100.00 & 893823 & 100.00 \\
\hline
\end{tabular}

20180228_NMilosev_NM-4-181_pure \#7-34 RT: 0.21-1.06 AV: 28 NL: 2.62E6

T: + p ESI Full ms [100.00-2000.00]

$$
100
$$

$100 \exists$
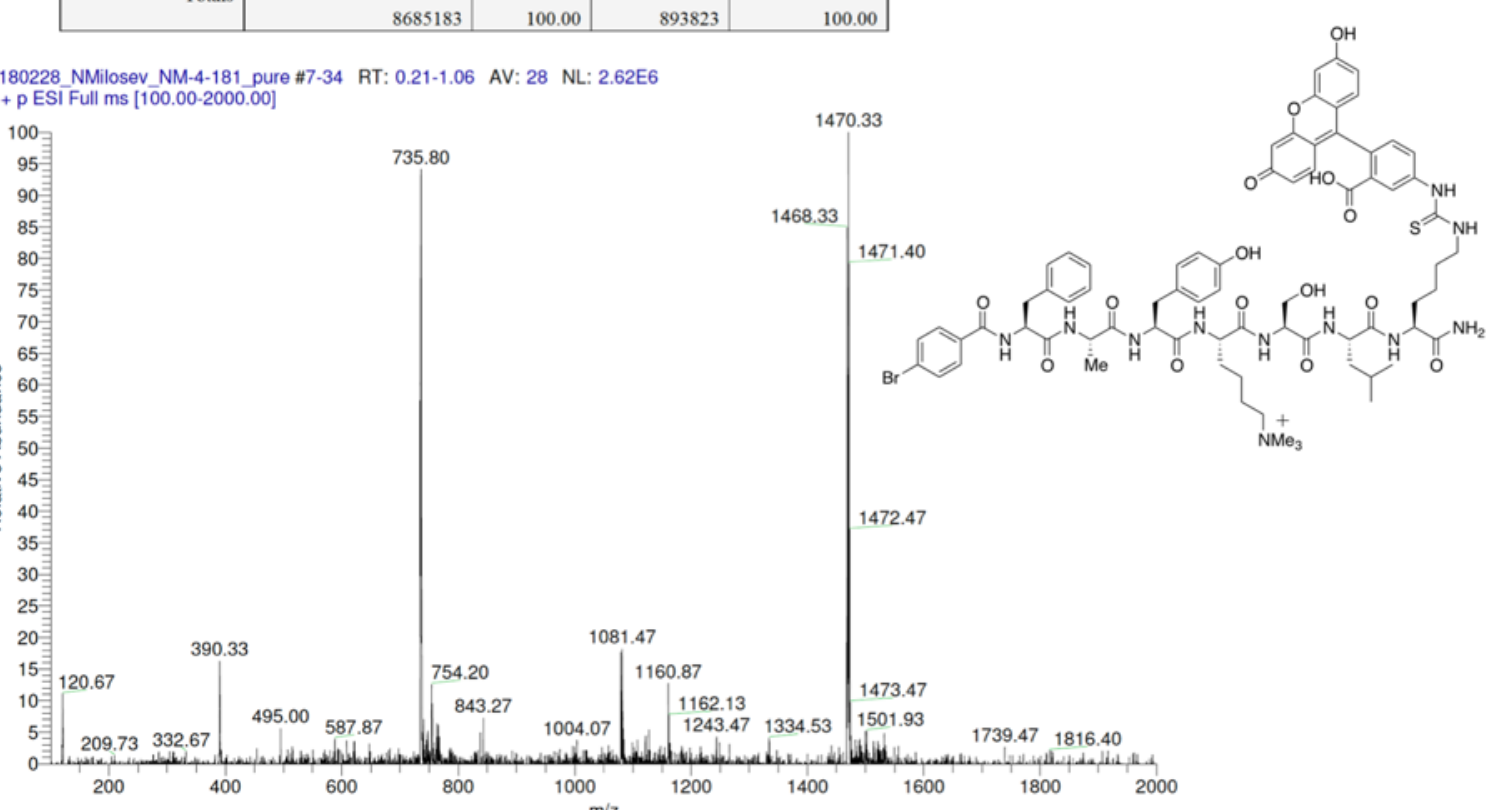

1468.33

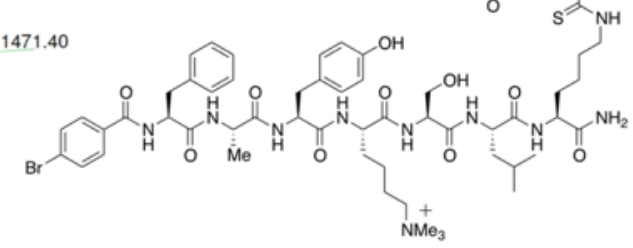

Figure S5. Characterization data for compound 3. A) Analytical LC/MS trace, B) Low resolution mass spectrum. LR-ESI-MS: $[\mathrm{m} / z]$ calcd. for $\mathrm{C}_{73} \mathrm{H}_{89} \mathrm{BrN}_{11} \mathrm{O}_{15} \mathrm{~S}^{+}$: 1470.54; found: 1470.33 . 
A)

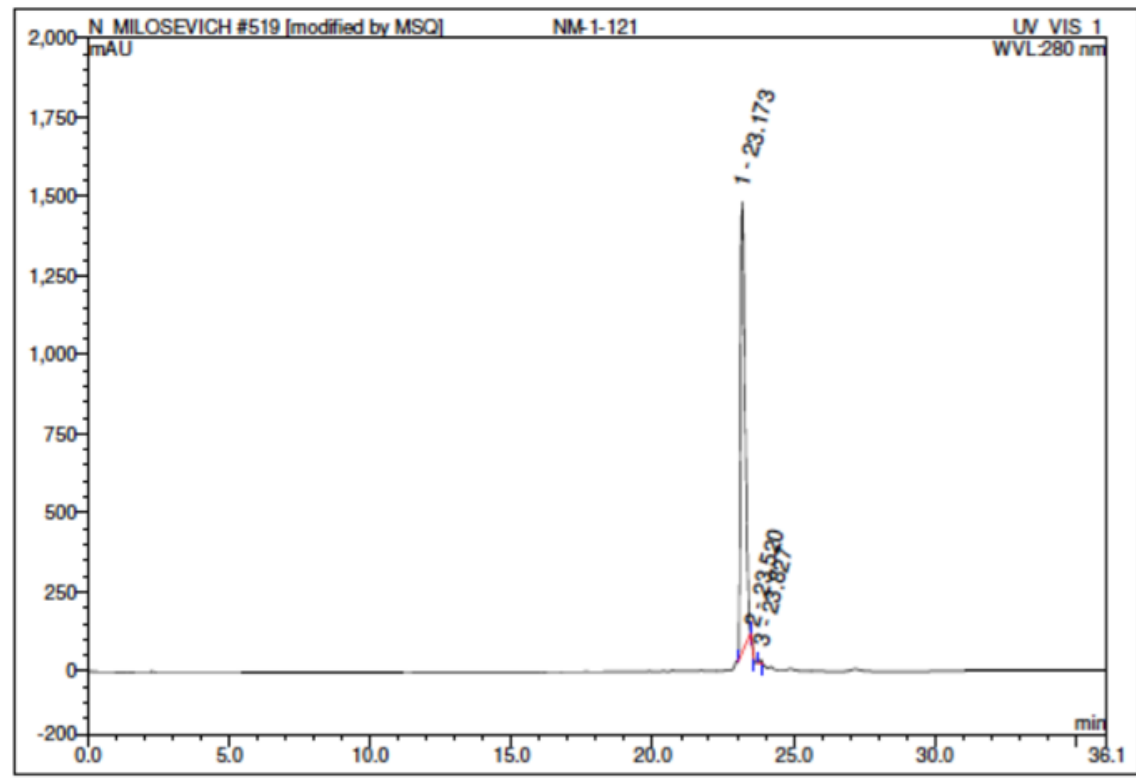

\begin{tabular}{|c|c|c|c|c|c|c|c|}
\hline No. & $\begin{array}{c}\text { Ret.Time } \\
\text { min }\end{array}$ & Peak Name & $\begin{array}{c}\text { Height } \\
\text { mAU }\end{array}$ & $\begin{array}{c}\text { Area } \\
\text { mAU*min }\end{array}$ & $\begin{array}{c}\text { Rel.Area } \\
\%\end{array}$ & $\begin{array}{c}\text { Amount } \\
\mu l\end{array}$ & Type \\
\hline 1 & 23.17 & n.a. & 1424.024 & 264.891 & 99.50 & n.a. & $\mathrm{BMb}^{*}$ \\
\hline 2 & 23.52 & n.a. & 5.588 & 0.269 & 0.10 & n.a. & bMB* \\
\hline 3 & 23.83 & n.a. & 11.773 & 1.050 & 0.39 & n.a. & BMB* $^{*}$ \\
\hline Total: & & & 1441.385 & 266.210 & 100.00 & 0.000 & \\
\hline
\end{tabular}

B)

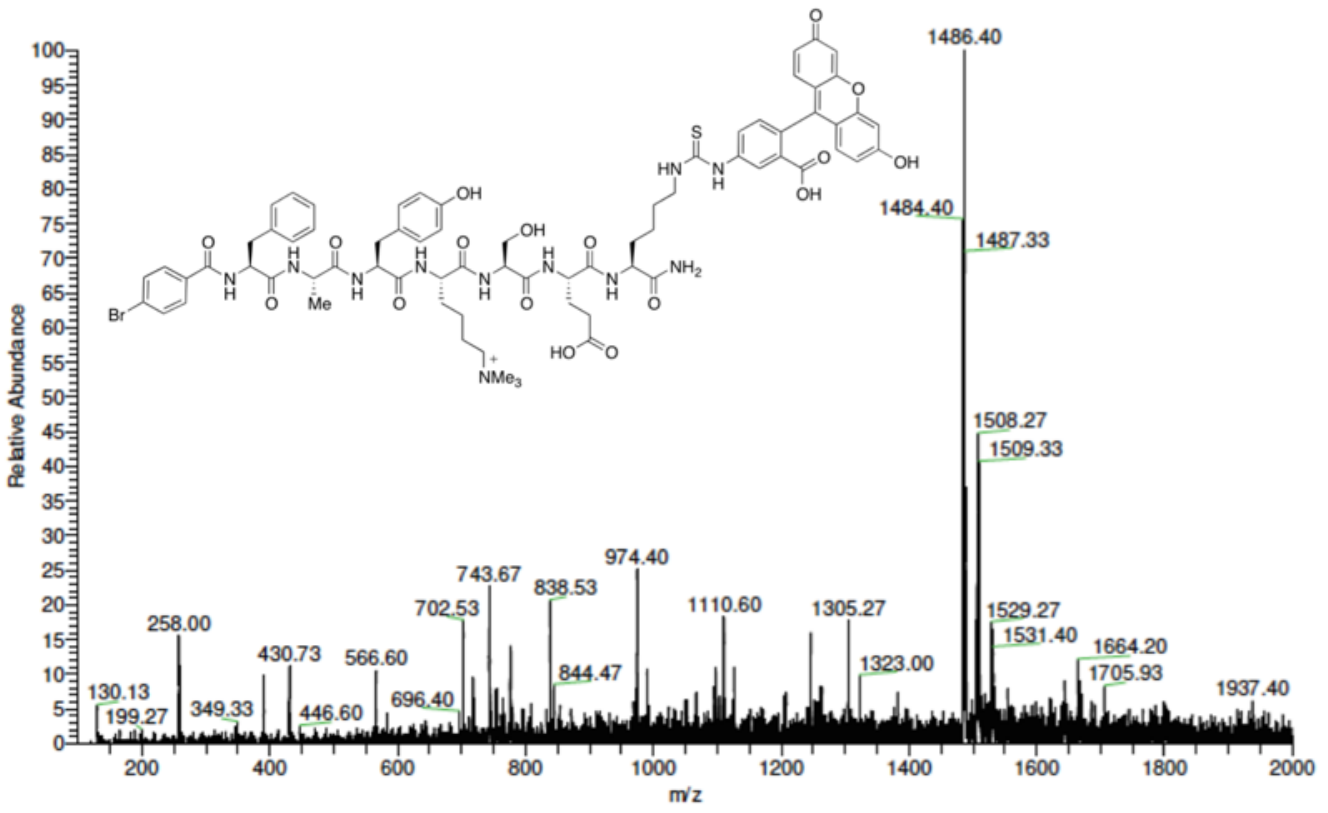

Figure S6. Characterization data for compound 4. A) Analytical LC/MS trace, B) Low resolution mass spectrum. LR-ESI-MS: [m/z] calcd. for $\mathrm{C}_{72} \mathrm{H}_{85} \mathrm{BrN}_{11} \mathrm{O}_{17} \mathrm{~S}^{+}: 1486.50$; found: 1486.40 . 
A)

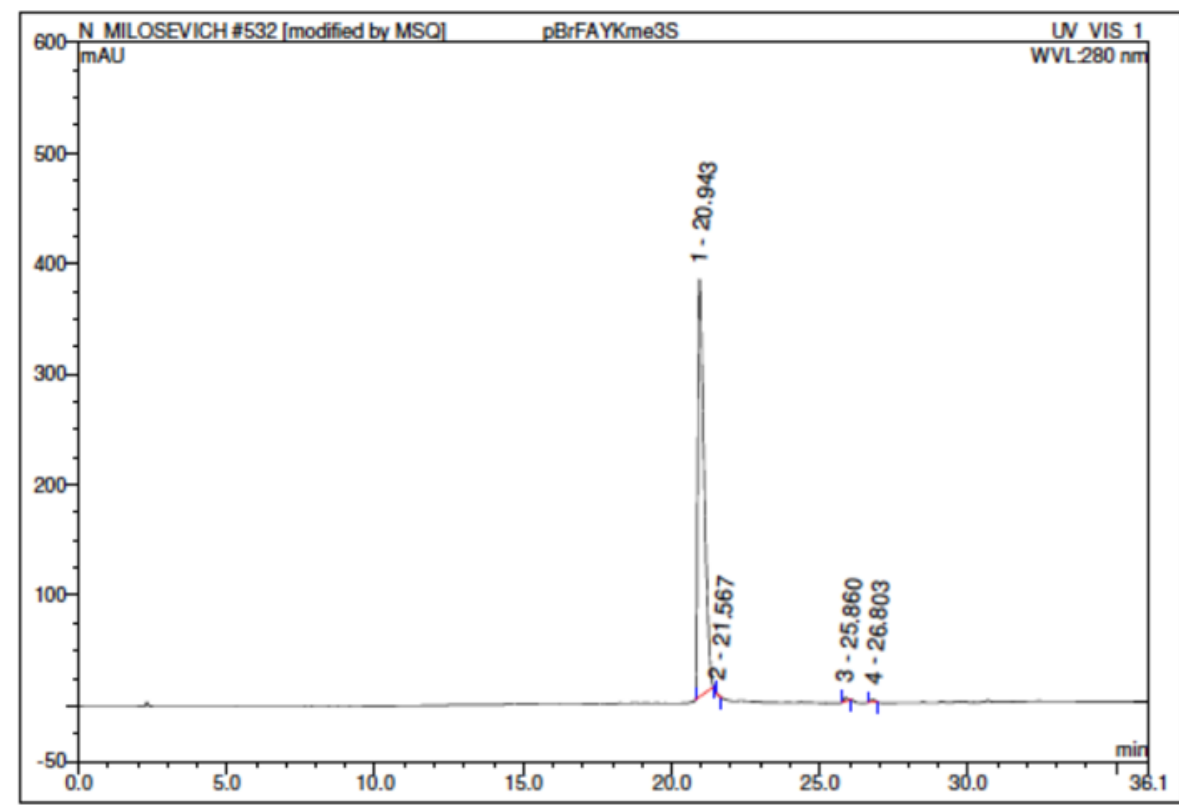

\begin{tabular}{|r|ccrrrrr|}
\hline No. & $\begin{array}{c}\text { Ret. Time } \\
\text { min }\end{array}$ & Peak Name & $\begin{array}{c}\text { Height } \\
\text { mAU }\end{array}$ & $\begin{array}{c}\text { Area } \\
\text { mAU*min }\end{array}$ & $\begin{array}{r}\text { Rel.Area } \\
\%\end{array}$ & $\begin{array}{c}\text { Amount } \\
\mu l\end{array}$ & Type \\
\hline 1 & 20.94 & n.a. & 377.219 & 94.395 & 99.05 & n.a. & BMB* $^{*}$ \\
2 & 21.57 & n.a. & 0.474 & 0.023 & 0.02 & n.a. & BMB* $^{*}$ \\
3 & 25.86 & n.a. & 3.386 & 0.466 & 0.49 & n.a. & BMB* $^{*}$ \\
4 & 26.80 & n.a. & 2.205 & 0.420 & 0.44 & n.a. & BMB* $^{*}$ \\
\hline Total: & & & 383.285 & 95.304 & 100.00 & 0.000 & \\
\hline
\end{tabular}

B)

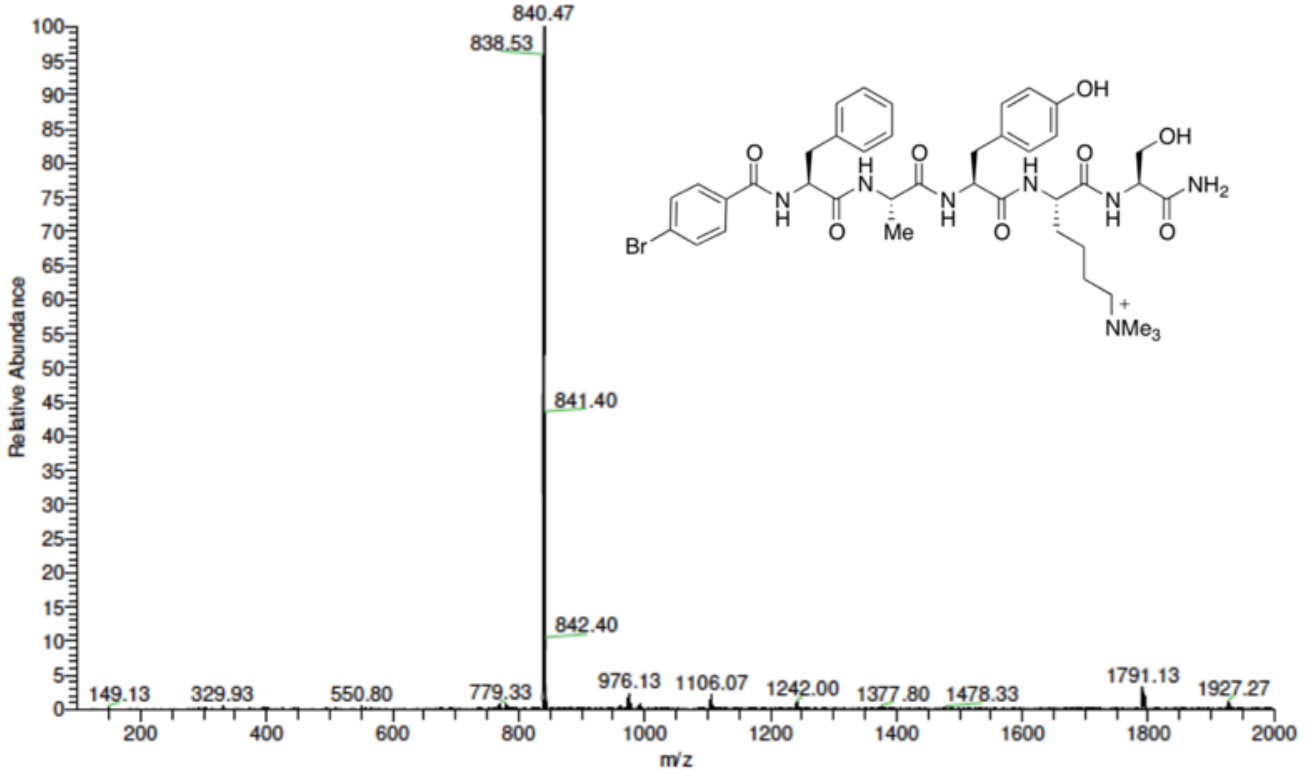

Figure S7. Characterization data for compound 5. A) Analytical LC/MS trace, B) Low resolution mass spectrum. LR-ESI-MS: $[\mathrm{m} / \mathrm{z}]$ calcd. for $\mathrm{C}_{40} \mathrm{H}_{53} \mathrm{BrN}_{7} \mathrm{O}^{+}:$838.31; found: 838.53. 
A)

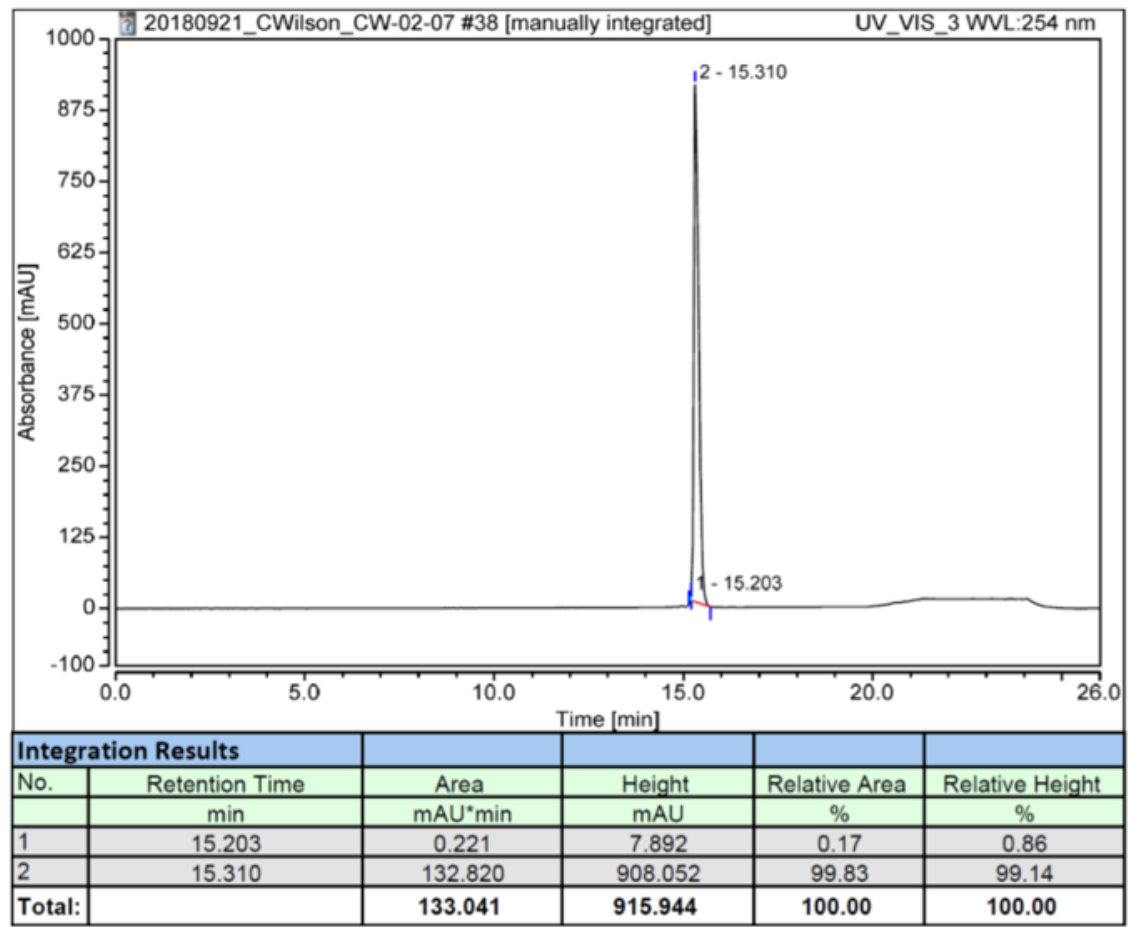

B)

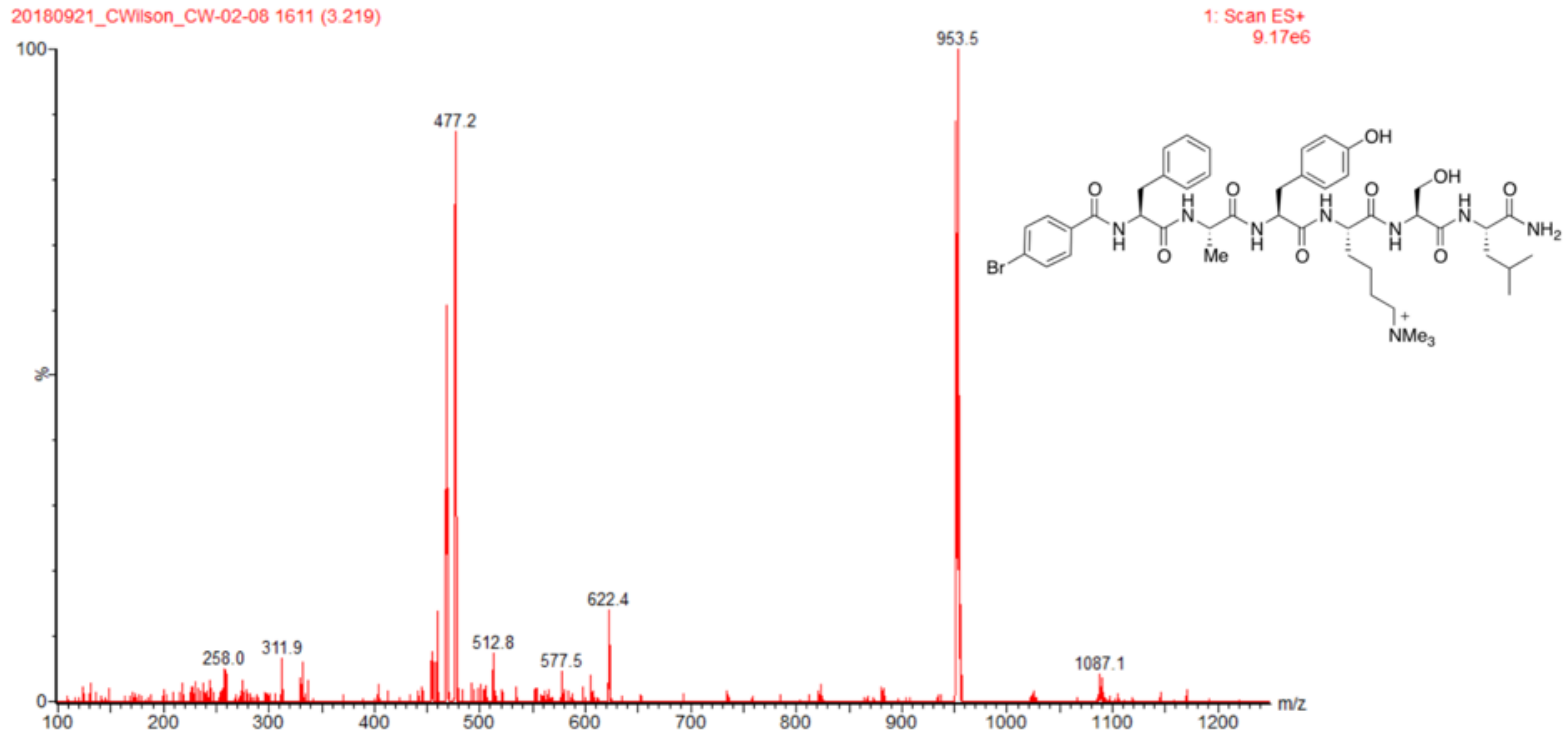

Figure S8. Characterization data for compound 6. A) Analytical LC/MS trace, B) Low resolution mass spectrum. LR-ESI-MS: [m/z] calcd. for $\mathrm{C}_{46} \mathrm{H}_{64} \mathrm{BrN}_{8} \mathrm{O}_{9}{ }^{+}$: 953.40; found: 953.50 . 
A)

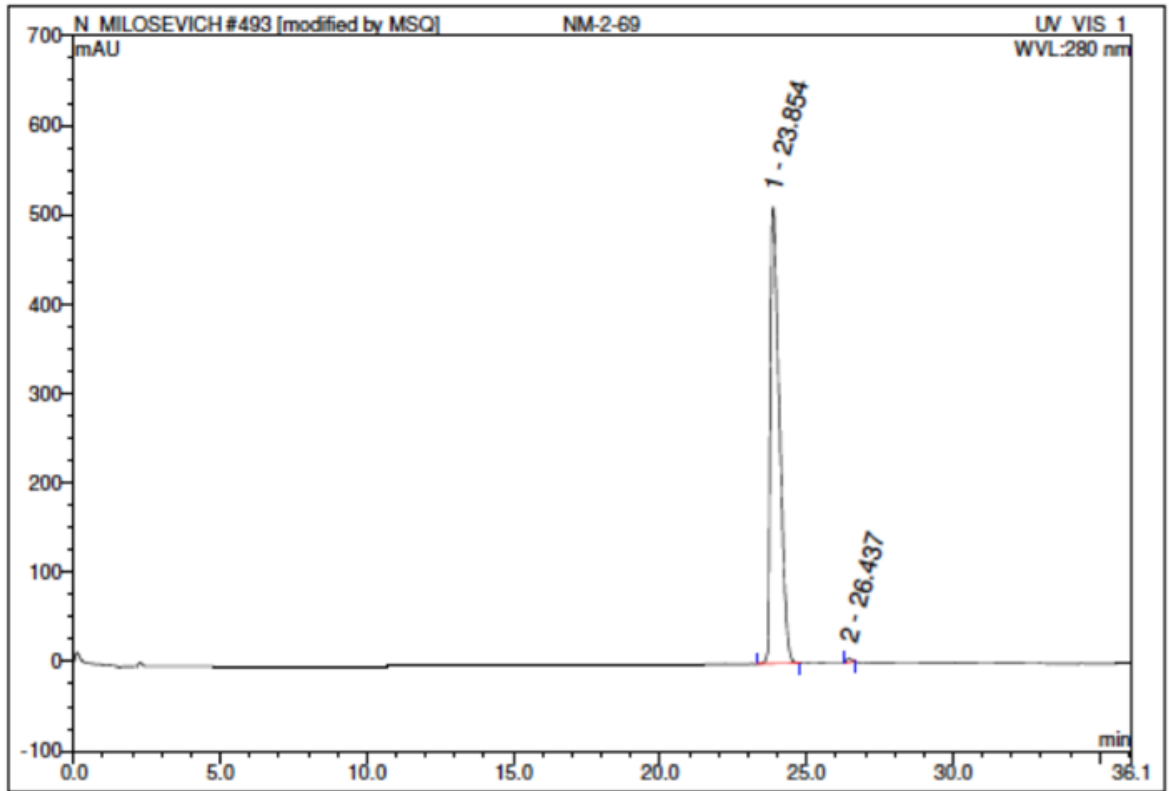

\begin{tabular}{|r|rrrrrrr|}
\hline No. & $\begin{array}{c}\text { Ret.Time } \\
\text { min }\end{array}$ & Peak Name & $\begin{array}{c}\text { Height } \\
\text { mAU }\end{array}$ & $\begin{array}{r}\text { Area } \\
\text { mAU*min }\end{array}$ & \multicolumn{1}{c|}{$\begin{array}{c}\text { Rel.Area } \\
\text { mamount }\end{array}$} & \multicolumn{1}{c|}{ Type } \\
\hline 1 & 23.85 & n.a. & 510.549 & 182.338 & 99.58 & n.a. & BMB \\
2 & 26.44 & n.a. & 4.092 & 0.765 & 0.42 & n.a. & BMB $^{*}$ \\
\hline Total: & & & 514.641 & 183.103 & 100.00 & 0.000 & \\
\hline
\end{tabular}

B)

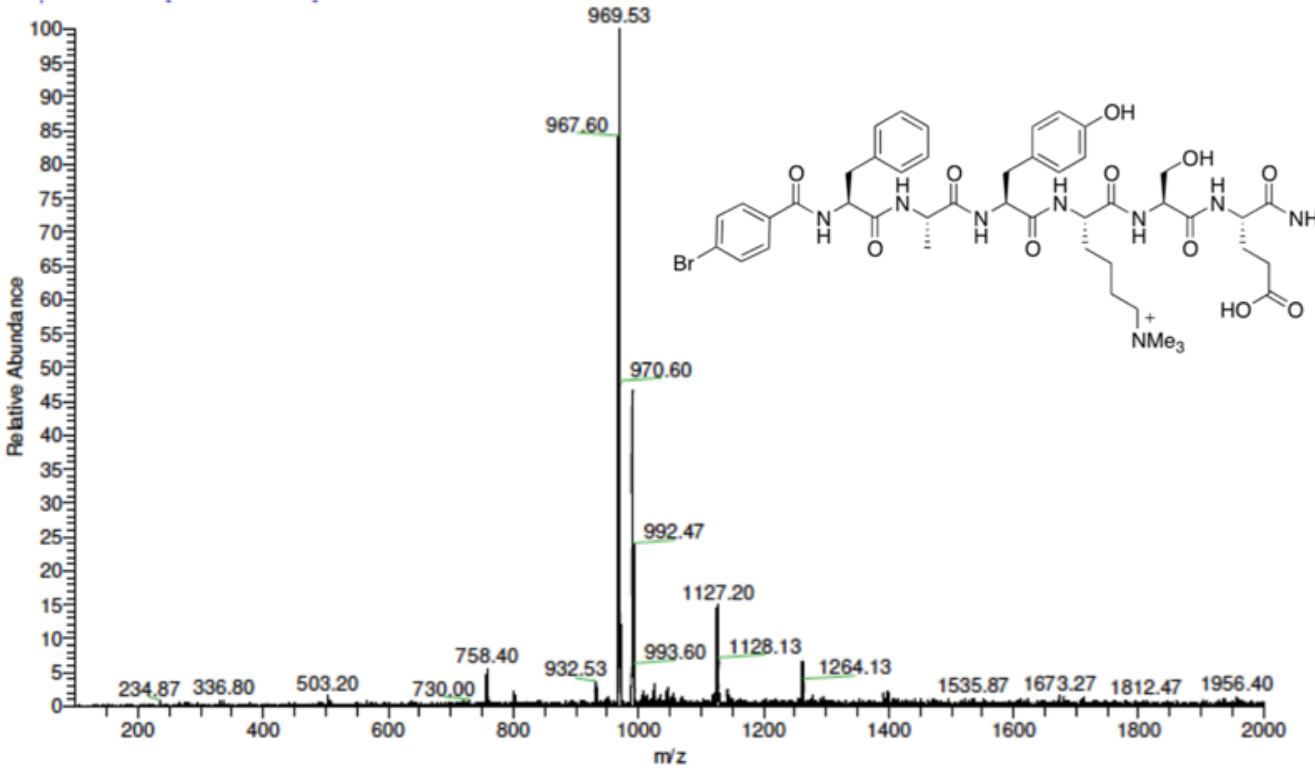

Figure S9. Characterization data for compound 7. A) Analytical LC/MS trace, B) Low resolution mass spectrum. LR-ESI-MS: [m/z] calcd. for $\mathrm{C}_{45} \mathrm{H}_{60} \mathrm{BrN}_{8} \mathrm{O}_{11}{ }^{+}$: 967.36; found: 967.60 . 
A)

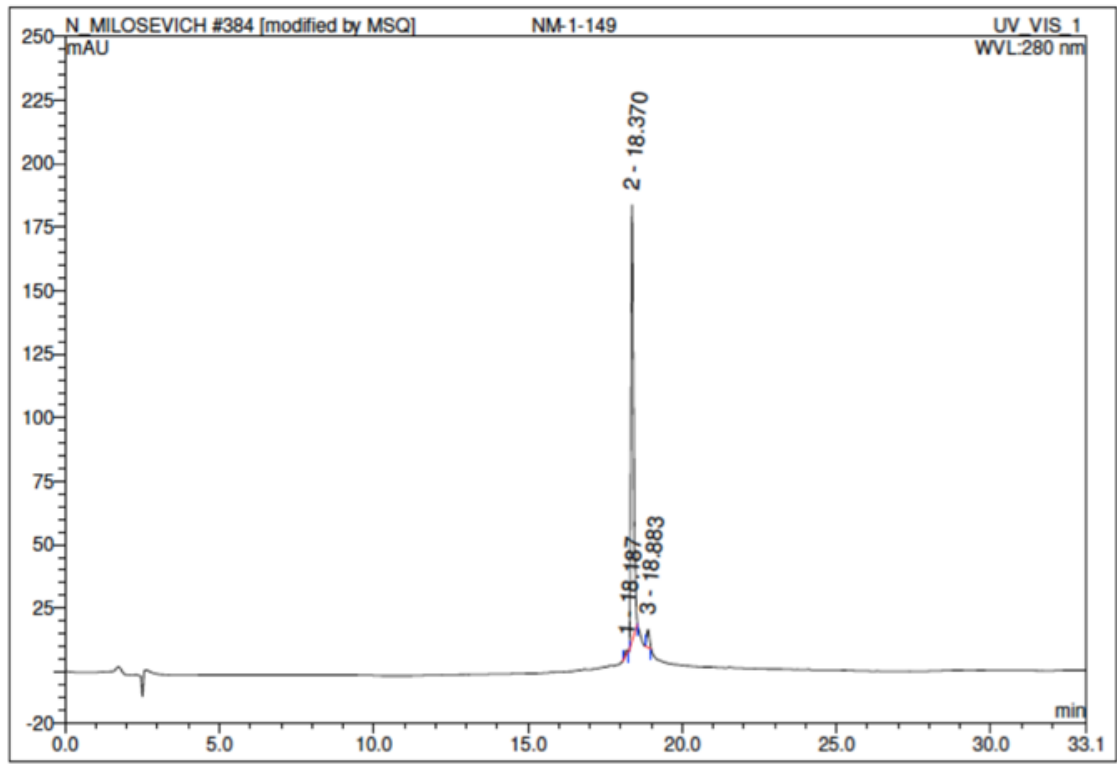

\begin{tabular}{|r|ccrrrrr|}
\hline No. & $\begin{array}{c}\text { Ret.Time } \\
\text { min }\end{array}$ & Peak Name & $\begin{array}{c}\text { Height } \\
\text { mAU }\end{array}$ & $\begin{array}{c}\text { Area } \\
\text { mAU'min }\end{array}$ & $\begin{array}{r}\text { Rel.Area } \\
\%\end{array}$ & $\begin{array}{c}\text { Amount } \\
\mu l\end{array}$ & Type \\
\hline 1 & 18.19 & n.a. & 1.691 & 0.170 & 0.90 & n.a. & BMB* $^{*}$ \\
2 & 18.37 & n.a. & 171.650 & 18.025 & 95.33 & n.a. & BMB* $^{*}$ \\
3 & 18.88 & n.a. & 7.016 & 0.713 & 3.77 & n.a. & BMB* $^{*}$ \\
\hline Total: & & & 180.358 & 18.908 & 100.00 & 0.000 & \\
\hline
\end{tabular}

B)

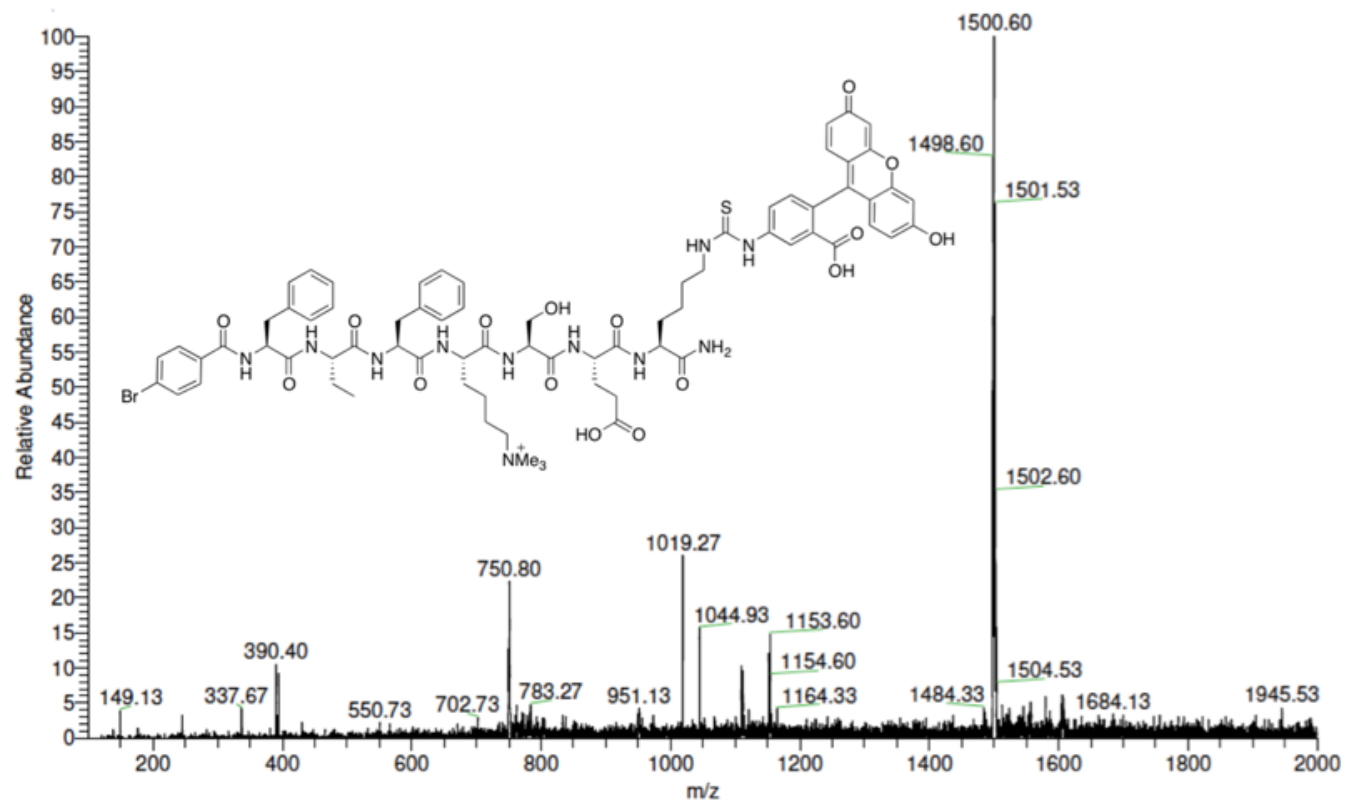

Figure S10. Characterization data for compound 8. A) Analytical LC/MS trace, B) Low resolution mass spectrum. LR-ESI-MS: [m/z] calcd. For $\mathrm{C}_{73} \mathrm{H}_{87} \mathrm{BrN}_{11} \mathrm{O}_{17} \mathrm{~S}^{+}: 1500.52$; found: 1500.60 . 
A)

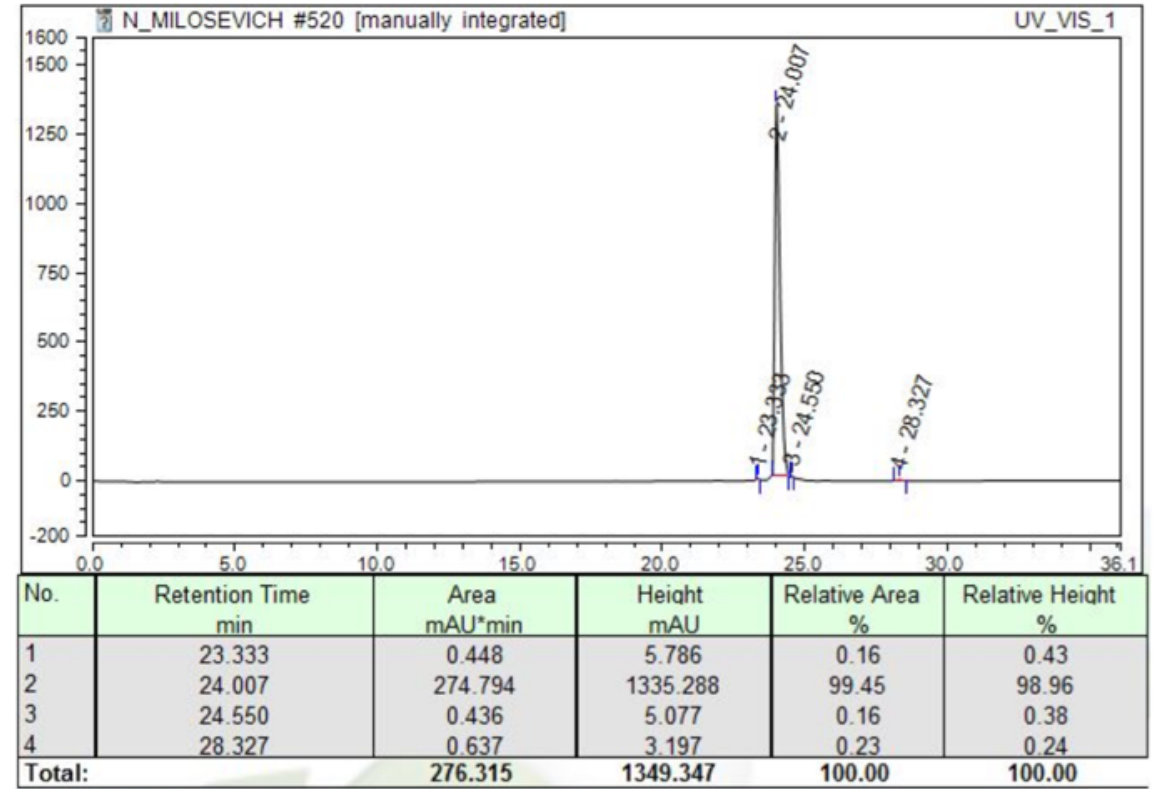

B)

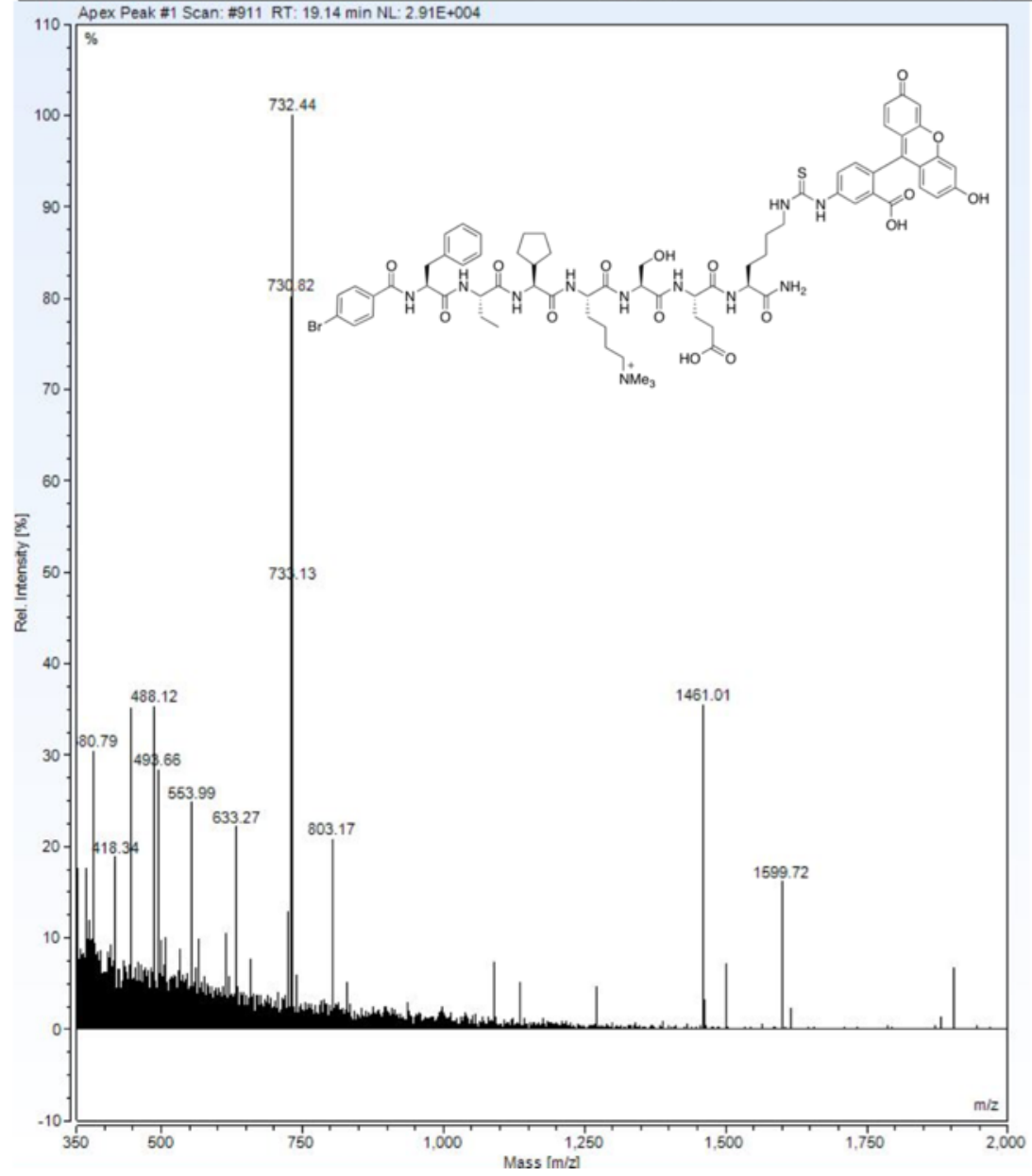

Figure S11. Characterization data for compound 9. A) Analytical LC/MS trace, B) Low resolution mass spectrum. LR-ESI-MS: [m/z] calcd. For $\mathrm{C}_{71} \mathrm{H}_{89} \mathrm{BrN}_{11} \mathrm{O}_{16} \mathrm{~S}^{+}:$732.27, 1464.54; found: $732.44,1461.01$. 
A)

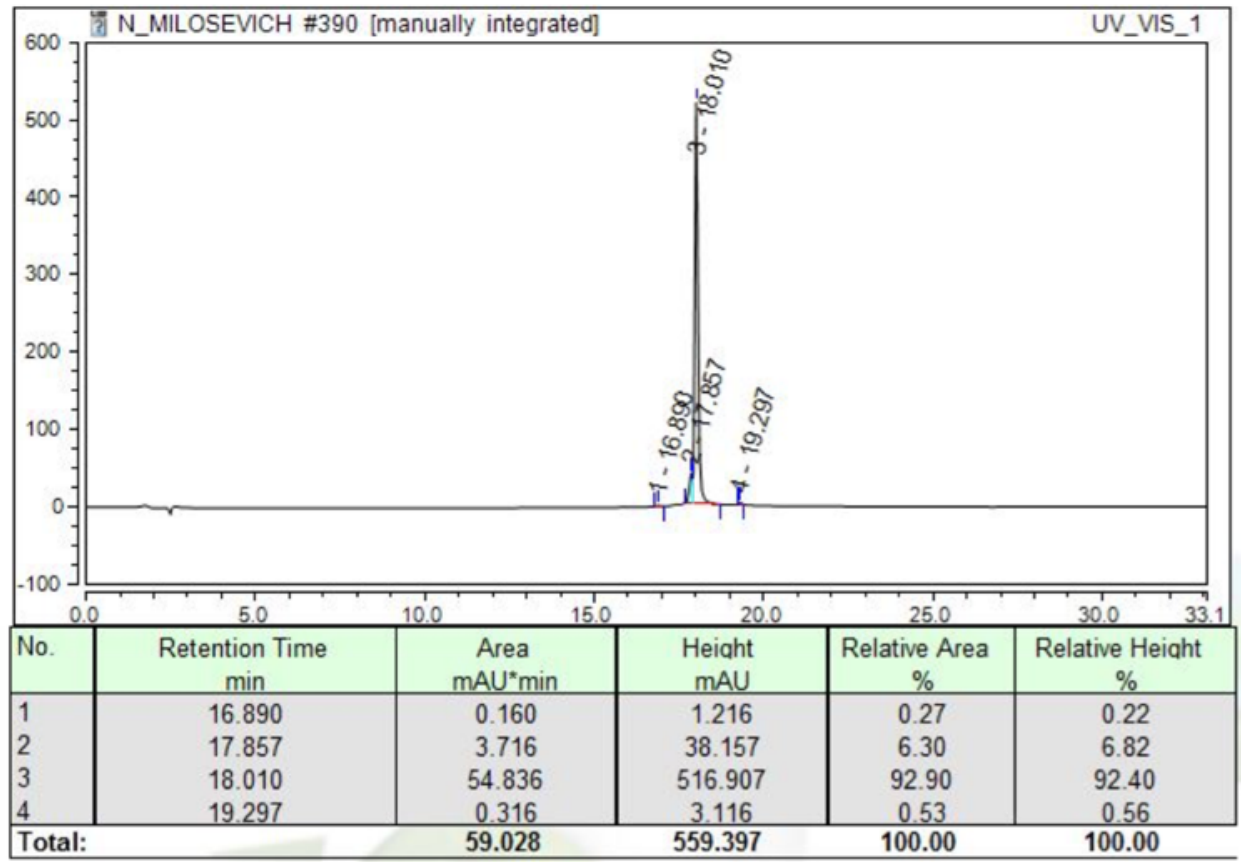

B)

NM-1-192pure_may2015 \#42-47 RT: 1.31-1.47 AV: 6 NL: 1.34E5

$\mathrm{T}:+\mathrm{p}$ ESI Full ms [100.00-2000.00]

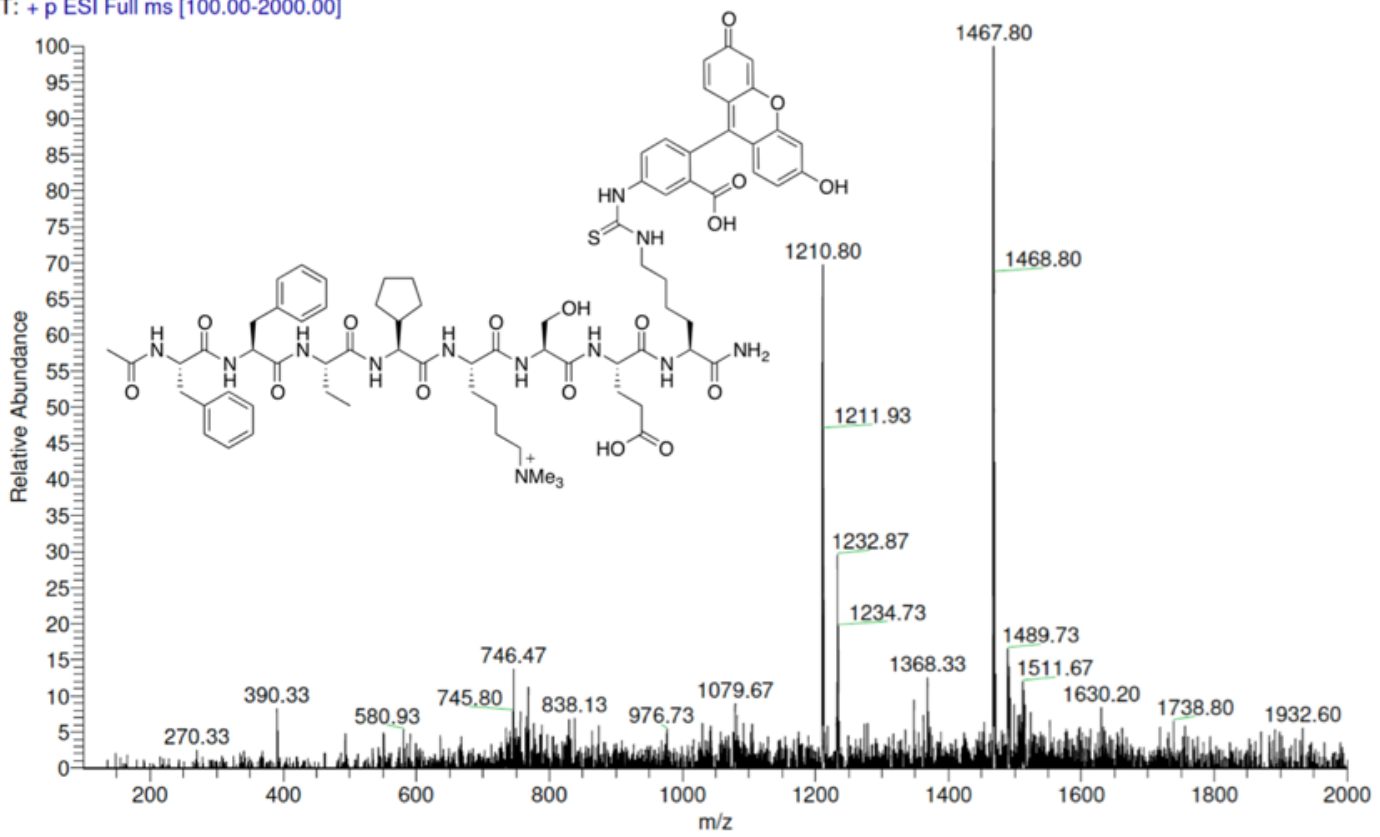

Figure S12. Characterization data for compound 10. A) Analytical LC/MS trace, B) Low resolution mass spectrum. LR-ESI-MS: $[\mathrm{m} / z]$ calcd. for $\mathrm{C}_{75} \mathrm{H}_{95} \mathrm{~N}_{12} \mathrm{O}_{17} \mathrm{~S}^{+}: 1469.68$; found: 1468.80 . 


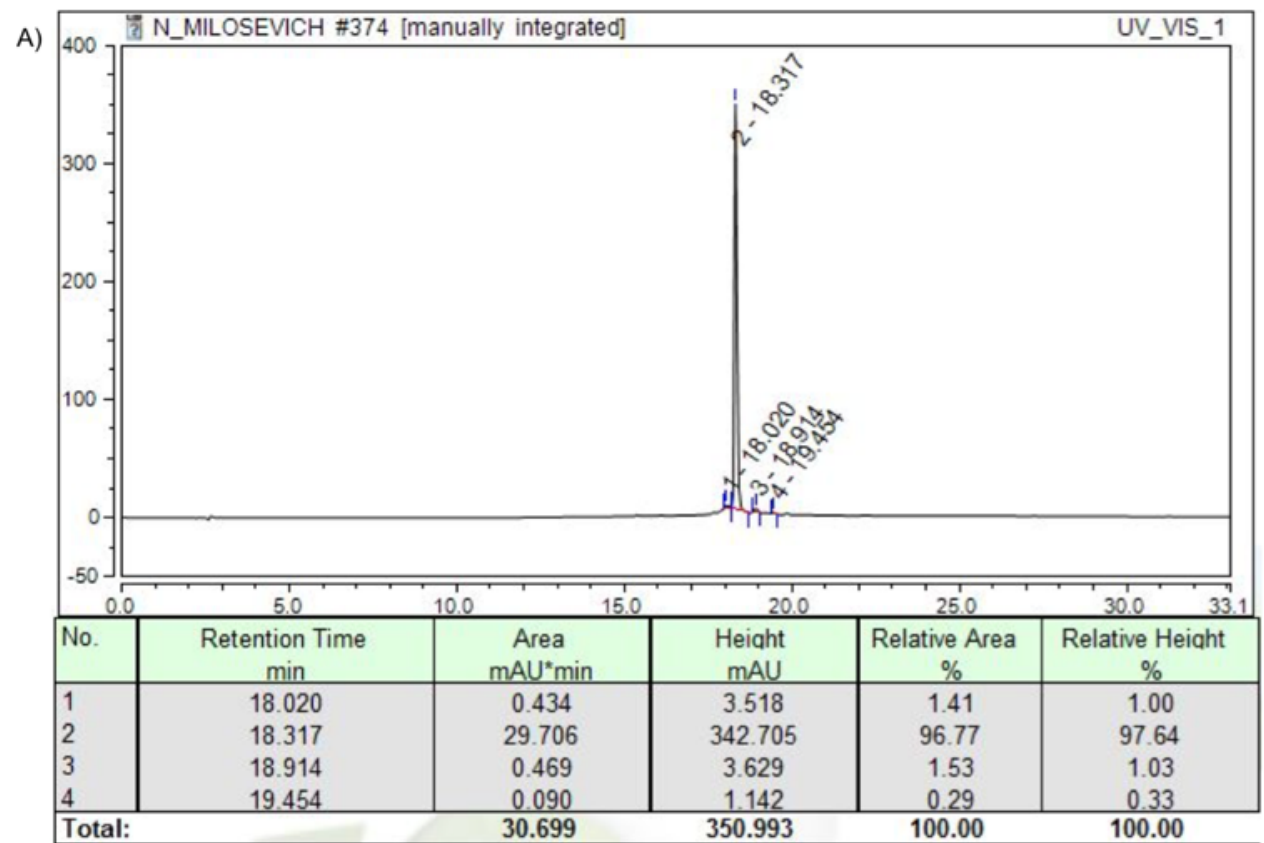

B)

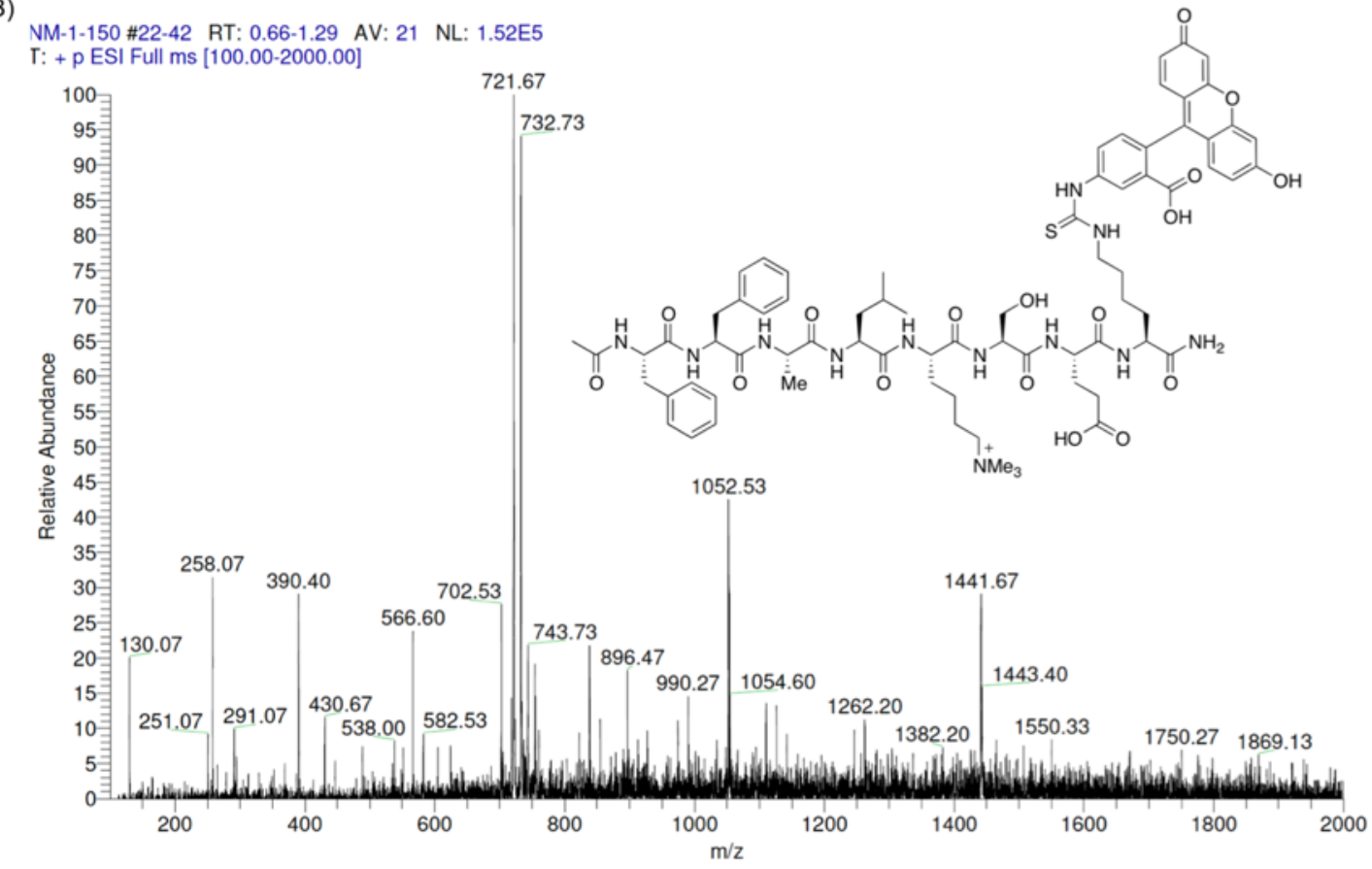

Figure S13. Characterization data for compound 11. A) Analytical LC/MS trace, B) Low resolution mass spectrum. LR-ESI-MS: $[\mathrm{m} / z]$ calcd. for $\mathrm{C}_{73} \mathrm{H}_{95} \mathrm{~N}_{12} \mathrm{O}_{17} \mathrm{~S}^{+}: 721.84,1443.67$; found: $721.67,1443.40$. 
A)

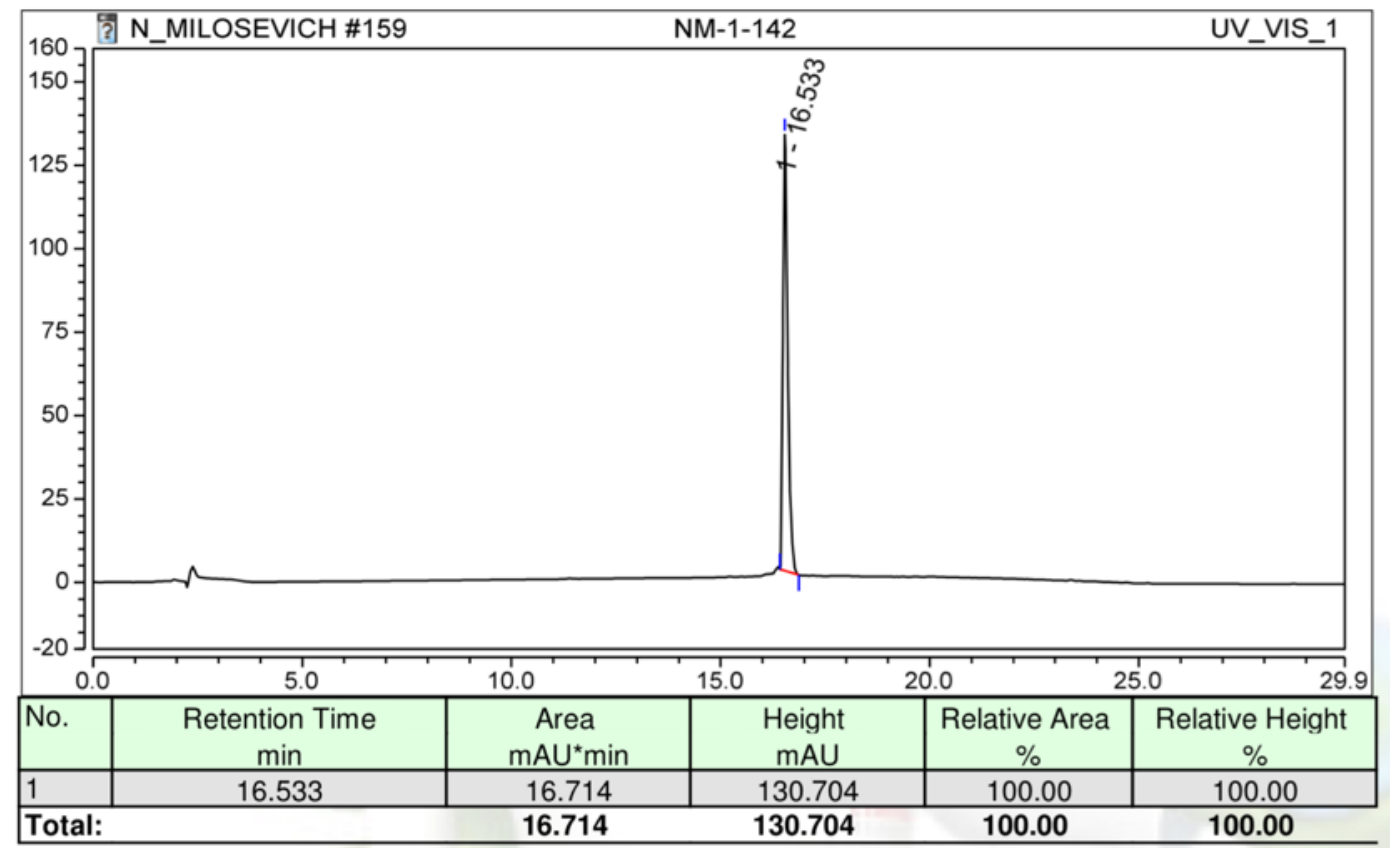

B)

phj0plqk \#768-810 RT: 16.16-17.04 AV: 43 NL: 4.63E4

$\mathrm{T}:\{0,1\}+\mathrm{c}$ ESI !corona $\mathrm{sid}=110.00 \mathrm{det}=1106.00$ Full $\mathrm{ms}[100.00-2000.00]$

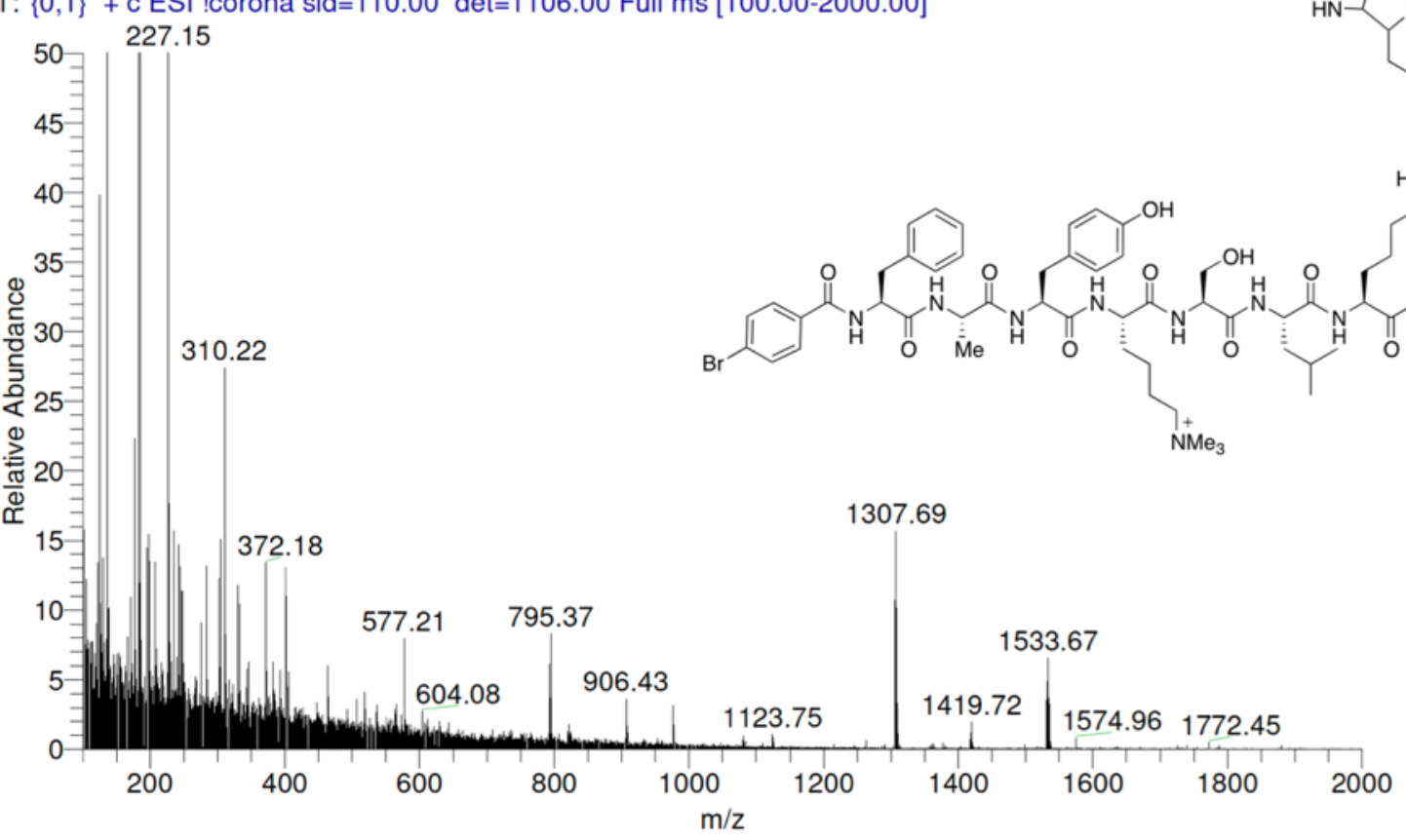

Figure S14. Characterization data for compound 12. A) Analytical LC/MS trace, B) Low resolution mass spectrum. LR-ESI-MS: [m/z] calcd. for $\mathrm{C}_{62} \mathrm{H}_{90} \mathrm{BrN}_{12} \mathrm{O}_{12} \mathrm{~S}^{+}$: 1307.57; found:1307.69.

\section{Protein Expression and Purification}




\section{Protein Expression}

Addgene plasmids 25245 (CBX1), 25158 (CBX2), 25237 (CBX4), 25296 (CBX6), 25241 (CBX7) and a CBX8 plasmid donated directly by C. Arrowsmith (Structural Genomics Consortium, Toronto, Canada) were used to transform competent BL21 CodonPlus RIL Eschericia coli cells (Stratagene). The chromodomains of CBX1 (20-73), CBX2 (8-62), CBX4 (8-65), CBX6 (8-65), CBX7 (8-62) and CBX8 (8-61) were overexpressed as N-terminal His6tagged proteins by culturing $E$. coli at $37^{\circ} \mathrm{C}$ in $2 \mathrm{XYT}$ media to OD $\sim 1.8$, dropping the temperature to $15^{\circ} \mathrm{C}$ for $30-60$ minutes to 1 hour, inducing with $1 \mathrm{mM}$ IPTG (Life Technologies) and culturing overnight ( $\sim 16$ hours) before pelleting cells, re-suspending in chromodomainspecific binding buffer plus protease inhibitor (Calbiochem), and freezing until required for purification.

\section{Protein Purification}

E. coli pellets were thawed overnight and sequentially lysed via a 30 minute incubation with a $\mathrm{CHAPS} / \mathrm{dH}_{2} \mathrm{O}$ solution (Biobasic) and sonication. After centrifugation to remove cell debris, the purification procedure involved two chromatographic steps. First, an affinity chromatographic step on a nickel-nitrilotriacetic acid chelating column (Qiagen) followed by a gel filtration step using an FPLC outfitted with a Hiload 16/600 Superdex 75 pg size exclusion column (GE). The FPLC step performed a buffer exchange into our 'minimal' fluorescence polarization (FP) buffer consisting of $20 \mathrm{mM}$ Tris $\mathrm{HCl}, 250 \mathrm{mM} \mathrm{NaCl}$, and $0.01 \%$ Tween-20. Purified protein was then concentrated to the desired volume using Amicon centrifugal filter units. Proteins were flash frozen and stored at $-80^{\circ} \mathrm{C}$ while purity was assessed by SDS page. It is worth noting that the His tags on CBX7 and CBX8 were cleaved off overnight after the nickel column step using our inhouse TEV protease.

\section{Fluorescence Polarization Methods}

\section{Direct FP Method}

Direct FP was done by titration of CBX proteins into FITC-labelled probes. Binding assays were performed in black 384 well plates with optical bottoms at a total volume of $50 \mu \mathrm{L}$ per well. A solution containing $100 \mathrm{nM}$ of the labelled probe and a varying concentration of the CBX protein in question (dissolved in full FP buffer) was titrated into wells containing constant concentrations (100 nM) of labelled probe in full FP buffer (PMSF, DTT and benzamidine added to minimal FP buffer to a $1 \mathrm{mM}$ final concentration). $100 \mu \mathrm{L}$ of the $\mathrm{CBX}$-containing solution was added to well 19 . Wells $2-18$ contained $50 \mu \mathrm{L}$ of the peptide only solution. $50 \mu \mathrm{L}$ of the well 19 solution was added to well 18 and mixed. These dilutions continued well 3, whereupon $50 \mu \mathrm{L}$ was discarded after mixing, leaving the total volume of all wells at $50 \mu \mathrm{L}$. Well 1 contained only full FP buffer and well 2 contained only the peptide in full FP buffer. The maximum concentrations used for each CBX protein varied $(120 \mu \mathrm{M}-600 \mu \mathrm{M})$ based on availability and solubility of the protein at high concentration, as well as the expected strength of the probe being tested. Assays were performed in triplicate or duplicate depending on CBX protein availability (noted in raw data). After removing any bubbles with a needle, plates were incubated in the dark 
at RT for 15 minutes and then read with a SpectraMax M5 plate reader (Molecular Devices). Raw data for perpendicular (P) and parallel (S) light was collected with SoftMax Pro software using a fluorescence polarization endpoint read. 100 reads were made and averaged per well with 5 second automix before reading and medium PMT sensitivity. Excitation was $450 \mathrm{~nm}$ for FITC and emission was $530 \mathrm{~nm}$ (with a $515 \mathrm{~nm}$ cutoff).

\section{Analysis of Direct FP data}

The background of the blank buffer was subtracted from the parallel and perpendicular intensities of emission. Average values for parallel and perpendicular emission intensities (minus the average values for buffer control wells) were determined for sets of replicates using Microsoft Excel and millipolarization units (mP) were calculated using the formula ((Parallel Perpendicular $) /($ Parallel + Perpendicular $))^{*} 1000$. Data were then plotted using Graphpad Prism 8. The mathematical model for the fit was described by the equation $y=\left(B L \max ^{*} x\right) /\left(K_{d}+x\right)+$ NS $* x+$ background. For certain assays, some of the data points ( 0 to 5 points) representing the highest $\mathrm{CBX}$ concentrations had to be excluded due to abnormally high $\mathrm{mP}$ values, likely arising from protein aggregation.

\section{Competitive FP Method}

Competitive FP analysis of 5-7 binding to $\mathrm{CBX} 6 / 7 / 8$ was used to determine $\mathrm{IC}_{50}$ values as with compound 4 as the competitive binding probe (Figures S20-22). Compound 4 and peptide inhibitors were dissolved in distilled $\mathrm{H}_{2} \mathrm{O}$. The assay was carried out in NUNC black 96-well plates and full FP buffer was used as described above $(20 \mathrm{mM}$ Tris- $\mathrm{HCl}, \mathrm{pH}=8.0,250 \mathrm{mM}$ $\mathrm{NaCl}, 1 \mathrm{mM}$ DTT, $1 \mathrm{mM}$ benzamidine, $1 \mathrm{mM}$ PMSF, $0.01 \%$ Tween). Probe 4 was at a constant concentration of $100 \mathrm{nM}$. Each CBX protein was at a constant concentration dependent on the $\mathrm{K}_{d}$ of the protein to probe 4 . $\mathrm{CBX} 1$ was used at $10 \mu \mathrm{M}, \mathrm{CBX} 2$ at $0.7 \mu \mathrm{M}, \mathrm{CBX} 4$ at $0.7 \mu \mathrm{M}, \mathrm{CBX} 6$ at $1 \mu \mathrm{M}, \mathrm{CBX} 7$ at $0.7 \mu \mathrm{M}$ and $\mathrm{CBX} 8$ at $4 \mu \mathrm{M}$. Inhibitor concentrations varied between $0-500 \mu \mathrm{M}$. All wells in the plate were made to final volume of $100 \mu \mathrm{L} .200 \mu \mathrm{L}$ of the inhibitor-containing solution was added to well 12 . Wells $2-11$ contained $100 \mu \mathrm{L}$ of the CBX and 4 only solution. 100 $\mu \mathrm{L}$ of the well 12 solution was added to well 11 and mixed. These dilutions continued to well 3, whereupon $100 \mu \mathrm{L}$ was discarded after mixing, leaving the total volume of all wells at $100 \mu \mathrm{L}$. Well 1 contained only full FP buffer and well 2 contained only CBX protein and 4 in full FP buffer. Following serial dilution of the inhibitor across the plate, plates were incubated for 15 minutes in the dark and then were read with the SpectraMax M5 plate reader as described above.

\section{Analysis of Competitive FP data}

The background of the blank buffer was subtracted from the parallel and perpendicular intensities of emission. Values were graphed using Graphpad Prism 8 and fitted using a sigmoidal curve function from which $\mathrm{IC}_{50}$ values were extrapolated. The equation used is described as follows: $\mathrm{y}=$ bottom $+($ top-bottom $) /\left(1+10^{\wedge}\left(\mathrm{X}-\log \mathrm{IC}_{50}\right)\right)$. Errors are reported as 95\% confidence intervals. Experiments were done in duplicate or triplicate and this is indicated in the raw data shown in Figures S16-S26. 


\section{Fluorescence Polarization Data}
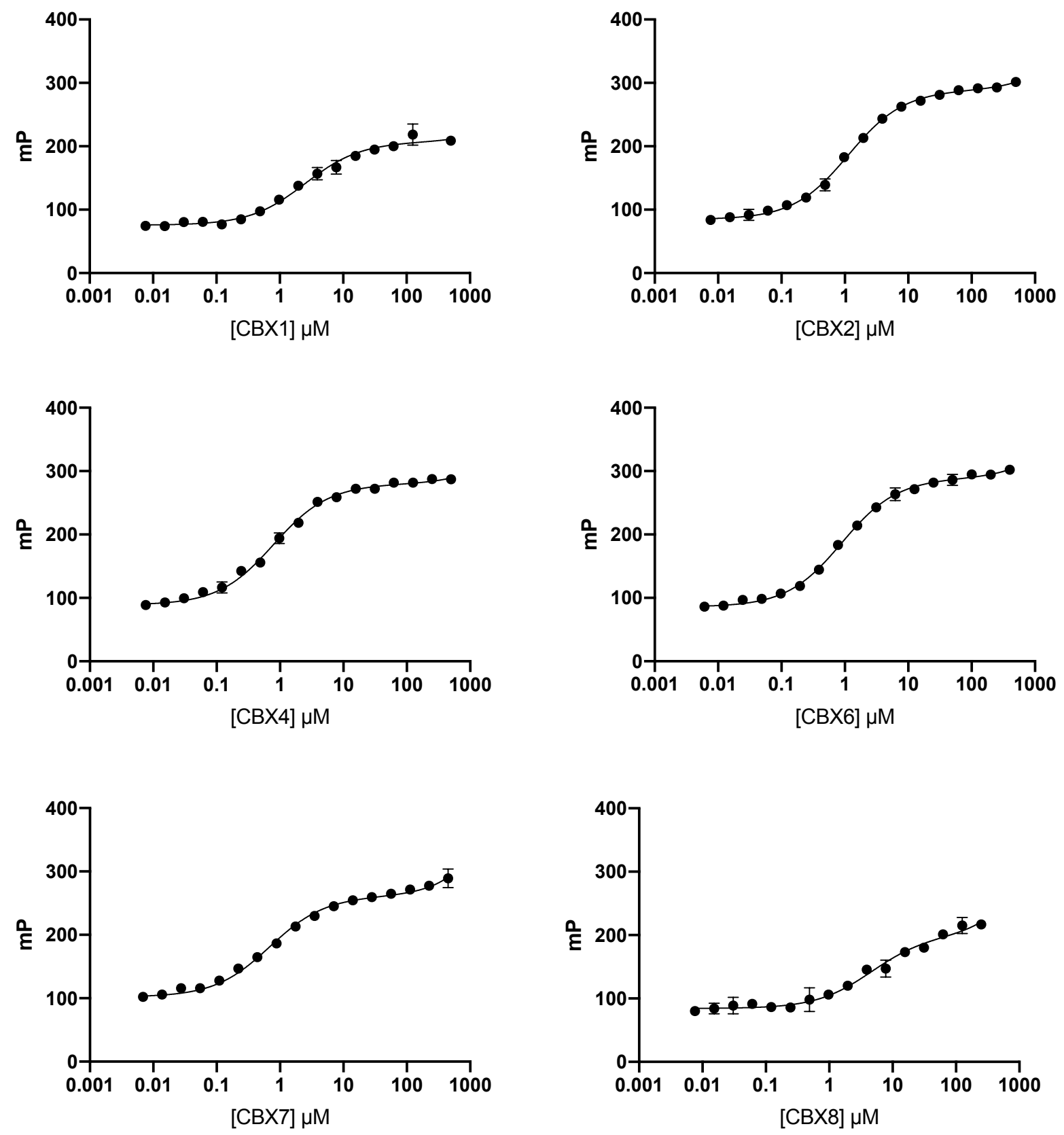

Figure S15. Direct fluorescence polarization data of compound 1 with CBX1/2/4/6/7/8. CBX1 $\left(\mathrm{K}_{\mathrm{d}}=2.5 \mu \mathrm{M}, 95 \%\right.$ CI $2.0 \mu \mathrm{M}$ to $\left.3.1 \mu \mathrm{M}, \mathrm{R}^{2}=0.983\right), \mathrm{CBX} 2\left(\mathrm{~K}_{\mathrm{d}}=1.14 \mu \mathrm{M}, 95 \% \mathrm{CI} 1.0 \mu \mathrm{M}\right.$ to $\left.1.2 \mu \mathrm{M}, \mathrm{R}^{2}=0.997\right), \mathrm{CBX} 4\left(\mathrm{~K}_{\mathrm{d}}=0.79 \mu \mathrm{M}, 95 \% \mathrm{CI} 0.70 \mu \mathrm{M}\right.$ to $\left.0.90 \mu \mathrm{M}, \mathrm{R}^{2}=0.994\right), \mathrm{CBX} 6$ $\left(\mathrm{K}_{\mathrm{d}}=0.90 \mu \mathrm{M}, 95 \%\right.$ CI $0.82 \mu \mathrm{M}$ to $\left.0.96 \mu \mathrm{M}, \mathrm{R}^{2}=0.998\right), \mathrm{CBX} 7\left(\mathrm{~K}_{\mathrm{d}}=0.69 \mu \mathrm{M}, 95 \%\right.$ CI 0.57 $\mu \mathrm{M}$ to $\left.0.83 \mu \mathrm{M}, \mathrm{R}^{2}=0.993\right), \mathrm{CBX} 8\left(\mathrm{~K}_{\mathrm{d}}=4.5 \mu \mathrm{M}, 95 \% \mathrm{CI} 3.0 \mu \mathrm{M}\right.$ to $\left.6.8 \mu \mathrm{M}, \mathrm{R}^{2}=0.967\right)$. Error reported as asymmetrical 95\% confidence intervals. Titrations for CBX1/2/4/8 performed in triplicate and CBX6/7 performed in duplicate. 

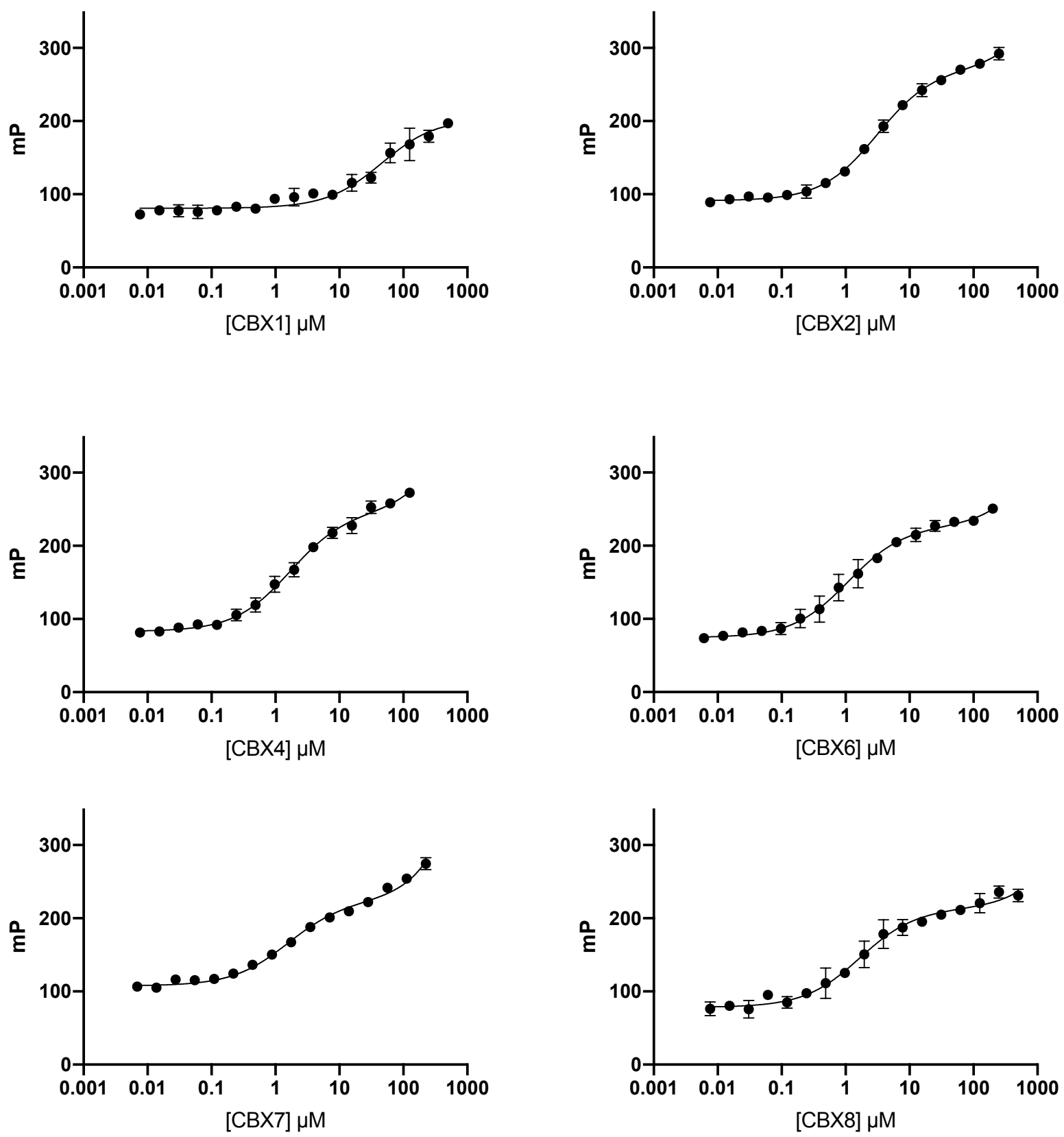

Figure S16. Direct fluorescence polarization data of compound 2 with CBX1/2/4/6/7/8. CBX1 $\left(\mathrm{K}_{\mathrm{d}}=47 \mu \mathrm{M}, 95 \%\right.$ CI $36 \mu \mathrm{M}$ to $\left.61 \mu \mathrm{M}, \mathrm{R}^{2}=0.944\right), \mathrm{CBX} 2\left(\mathrm{~K}_{\mathrm{d}}=3.1 \mu \mathrm{M}, 95 \%\right.$ CI $2.8 \mu \mathrm{M}$ to 3.5 $\left.\mu \mathrm{M}, \mathrm{R}^{2}=0.995\right), \mathrm{CBX} 4\left(\mathrm{~K}_{\mathrm{d}}=1.7 \mu \mathrm{M}, 95 \% \mathrm{CI} 1.4 \mu \mathrm{M}\right.$ to $\left.2.0 \mu \mathrm{M}, \mathrm{R}^{2}=0.991\right), \mathrm{CBX} 6\left(\mathrm{~K}_{\mathrm{d}}=1.1\right.$ $\mu \mathrm{M}, 95 \%$ CI $0.83 \mu \mathrm{M}$ to $\left.1.4 \mu \mathrm{M}, \mathrm{R}^{2}=0.987\right), \mathrm{CBX} 7\left(\mathrm{~K}_{\mathrm{d}}=1.6 \mu \mathrm{M}, 95 \% \mathrm{CI} 1.2 \mu \mathrm{M}\right.$ to $2.0 \mu \mathrm{M}$, $\left.\mathrm{R}^{2}=0.992\right), \mathrm{CBX} 8\left(\mathrm{~K}_{\mathrm{d}}=1.7 \mu \mathrm{M}, 95 \% \mathrm{CI} 1.2 \mu \mathrm{M}\right.$ to $\left.2.3 \mu \mathrm{M}, \mathrm{R}^{2}=0.977\right)$. Error reported as asymmetrical $95 \%$ confidence intervals. CBX1/2/4/7 performed in triplicate, and CBX6/8 titrations performed in duplicate. 


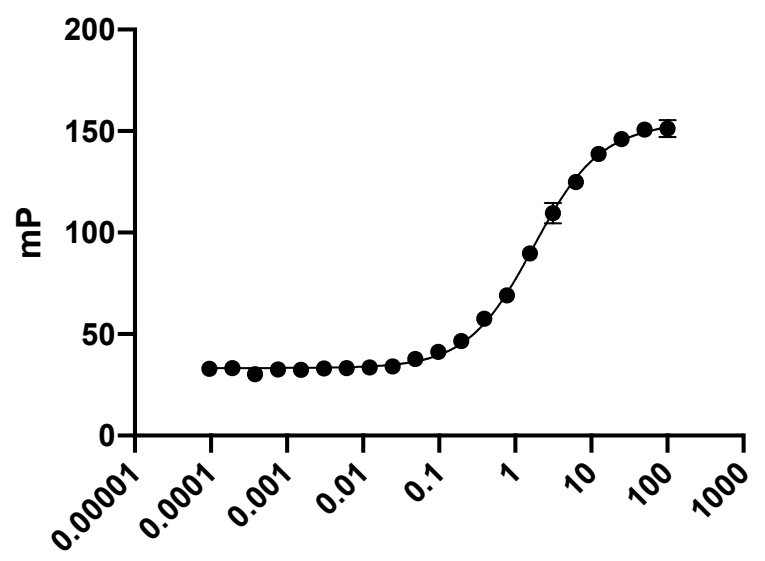

[CBX1] $\mu \mathrm{M}$

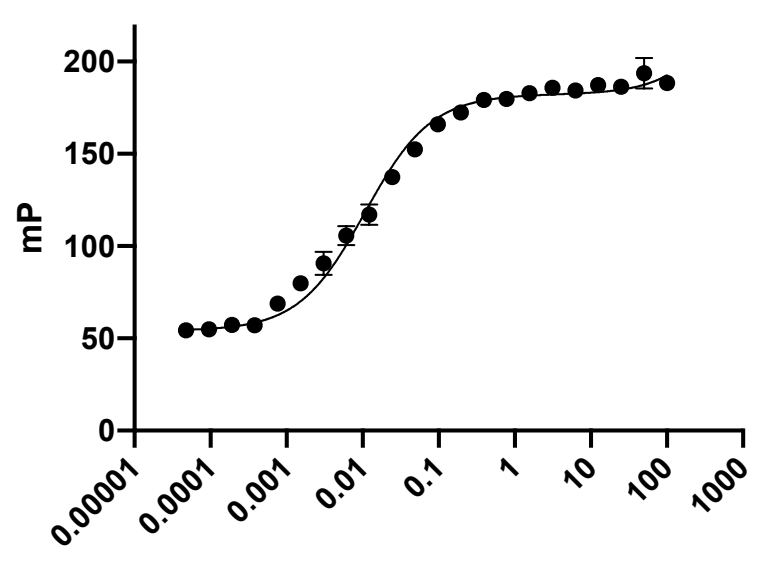

[CBX7] $\mu \mathrm{M}$

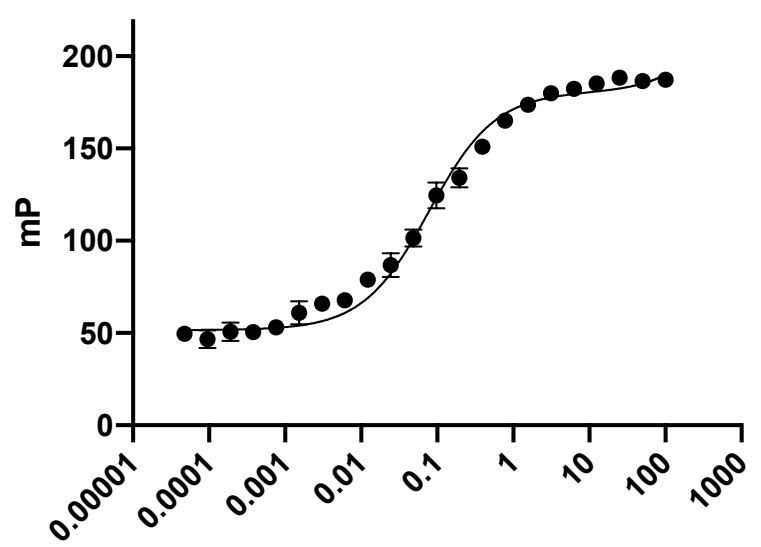

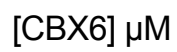

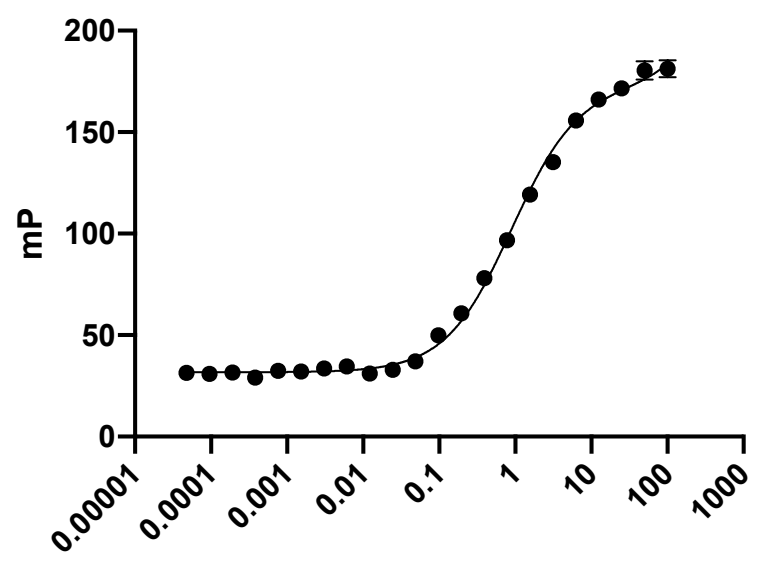

[CBX8] $\mu \mathrm{M}$

Figure S17. Direct fluorescence polarization data of compound 3 with CBX1/6/7/8 performed in triplicate. $\mathrm{CBX} 1\left(\mathrm{~K}_{\mathrm{d}}=1.75 \mu \mathrm{M}, 95 \% \mathrm{CI} 1.62 \mu \mathrm{M}\right.$ to $\left.1.89 \mu \mathrm{M}, \mathrm{R}^{2}=0.998\right), \mathrm{CBX} 6\left(\mathrm{~K}_{\mathrm{d}}=0.078\right.$ $\mu \mathrm{M}, 95 \%$ CI $0.063 \mu \mathrm{M}$ to $\left.0.097 \mu \mathrm{M}, \mathrm{R}^{2}=0.984\right), \mathrm{CBX} 7\left(\mathrm{~K}_{\mathrm{d}}=0.011 \mu \mathrm{M}, 95 \% \mathrm{CI} 0.0090 \mu \mathrm{M}\right.$ to $\left.0.013 \mu \mathrm{M}, \mathrm{R}^{2}=0.987\right), \mathrm{CBX} 8\left(\mathrm{~K}_{\mathrm{d}}=0.89 \mu \mathrm{M}, 95 \% \mathrm{CI} 0.81 \mu \mathrm{M}\right.$ to $\left.0.98 \mu \mathrm{M}, \mathrm{R}^{2}=0.997\right)$. Error reported as asymmetrical $95 \%$ confidence intervals. 


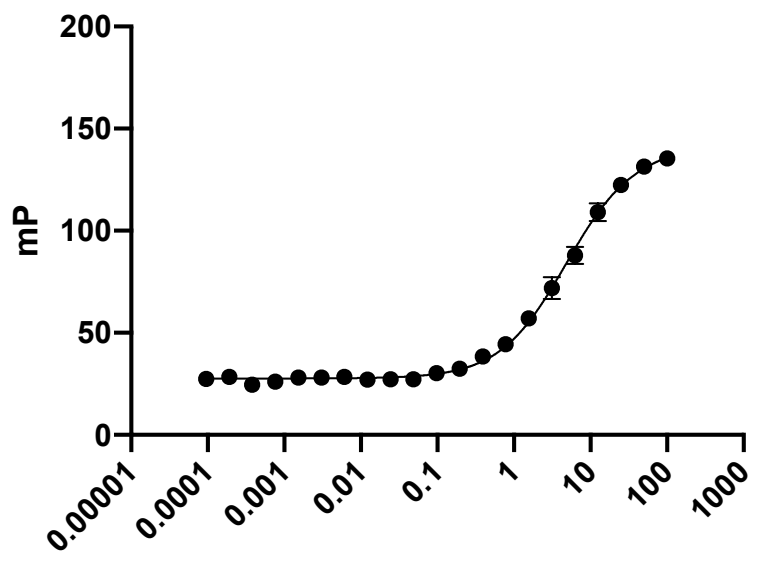

$[\mathrm{CBX} 1] \mu \mathrm{M}$

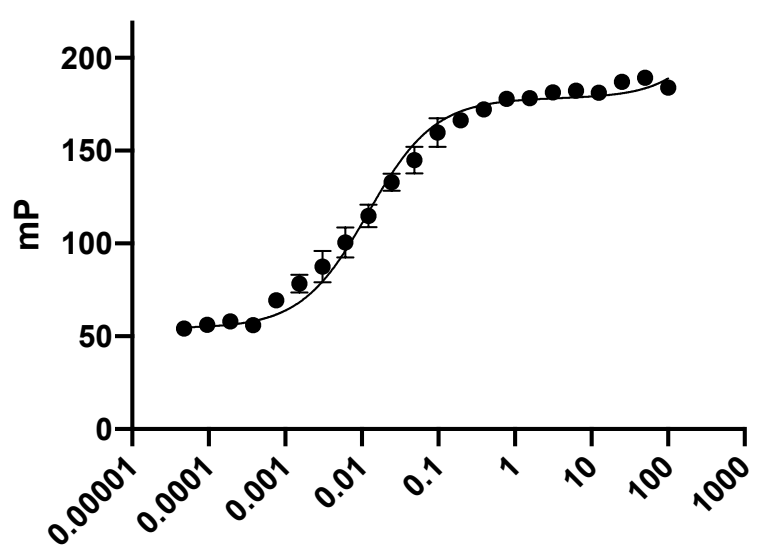

[CBX7] $\mu \mathrm{M}$

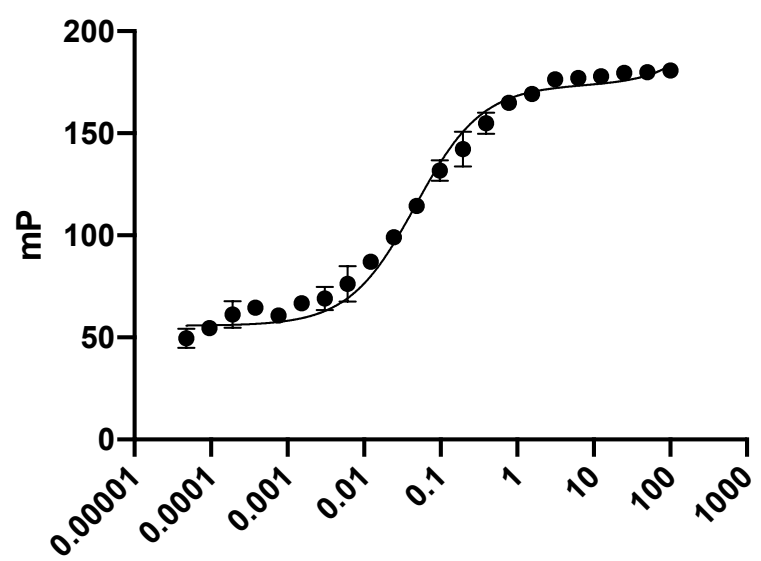

[CBX6] $\mu \mathrm{M}$

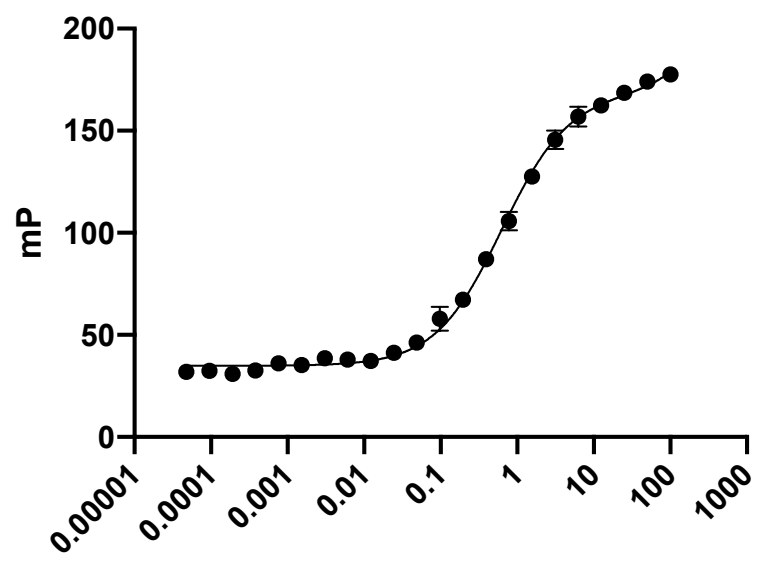

[CBX8] $\mu \mathrm{M}$

Figure S18. Direct fluorescence polarization data of compound 4 with CBX1/6/7/8 performed in triplicate. CBX1 $\left(\mathrm{K}_{\mathrm{d}}=4.8 \mu \mathrm{M}, 95 \%\right.$ CI $4.1 \mu \mathrm{M}$ to $\left.5.5 \mu \mathrm{M}, \mathrm{R}^{2}=0.944\right), \mathrm{CBX} 6\left(\mathrm{~K}_{\mathrm{d}}=0.047 \mu \mathrm{M}\right.$, $95 \%$ CI $0.035 \mu \mathrm{M}$ to $\left.0.062 \mu \mathrm{M}, \mathrm{R}^{2}=0.972\right), \mathrm{CBX} 7\left(\mathrm{~K}_{\mathrm{d}}=0.012 \mu \mathrm{M}, 95 \%\right.$ CI $0.0097 \mu \mathrm{M}$ to $\left.0.015 \mu \mathrm{M}, \mathrm{R}^{2}=0.982\right), \mathrm{CBX} 8\left(\mathrm{~K}_{\mathrm{d}}=0.62 \mu \mathrm{M}, 95 \% \mathrm{CI} 0.57 \mu \mathrm{M}\right.$ to $\left.0.68 \mu \mathrm{M}, \mathrm{R}^{2}=0.998\right)$. Error reported as asymmetrical $95 \%$ confidence intervals. 

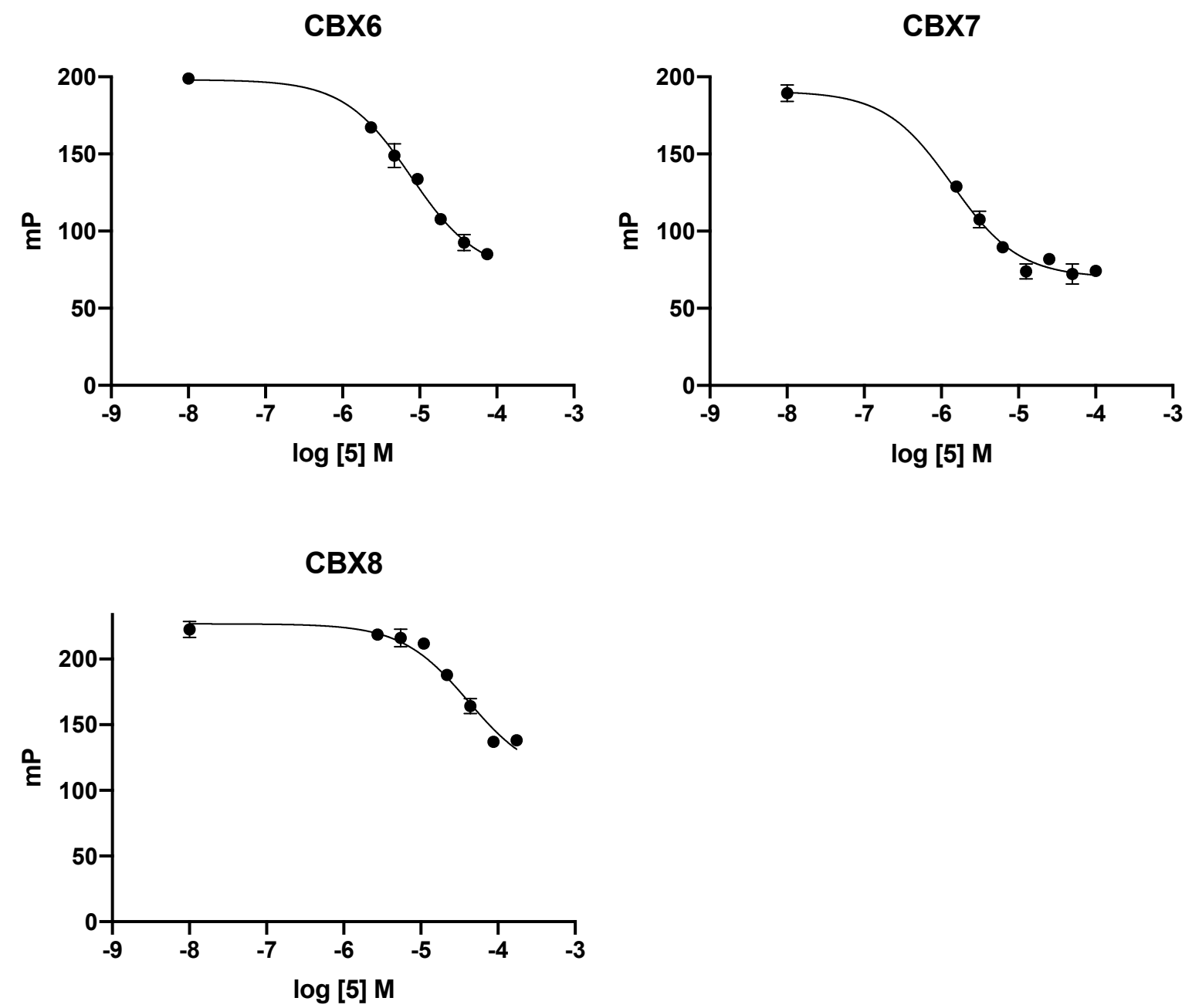

Figure S19. Competitive fluorescence polarization data of compound 5 with CBX6/7/8 performed in duplicate. $\mathrm{CBX} 6\left(\log \mathrm{IC}_{50}=-5.113 \mathrm{M}, 95 \% \mathrm{CI}-5.222\right.$ to $\left.-5.000, \mathrm{R}^{2}=0.990\right)$, CBX7 $\left(\log \mathrm{IC}_{50}=-5.862 \mathrm{M}, 95 \% \mathrm{CI}-5.983\right.$ to $\left.-5.746, \mathrm{R}^{2}=0.983\right), \mathrm{CBX} 8\left(\log \mathrm{IC}_{50}=-4.385 \mathrm{M}\right.$, $95 \% \mathrm{CI}-4.593$ to $\left.-4.162, \mathrm{R}^{2}=0.967\right)$. Error reported as asymmetrical $95 \%$ confidence intervals. 
CBX6

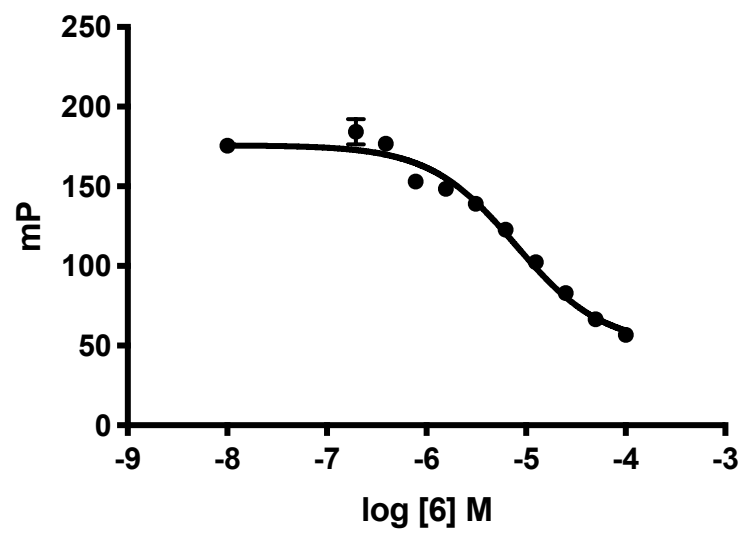

CBX8

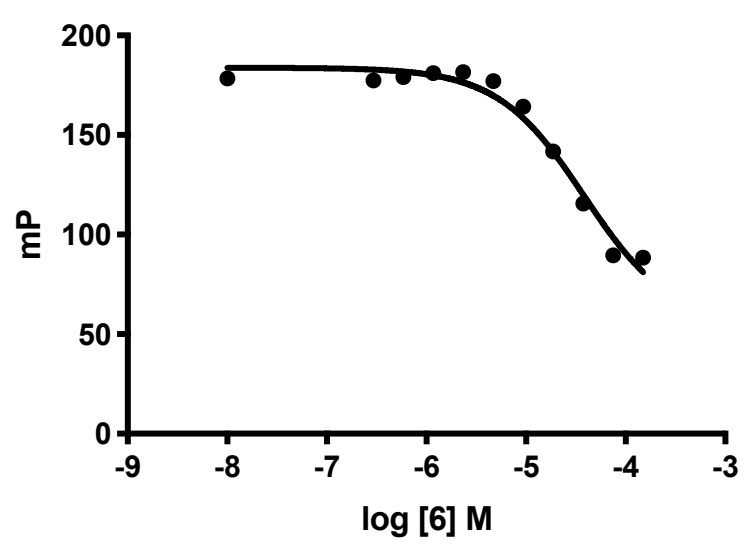

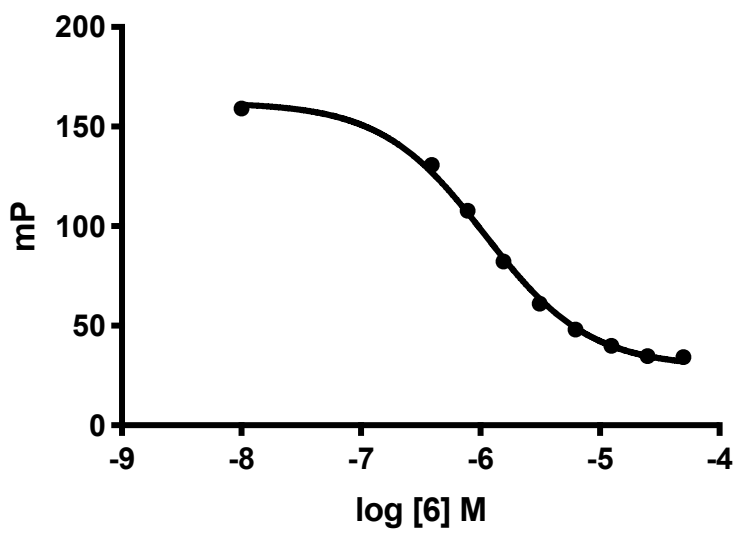

Figure S20. Competitive fluorescence polarization data of compound 6 with CBX6/7/8 performed in triplicate. $\mathrm{CBX} 6\left(\log \mathrm{IC}_{50}=-5.102 \mathrm{M}, 95 \% \mathrm{CI}-5.219\right.$ to $\left.-4.985, \mathrm{R}^{2}=0.980\right)$, CBX7 $\left(\log \mathrm{IC}_{50}=-5.962 \mathrm{M}, 95 \% \mathrm{CI}-5.996\right.$ to $\left.-5.982, \mathrm{R}^{2}=0.997\right), \mathrm{CBX} 8\left(\log \mathrm{CC}_{50}=-4.419 \mathrm{M}\right.$, $95 \% \mathrm{CI}-4.533$ to $\left.-4.300, \mathrm{R}^{2}=0.975\right)$. Error reported as asymmetrical $95 \%$ confidence intervals. 
CBX6

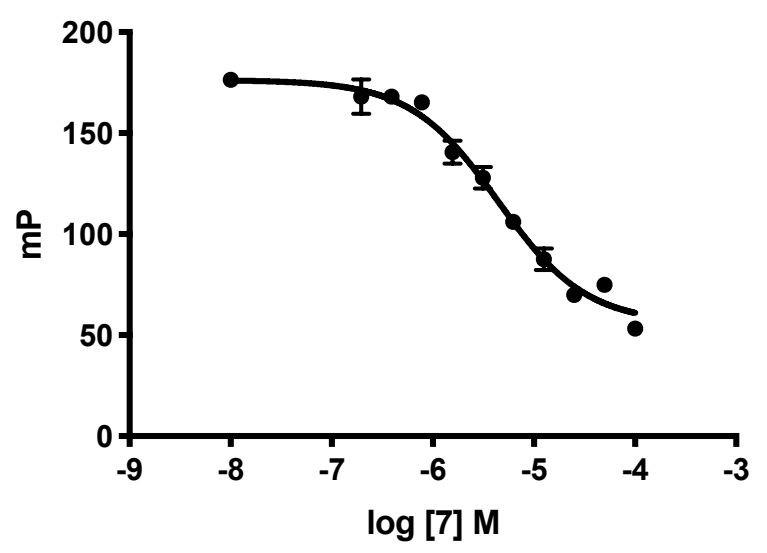

\section{CBX8}

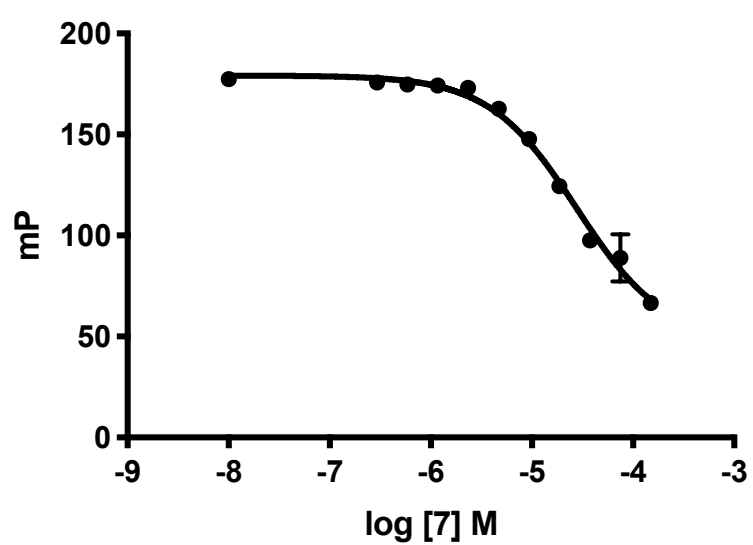

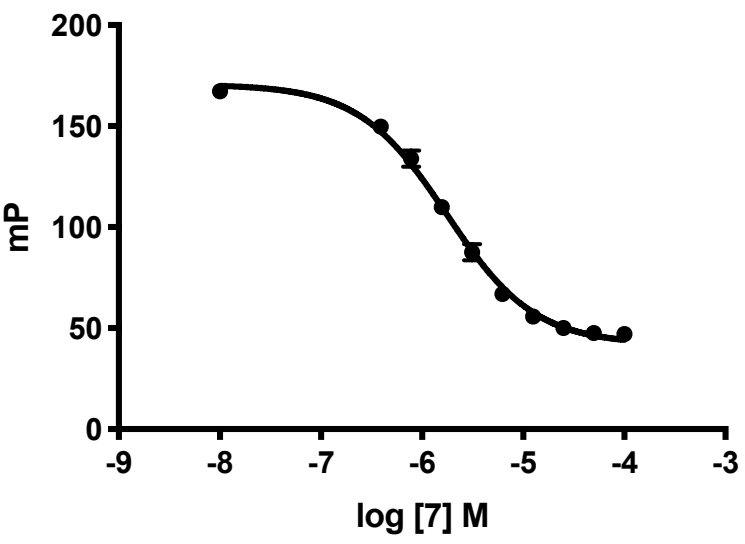

Figure S21. Competitive fluorescence polarization data of compound 7 with CBX6/7/8 performed in triplicate. $\mathrm{CBX} 6\left(\log \mathrm{IC}_{50}=-5.338 \mathrm{M}, 95 \% \mathrm{CI}-5.447\right.$ to $\left.-5.227, \mathrm{R}^{2}=0.979\right)$, CBX7 $\left(\log \mathrm{IC}_{50}=-5.756 \mathrm{M}, 95 \% \mathrm{CI}-5.800\right.$ to $\left.-5.711, \mathrm{R}^{2}=0.995\right), \mathrm{CBX} 8\left(\operatorname{logIC} \mathrm{C}_{50}=-4.559 \mathrm{M}\right.$, $95 \% \mathrm{CI}-4.648$ to $\left.-4.467, \mathrm{R}^{2}=0.986\right)$. Error reported as asymmetrical $95 \%$ confidence intervals. 

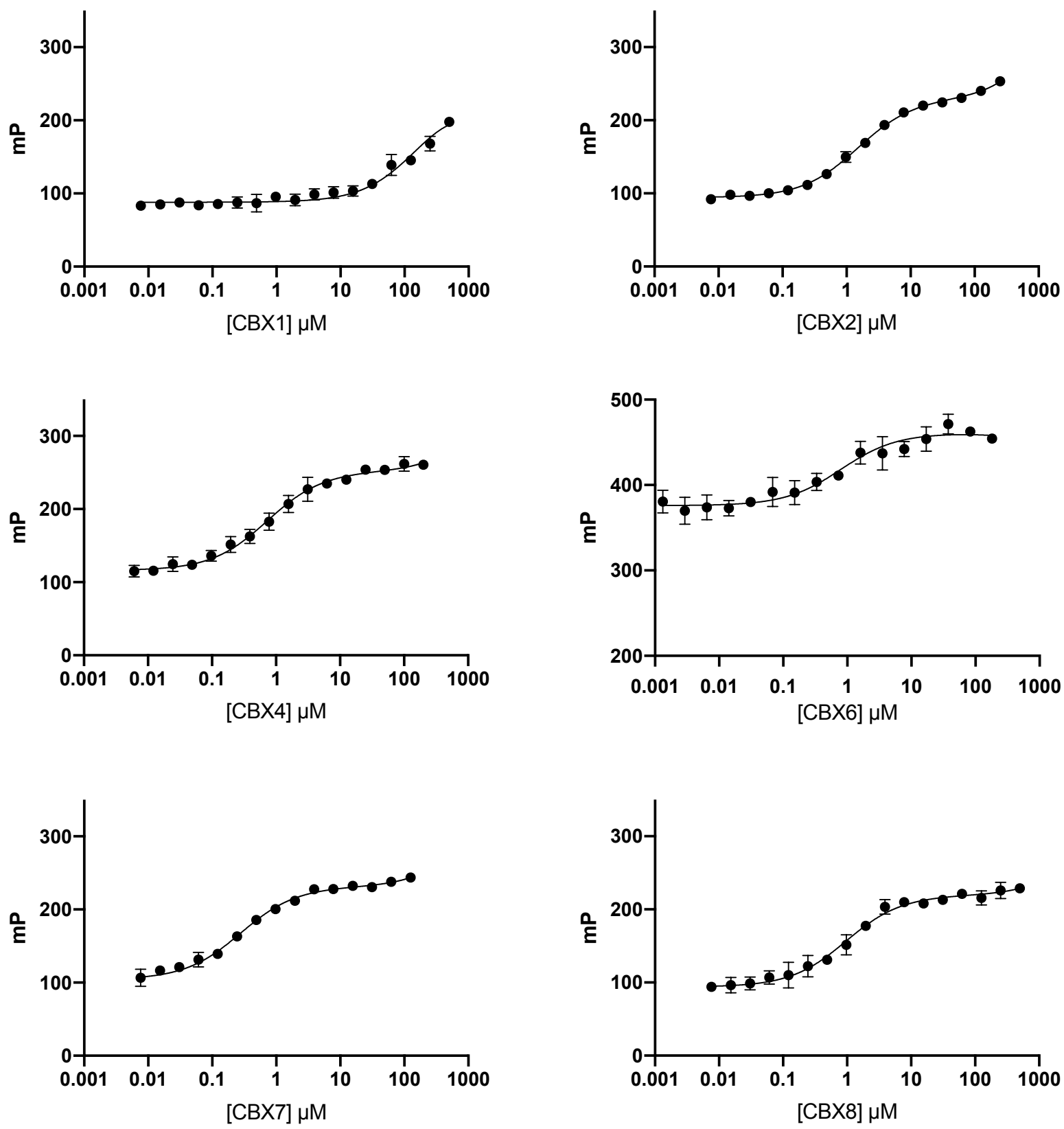

Figure S22. Direct fluorescence polarization data of compound 8 with CBX1/2/4/6/7/8. CBX1 $\left(\mathrm{K}_{\mathrm{d}}=178 \mu \mathrm{M}, 95 \%\right.$ CI $143 \mu \mathrm{M}$ to $\left.225 \mu \mathrm{M}, \mathrm{R}^{2}=0.941\right), \mathrm{CBX} 2\left(\mathrm{~K}_{\mathrm{d}}=1.5 \mu \mathrm{M}, 95 \%\right.$ CI $1.3 \mu \mathrm{M}$ to $\left.1.7 \mu \mathrm{M}, \mathrm{R}^{2}=0.996\right), \mathrm{CBX} 4\left(\mathrm{~K}_{\mathrm{d}}=0.73 \mu \mathrm{M}, 95 \% \mathrm{CI} 0.57 \mu \mathrm{M}\right.$ to $\left.0.93 \mu \mathrm{M}, \mathrm{R}^{2}=0.981\right), \mathrm{CBX} 6$ $\left(\mathrm{K}_{\mathrm{d}}=0.80 \mu \mathrm{M}, 95 \%\right.$ CI $0.4 \mu \mathrm{M}$ to $\left.1.6 \mu \mathrm{M}, \mathrm{R}^{2}=0.896\right), \mathrm{CBX} 7\left(\mathrm{~K}_{\mathrm{d}}=0.30 \mu \mathrm{M}, 95 \%\right.$ CI $0.23 \mu \mathrm{M}$ to $\left.0.33 \mu \mathrm{M}, \mathrm{R}^{2}=0.988\right), \mathrm{CBX} 8\left(\mathrm{~K}_{\mathrm{d}}=0.96 \mu \mathrm{M}, 95 \% \mathrm{CI} 0.73 \mu \mathrm{M}\right.$ to $\left.1.30 \mu \mathrm{M}, \mathrm{R}^{2}=0.980\right)$. Error reported as asymmetrical 95\% confidence intervals. CBX2/7/8 titrations performed in triplicate. CBX1/2/4/6/7 titrations performed in triplicate and CBX8 titration performed in duplicate. 

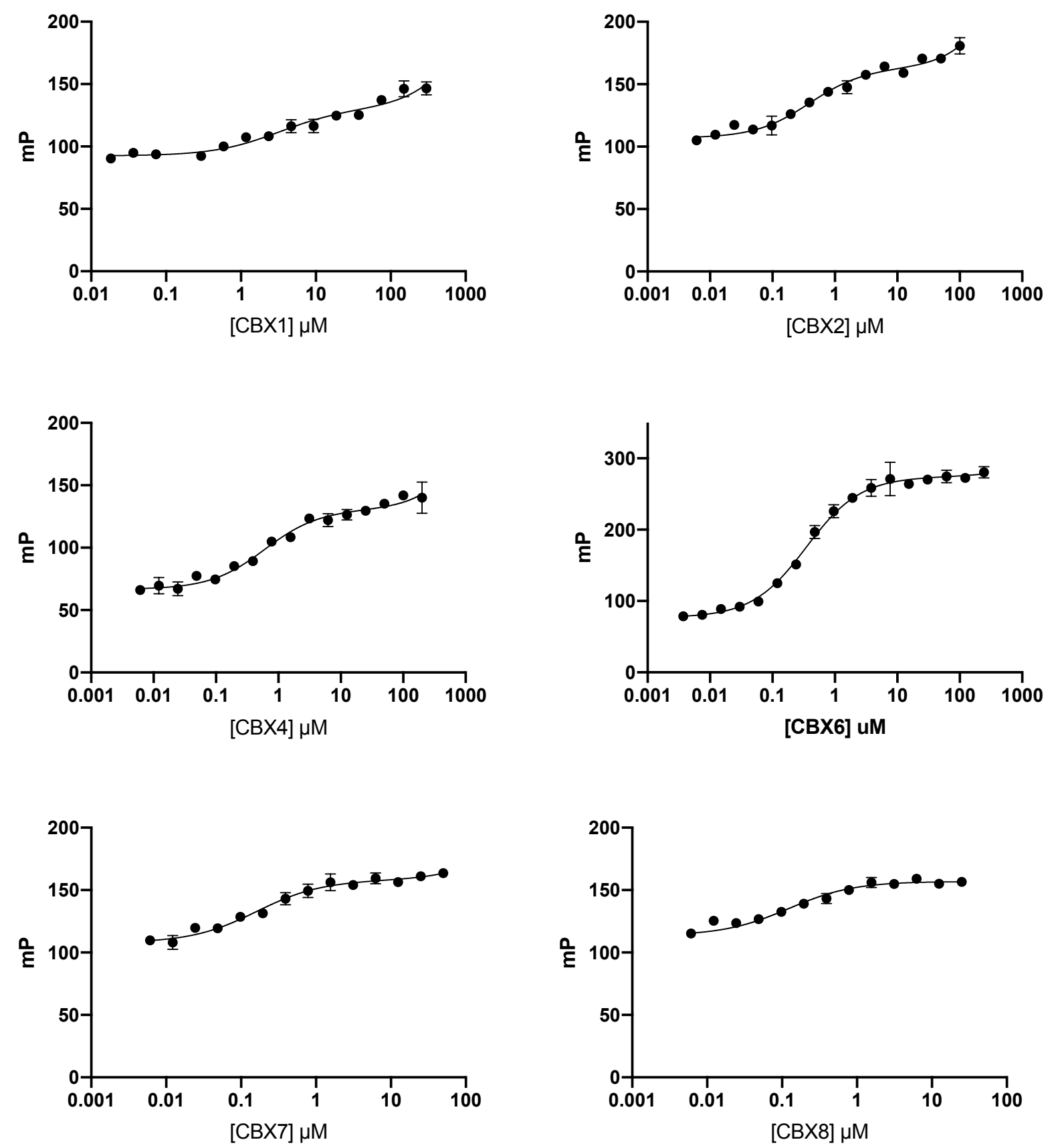

Figure S23. Direct fluorescence polarization data of compound 9 with CBX1/2/4/6/7/8. CBX1 $\left(\mathrm{K}_{\mathrm{d}}=3.2 \mu \mathrm{M}, 95 \%\right.$ CI $1.5 \mu \mathrm{M}$ to $\left.7.0 \mu \mathrm{M}, \mathrm{R}^{2}=0.956\right)$, CBX2 $\left(\mathrm{K}_{\mathrm{d}}=0.39 \mu \mathrm{M}, 95 \%\right.$ CI $0.27 \mu \mathrm{M}$ to $\left.0.56 \mu \mathrm{M}, \mathrm{R}^{2}=0.971\right), \mathrm{CBX} 4\left(\mathrm{~K}_{\mathrm{d}}=0.60 \mu \mathrm{M}, 95 \%\right.$ CI $0.41 \mu \mathrm{M}$ to $\left.0.87 \mu \mathrm{M}, \mathrm{R}^{2}=0.974\right), \mathrm{CBX} 6$ $\left(\mathrm{K}_{\mathrm{d}}=0.35 \mu \mathrm{M}, 95 \%\right.$ CI $0.299 \mu \mathrm{M}$ to $\left.0.401 \mu \mathrm{M}, \mathrm{R}^{2}=0.993\right)$, CBX7 $\left(\mathrm{K}_{\mathrm{d}}=0.16 \mu \mathrm{M}, 95 \%\right.$ CI 0.11 $\mu \mathrm{M}$ to $\left.0.23 \mu \mathrm{M}, \mathrm{R}^{2}=0.965\right)$, CBX8 $\left(\mathrm{K}_{\mathrm{d}}=0.12 \mu \mathrm{M}, 95 \% \mathrm{CI} 0.08 \mu \mathrm{M}\right.$ to $\left.0.19 \mu \mathrm{M}, \mathrm{R}^{2}=0.960\right)$. Error reported as asymmetrical $95 \%$ confidence intervals. CBX2/7/8 titrations performed in triplicate. CBX1/4/6 titrations performed in duplicate. 

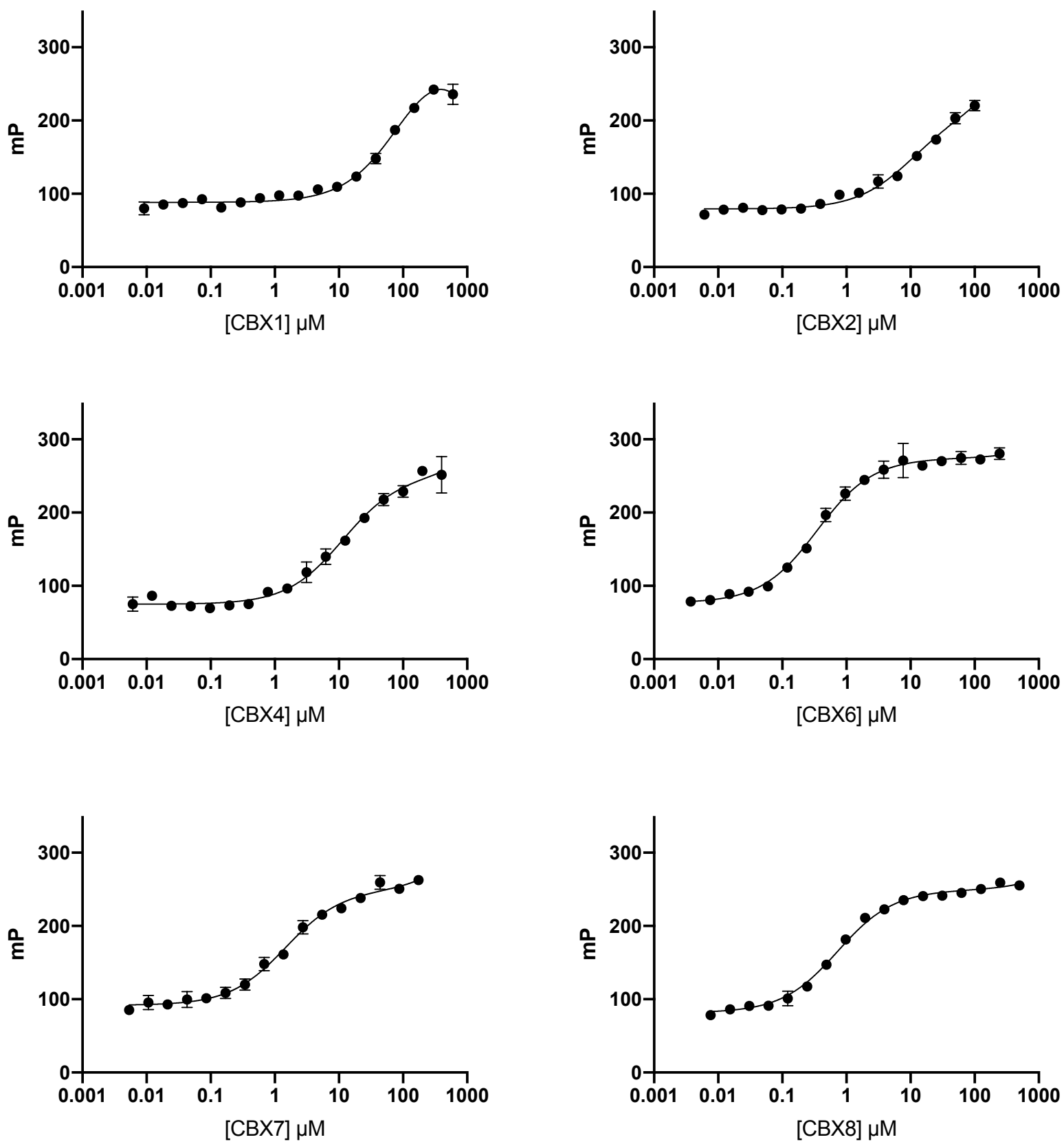

Figure S24. Direct fluorescence polarization data of compound 10 with CBX1/2/4/6/7/8. CBX1 $\left(\mathrm{K}_{\mathrm{d}}=99 \mu \mathrm{M}, 95 \% \mathrm{CI} 70 \mu \mathrm{M}\right.$ to $\left.142 \mu \mathrm{M}, \mathrm{R}^{2}=0.989\right), \mathrm{CBX} 2\left(\mathrm{~K}_{\mathrm{d}}=10 \mu \mathrm{M}, 95 \% \mathrm{CI} 8.6 \mu \mathrm{M}\right.$ to 12 $\left.\mu \mathrm{M}, \mathrm{R}^{2}=0.984\right), \mathrm{CBX} 4\left(\mathrm{~K}_{\mathrm{d}}=11.3 \mu \mathrm{M}, 95 \% \mathrm{CI} 8.2 \mu \mathrm{M}\right.$ to $\left.15.7 \mu \mathrm{M}, \mathrm{R}^{2}=0.985\right), \mathrm{CBX} 6\left(\mathrm{~K}_{\mathrm{d}}=\right.$ $0.35 \mu \mathrm{M}, 95 \%$ CI $0.30 \mu \mathrm{M}$ to $\left.0.41 \mu \mathrm{M}, \mathrm{R}^{2}=0.993\right), \mathrm{CBX} 7\left(\mathrm{~K}_{\mathrm{d}}=1.5 \mu \mathrm{M}, 95 \%\right.$ CI $1.21 \mu \mathrm{M}$ to $\left.1.78 \mu \mathrm{M}, \mathrm{R}^{2}=0.989\right), \mathrm{CBX} 8\left(\mathrm{~K}_{\mathrm{d}}=0.73 \mu \mathrm{M}, 95 \% \mathrm{CI} 0.63 \mu \mathrm{M}\right.$ to $\left.0.84 \mu \mathrm{M}, \mathrm{R}^{2}=0.991\right)$. Error reported as asymmetrical $95 \%$ confidence intervals. Titrations performed in duplicate. 

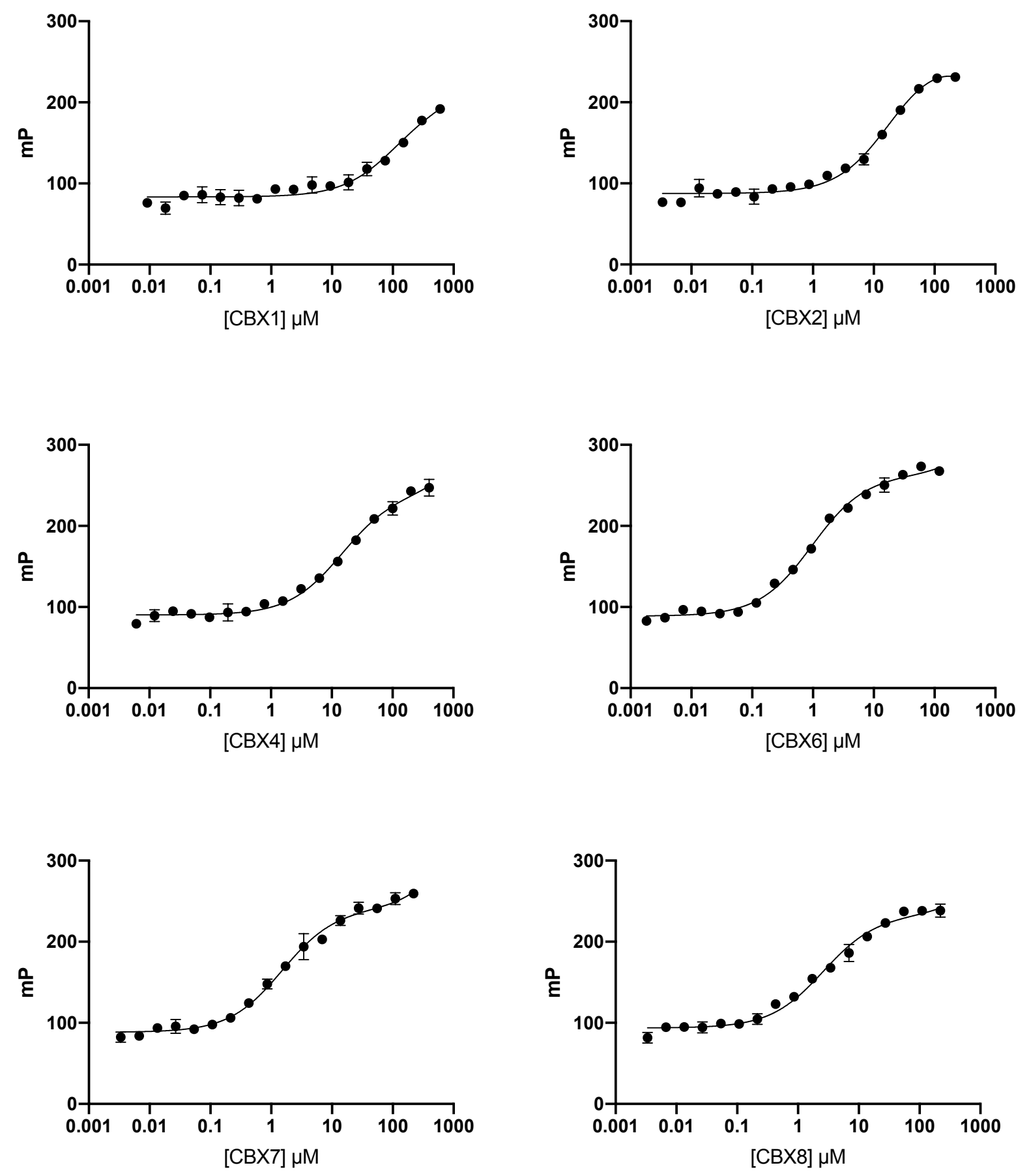

Figure S25. Direct fluorescence polarization data of compound 11 with CBX1/2/4/6/7/8. CBX1 $\left(\mathrm{K}_{\mathrm{d}}=110 \mu \mathrm{M}, 95 \%\right.$ CI $84 \mu \mathrm{M}$ to $\left.148 \mu \mathrm{M}, \mathrm{R}^{2}=0.958\right), \mathrm{CBX} 2\left(\mathrm{~K}_{\mathrm{d}}=18 \mu \mathrm{M}, 95 \%\right.$ CI $13 \mu \mathrm{M}$ to 25 $\left.\mu \mathrm{M}, \mathrm{R}^{2}=0.998\right), \mathrm{CBX} 4\left(\mathrm{~K}_{\mathrm{d}}=15 \mu \mathrm{M}, 95 \%\right.$ CI $11 \mu \mathrm{M}$ to $\left.19 \mu \mathrm{M}, \mathrm{R}^{2}=0.991\right), \mathrm{CBX} 6\left(\mathrm{~K}_{\mathrm{d}}=0.96\right.$ $\mu \mathrm{M}, 95 \%$ CI $0.82 \mu \mathrm{M}$ to $\left.1.3 \mu \mathrm{M}, \mathrm{R}^{2}=0.995\right)$, CBX7 ( $\mathrm{K}_{\mathrm{d}}=1.5 \mu \mathrm{M}, 95 \%$ CI $1.2 \mu \mathrm{M}$ to $1.9 \mu \mathrm{M}$, $\left.\mathrm{R}^{2}=0.992\right)$, CBX8 $\left(\mathrm{K}_{\mathrm{d}}=2.6 \mu \mathrm{M}, 95 \%\right.$ CI $1.9 \mu \mathrm{M}$ to $\left.3.5 \mu \mathrm{M}, \mathrm{R}^{2}=0.987\right)$. Error reported as asymmetrical $95 \%$ confidence intervals. Titrations performed in duplicate. 


\section{Docking and MD Methods}

File Preparation

Residues unavailable in the Amber16 ff14SB force field were constructed using the Avogadro molecular visualization tool to include $\mathrm{C}$ - and $\mathrm{N}$-terminal methyl caps. These residues include the trimethyllysine and brominated phenyl $\mathrm{N}$-terminal residue. The capped structures were minimized using Gaussian09 at the HF-6-31G* level of theory and the following outputs were used to generate an electrostatic potential map for later fitting.

AmberTools16 residuegen utility was then used to fit the electrostatic potential map and assign force field parameters to the uncapped versions of the residues. The generated prepi file and antechamber generated frcmod file were loaded into tleap along with the Amber ff14SB force field parameters. Connectivity information for both residues was assigned and compounds 6 and 7 were generated using the sequence function to generate PDB files for both compounds.

PDBQT files were generated by first loading the previous PDB files into UCSF Chimera. Applying the built-in AutoDock Vina tool to an arbitrary system generated the ligand PDBQT files used later by our in-house software designed for the exhaustive use of use of AutoDock Vina.

\section{SLICE Method Application}

\section{Initial Molecular Docking}

Our in-house software combines ligand PDBQTs with an ensemble of MD pre-generated CBX8 host configurations. Each system is assigned a docking box generated by a residue list and a buffer of 5 angstroms outside of the assumed docked location. Using exhaustiveness 7 on 50 host configurations, AutoDock Vina was executed and 10 poses were generated for each configuration, resulting in 500 poses of which the top ten were selected for molecular dynamics.

Table S2. Progression of Top-Docked Scores for Compounds 6 and 7

\begin{tabular}{cccc}
\hline & $\begin{array}{c}\text { Crystal } \\
\text { Structure } \\
\text { Docking } \\
/ \mathrm{kcal} \mathrm{mol}^{-1}\end{array}$ & $\begin{array}{c}1^{\text {st }} \mathrm{MD} \\
\text { Ensemble } \\
\text { Docking } \\
/ \mathrm{kcal} \mathrm{mol}^{-1}\end{array}$ & $\begin{array}{c}2^{\text {nd }} \mathrm{MD} \\
\text { Ensemble } \\
\text { Docking } \\
/ \mathrm{kcal} \mathrm{mol}^{-1}\end{array}$ \\
\hline $\begin{array}{c}\text { Compound } \\
\mathbf{6}\end{array}$ & -8.0 & -8.2 & $-8.6^{*}$ \\
$\begin{array}{c}\text { Compound } \\
\mathbf{7}\end{array}$ & -8.4 & -8.7 & $-9.2^{* *}$ \\
\hline
\end{tabular}

* Incorrectly bound

** Pose submitted for 100 ns molecular dynamics

\section{Intermediate and 100 ns Molecular Dynamics}

MD simulation starting coordinates and topology files were constructed using tleap. Complexes were initially loaded as PDBs, solvated with approximately 8000 TIP3PBOX waters, and chloride counter-ions were added for charge neutrality. Systems were then minimized using steepest slope 
descent, thermally ramped to $300 \mathrm{~K}$ over $200 \mathrm{ps}$, and run for either $1 \mathrm{~ns}$ or $100 \mathrm{~ns}$ with a 2 fs time step, periodic boundary conditions, SHAKE algorithm, and under NPT conditions with an 8 angstrom electrostatic cutoff.

\section{Free Energy Analysis}

Ante-MMPBSA.py was used to generate the individual topology files for use in MMPBSA.py from the single 100ns trajectories of compounds 6 and 7 with CBX8. GB radii set to setting 2, and a sampling frequency of 1000 snapshots over 2000 MD frames was set. Per-residue analysis was also done. Both GB and PB energies were calculated. PB and GB energies showed consistent trends with relative binding energies and $\mathrm{PB}$ energies were reported.

\section{Computational Resources}

Each 10-pose iteration for $1 \mathrm{~ns}$ trajectories required 1 hour on 280 cores ( 10 nodes with 2 Intel Xeon E5-2680 v4 processors each). $100 \mathrm{~ns}$ trajectories required approximately 120 hours using 28 cores each. Total simulation time for both systems including starting pose generation was approximately 180 hours

\section{Protein Microarray}

The methyl domain reader array consists of 96 purified chromatin-associated effector proteins. Currently, 20 of these proteins are known to bind to H3K9me3 and H3K27me3. The array contains 28 chromodomain containing proteins. Each protein is spotted in duplicate onto a nitrocellulose-coated membrane. Visualization of binding is achieved by using streptavidin covalently tagged with a florescent dye.

Methyl Domain Readers Array

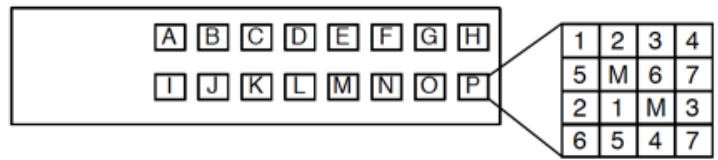

\begin{tabular}{|c|c|c|c|c|c|c|c|}
\hline \begin{tabular}{|l} 
TUDOR \\
A1) 53BP1(1-2) \\
A2) 53BP1(1-2)* \\
A3) TDRD1-2 \\
A4) TDRD1-3 \\
A5) TDRD1-4 \\
A6) TDRD2 \\
A7) TDRD3
\end{tabular} & \begin{tabular}{|l} 
TUDOR \\
B1) TDRD4-1 \\
B2) TDRD4-3 \\
B3) TDRD4-4 \\
B4) TDRD5 \\
B5) TDRD6-5 \\
B6) TDRD6-6 \\
B7) TDRD6-7
\end{tabular} & \begin{tabular}{|l} 
TUDOR \\
C1) TDRD8 \\
C2) TDRD9 \\
C3) TDRD10 \\
C4) TDRD11 \\
C5) TDRD12-1 \\
C6) ARID4A \\
C7) ARID4B
\end{tabular} & $\begin{array}{l}\text { TUDOR } \\
\text { D1) AKAP1 } \\
\text { D2) LBR } \\
\text { D3) PHF1 } \\
\text { D4) PHF19 } \\
\text { D5) PHF20 } \\
\text { D6) PHF20-2 } \\
\text { D7) PHF20L1 }\end{array}$ & $\begin{array}{l}\text { TUDOB } \\
\text { E1) SETDB1 } \\
\text { E2) SMN } \\
\text { E3) SMN* } \\
\text { E4) SPF30 } \\
\text { E5) UHRF1 } \\
\text { E6) ZGPAT } \\
\text { E7) JMJD2A(1-2) }\end{array}$ & $\begin{array}{l}\text { TUDOR+PHD } \\
\text { F1) JMJD2B } \\
\text { F2) JMJD2C } \\
\text { F3) MTF2 } \\
\text { F4) PHF1* } \\
\text { TUDOR } \\
\text { F5) Pombe1* } \\
\text { F6) Spindlin1* } \\
\text { F7) TDRKH" }\end{array}$ & $\begin{array}{l}\text { PHD } \\
\text { G1) ING2 } \\
\text { G2) TAF3 } \\
\text { G3) TRIM24 PHD+BRD' } \\
\text { G4) CHD5(1-2)* } \\
\text { CHROMO+PHD } \\
\text { G5) CHD3 } \\
\text { G6) CHD4 } \\
\text { G7) CHD5 }\end{array}$ & \begin{tabular}{|l} 
TUDOR \\
H1) SGF29 \\
H2) SPIN1 \\
H3) TDRD22TDRKH \\
H4) LIN9
\end{tabular} \\
\hline $\begin{array}{l}\text { CHROMO } \\
\text { 11) ARID4A } \\
\text { 12) ARID4B } \\
\text { 13) CBX2 } \\
\text { 14) } \mathrm{CBX} 4 \\
\text { 15) CBX6 } \\
\text { 16) } \mathrm{CBX7} \\
\text { 17) } \mathrm{CBX} 8\end{array}$ & $\begin{array}{l}\text { CHROMO } \\
\text { J1) HP1a/CBX5 } \\
\text { J2) HP1 } 1 \beta \\
\text { J3) HP1Y/CBX3 } \\
\text { J4) CDY1 } \\
\text { J5) CDYL1b } \\
\text { J6) CDYL2 } \\
\text { J7) MSL3 }\end{array}$ & $\begin{array}{l}\text { CHROMO } \\
\text { K1) CHD1 } \\
\text { K2) CHD2 } \\
\text { K3) CHD6 } \\
\text { K4) CHD7 } \\
\text { K5) CHD8 } \\
\text { K6) CHD9 } \\
\text { K7) TIP60 }\end{array}$ & $\begin{array}{l}\text { CHROMO } \\
\text { L1) MPP8 } \\
\text { L2) MRG15 } \\
\text { L3) MYST1/MOF } \\
\text { L4) SMARCC1 } \\
\text { L5) SMARCC2 } \\
\text { L6) SUV39H1 } \\
\text { L7) SUV39H2 }\end{array}$ & \begin{tabular}{|l|} 
AGENEI \\
M1) FMR1 \\
M2) FXR1 \\
M3) FXR2 \\
ANK \\
M4) GLP \\
M5) IkB FL2 \\
BAH \\
M6) ORC1 \\
\end{tabular} & 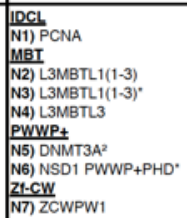 & $\begin{array}{l}\text { BROMO } \\
\text { O1) SP140* } \\
\text { O2) BRD4(1)* } \\
\text { O3) WDR9(1-2) } \\
\text { O4) SMAP* } \\
\text { HEAT } \\
\text { O5) N-CAPD3(1-4) } \\
\text { O6) N-CAPD3(5-8) }\end{array}$ & $\begin{array}{l}\text { YEATS } \\
\text { P1) YEATS4/GAS41 } \\
\text { P2) ENLMMLLT1 } \\
\text { P3) AF9/MLLT3 } \\
\text { P4) YEATS2 }\end{array}$ \\
\hline
\end{tabular}

Figure S26: List of the methyl reader domains evaluated in the protein microarray seen in Figure 10. The letter associated with each domain specifies the section of the array containing the protein and the number designates the position of each replicate within that section. 


\section{Methods for Cell-based Studies}

\section{FACS analysis of Inhibitor Uptake, Cell Viability and Cell Cycle Distribution}

TOV21G cells (ATCC ${ }^{\circledR}$ CRL- $11730^{\mathrm{TM}}$ ) seeded at $2.5 \times 10^{5}$ cells/well in a 6-well plate were adhered overnight at $37^{\circ} \mathrm{C}, 5 \% \mathrm{CO}_{2}$ then treated for $21 \mathrm{hr}$ with $0 \mu \mathrm{M}, 5 \mu \mathrm{M}, 10 \mu \mathrm{M}, 25 \mu \mathrm{M}$ or 50 $\mu \mathrm{M}$ of compound 2 at $37^{\circ} \mathrm{C}, 5 \% \mathrm{CO}_{2}$. After incubation, cells were washed with media (RPMI1640 medium containing $25 \mathrm{mM}$ HEPES and L-Glutamine (Thermo Scientific (Hyclone) SH30255.01), supplemented with $10 \%$ fetal bovine serum (FBS)(Life Technologies, 16000044), 1\% L-Glutamine (Hyclone SH3003401) and 1\% penicillin/streptomycin (Hyclone SV30010). Cells were were rinsed with $1 \times$ PBS, trypsinized and collected by centrifuging at $1200 \mathrm{RPM}$ for 5 min at $4^{\circ} \mathrm{C}$. Cells were resuspended and washed with $1 \times \mathrm{PBS}$, pelleted at $1200 \mathrm{RPM}$ for 5 min at $4^{\circ} \mathrm{C}$, resuspended in 1:1000 Fixable Viability Dye eFluor 780 (eBioscience, 65-0865-14) and incubated on ice for $30 \mathrm{~min}$. After incubation, cells were collected by centrifuging at $1400 \mathrm{rpm}$ for $5 \mathrm{~min}$ at $4{ }^{\circ} \mathrm{C}$ and washed twice with ice cold $1 \times$ PBS. Cells were simultaneously fixed with $500 \mu \mathrm{L}$ ice cold $70 \%$ ethanol and stained with propidium iodide (PI) $(30 \mu \mathrm{L}$ of $20 \mathrm{mg} / \mathrm{mL}$ RNaseA (Invitrogen, 60216-RN) and $26 \mu \mathrm{L}$ PI (eBioscience, BMS5-FI/100)) for $30 \mathrm{~min}$ at room temperature. Cells were centrifuged at $1400 \mathrm{rpm}$ for $8 \mathrm{~min}$ at $4^{\circ} \mathrm{C}$ to remove staining solution, washed with $1 \times \mathrm{PBS}$, centrifuged, resuspended with $0.3 \% \mathrm{FBS}$ in $1 \times \mathrm{PBS}$ and stored at $4^{\circ} \mathrm{C}$ until analysis. Samples were filtered (BD Falcon 352235) immediately before running on a Becton Dickinson FACSCalibur ${ }^{\mathrm{TM}}$ and analyzed using FlowJo 7.6 .5 software.

\section{MTT Assay}

TOV21G cells were seeded at 2000 or 3000 cells per well in 96 well culture plates and allowed to adhere overnight at $37^{\circ} \mathrm{C}, 5 \% \mathrm{CO}_{2}$ prior to treatment with inhibitor solutions for $72 \mathrm{hr}$ at $37^{\circ} \mathrm{C}$, $5 \% \mathrm{CO}_{2}$. Cell viability was assessed by adding $20 \mu \mathrm{L}$ of $5 \mathrm{mg} / \mathrm{mL}$ MTT in $1 \mathrm{x}$ PBS solution (Molecular Probes M6494) to each well and incubating at $37^{\circ} \mathrm{C}, 5 \% \mathrm{CO}_{2}$ for $4 \mathrm{hr}$. Media was replaced with $100 \mu \mathrm{L}$ DMSO and absorbance was measured at $560 \mathrm{~nm}$ and $670 \mathrm{~nm}$. Cell viability was calculated as follows:

$$
\begin{gathered}
\text { Cell viability }=(\text { average A560nm - A670nm of sample }) \div(\text { average A560nm - A670nm of } 0 \mu \mathrm{M} \\
\text { sample }) \times 100 \%
\end{gathered}
$$

